NATL INST OF STANDARDS \& TECH R.I.C.

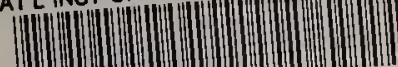

1.m.

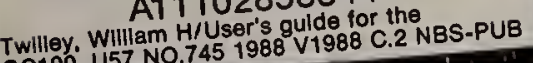

NBS Special Publication 745

User's Guide for the

Cone Calorimeter

William H. Twilley and Vytenis Babrauskas 

U.S. DEPARTMENT OF COMMERCE

National Bureau of Standards

NBS Special Publication 745

\section{User's Guide for the Cone Calorimeter}

William H. Twilley and Vytenis Babrauskas

NBS NBS NBS NBS NBS NBS NBS NBS NBS $\backslash B S$ IS NBS NBS NBS NBS NBS NBS NBS NBS NBS NB NBS NBS NBS NBS NBS NBS NBS NBS NBS NBS iS NBS NBS NBS NBS NBS NBS NBS NBS NBS NB NBS NBS NBS NBS NBS NBS NBS NBS NBS NBS iS NBS NBS NBS NBS NBS NBS NBS NBS NBS NB NBS NBS NBS NBS NBS NBS NBS NBS NBS NB iS NBS NBS NBS NBS NBS NBS NBS NBS NBS NB NBS NBS NBS NBS NBS NBS NBS NBS NBS NBS iS NBS NBS NBS NBS NBS NBS NBS NBS NBS NB NBS NBS NBS National Bureau of Standards NBS NB iS NBS NBS NBS NBS NBS NBS NBS NBS NBS NB NBS NBS NBS NBS NBS NBS $\triangle B S$ NBS NBS NB is NBS NBS NBS NBS NBS NBS NBS NBS NBS NB NBS NBS NBS NBS NBS NBS NBS NBS NBS \BS is NBS NBS NBS NBS NBS NBS NBS NBS NBS NB 
he National Bureau of Standards ${ }^{1}$ was established by an act of Congress on March 3, 1901. The

Bureau's overall goal is to strengthen and advance the Nation's science and technology and facilitate their effective application for public benefit. To this end, the Bureau conducts research to assure international competitiveness and leadership of U.S. industry, science and technology. NBS work involves development and transfer of measurements, standards and related science and technology, in support of continually improving U.S. productivity, product quality and reliability, innovation and underlying science and engineering. The Bureau's technical work is performed by the National Measurement Laboratory, the National Engineering Laboratory, the Institute for Computer Sciences and Technology, and the Institute for Materials Science and Engineering.

\section{The National Measurement Laboratory}

Provides the national system of physical and chemical measurement; coordinates the system with measurement systems of other nations and furnishes essential services leading to accurate and uniform physical and chemical measurement throughout the Nation's scientific community, industry, and commerce; provides advisory and research services to other Government agencies; conducts physical and chemical research; develops, produces, and distributes Standard Reference Materials; provides calibration services; and manages the National Standard Reference Data System. The Laboratory consists of the following centers:

\section{The National Engineering Laboratory}

Provides technology and technical services to the public and private sectors to address national needs and to solve national problems; conducts research in engineering and applied science in support of these efforts; builds and maintains competence in the necessary disciplines required to carry out this research and technical service; develops engineering data and measurement capabilities; provides engineering measurement traceability services; develops test methods and proposes engineering standards and code changes; develops and proposes new engineering practices; and develops and improves mechanisms to transfer results of its research to the ultimate user. The Laboratory consists of the following centers:

\section{The Institute for Computer Sciences and Technology}

Conducts research and provides scientific and technical services to aid Federal agencies in the selection, acquisition, application, and use of computer technology to improve effectiveness and economy in Government operations in accordance with Public Law 89-306 (40 U.S.C. 759), relevant Executive Orders, and other directives; carries out this mission by managing the Federal Information Processing Standards Program, developing Federal ADP standards guidelines, and managing Federal participation in ADP voluntary standardization activities; provides scientific and technological advisory services and assistance to Federal agencies; and provides the technical foundation for computer-related policies of the Federal Government. The Institute consists of the following divisions:

\section{The Institute for Materials Science and Engineering}

Conducts research and provides measurements, data, standards, reference materials, quantitative understanding and other technical information fundamental to the processing, structure, properties and performance of materials; addresses the scientific basis for new advanced materials technologies; plans research around cross-cutting scientific themes such as nondestructive evaluation and phase diagram development; oversees Bureau-wide technical programs in nuclear reactor radiation research and nondestructive evaluation; and broadly disseminates generic technical information resulting from its programs. The Institute consists of the following divisions:
- Basic Standards ${ }^{2}$
- Radiation Research
- Chemical Physics
- Analytical Chemistry 


\section{NBS Special Publication 745}

\section{User's Guide for the Cone Calorimeter}

William H. Twilley and Vytenis Babrauskas

Fire Measurement and Research Division

Center for Fire Research

National Bureau of Standards

Gaithersburg, MD 20899

Edition 1.0
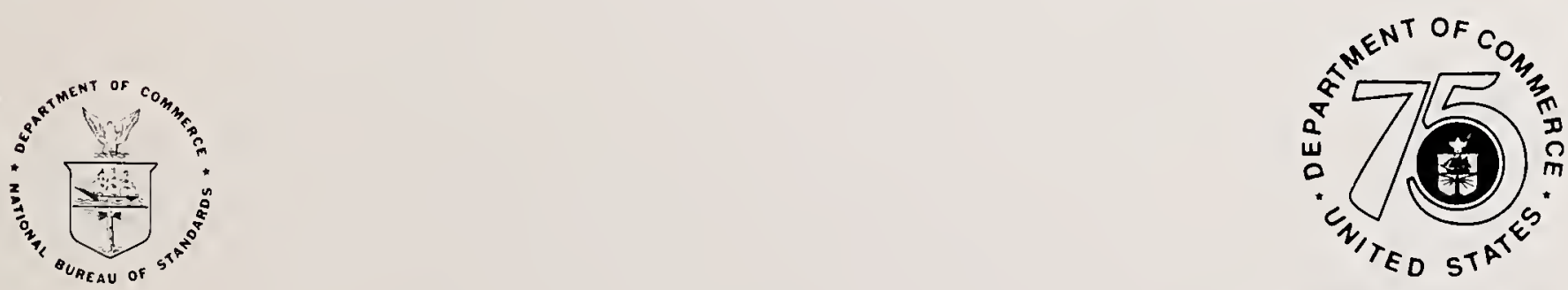

Stumulatino America's Progress $1913-1988$

August 1988

U.S. Department of Commerce

C. William Verity, Secretary

National Bureau of Standards

Ernest Ambler, Director 


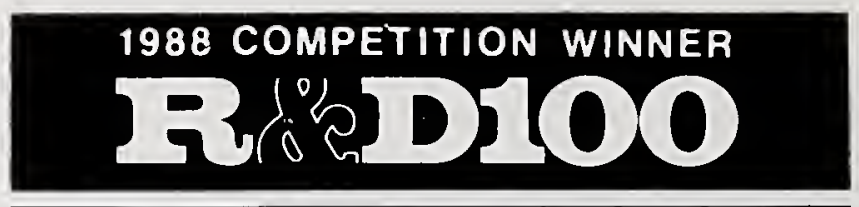

Cited by Research \& Development magazine

for developing one of the 100 most-significant

technical products of the year

Library of Congress

Catalog Card Number: 88-600556

National Bureau of Standards

Special Publication 745

Natl. Bur. Stand. (U.S.),

125 pages (Aug. 1988)

CODEN: XNBSAV
U.S. Government Printing Office

Washington: 1988
For sale by the Superintendent of Documents, U.S. Government Printing Office, Washington, DC 20402 


\section{Contents}

1 Introduction 1

1.1 Customized guides . . . . . . . . . . . . . . . 2

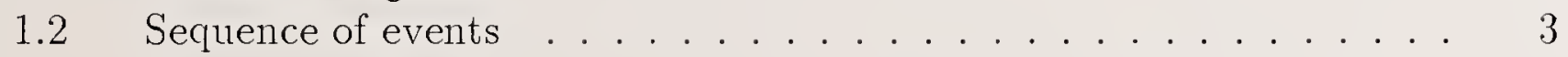

1.3 User comments . . . . . . . . . . . . . . . . 3

2 Installation and initial set-up 4

2.1 Laboratory environment .................. . . . . . . 4

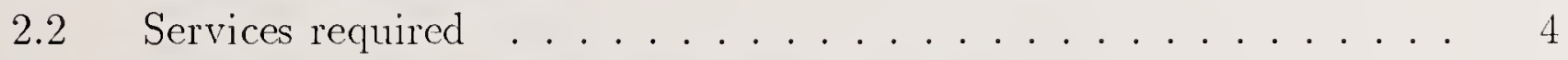

2.3 Calibration and auxiliary equipment required . . . . . . . . . . . . 5

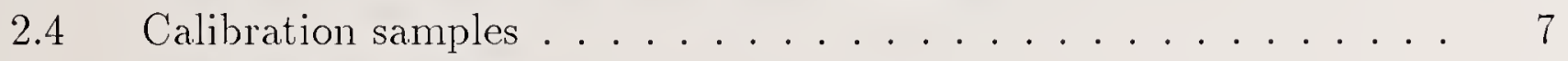

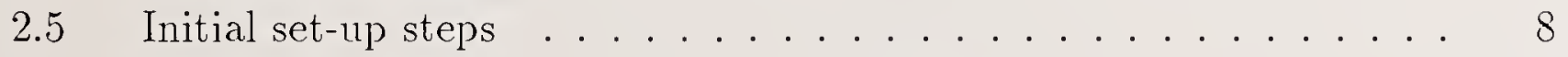

2.6 Calibration levels ...................... 10

3 Spares and supplies $\quad 11$

4 Data collection and analysis software 14

4.1 Data collection ................... 14

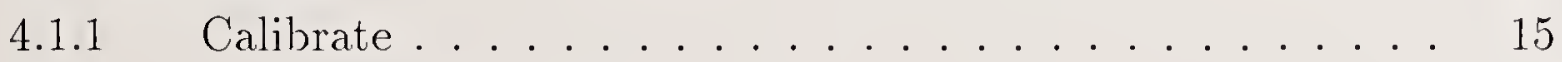

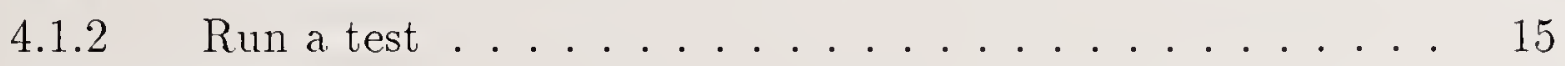

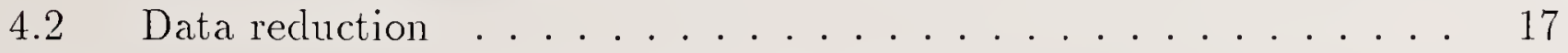

5 Daily start-up and calibration procedures 24

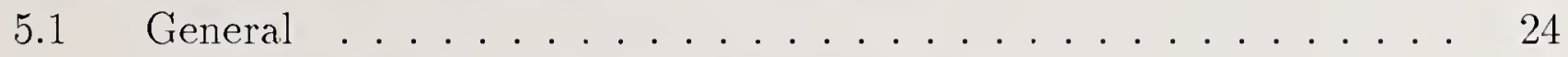

5.2 Checking the cold trap temperature setting . . . . . . . . . . . 25

5.3 Changing the drying and $\mathrm{CO}_{2}$ removal media . . . . . . . . . . . 26

5.4 Draining the condensed water from the cold trap . . . . . . . . . 27

5.5 Changing the soot filters . . . . . . . . . . 27

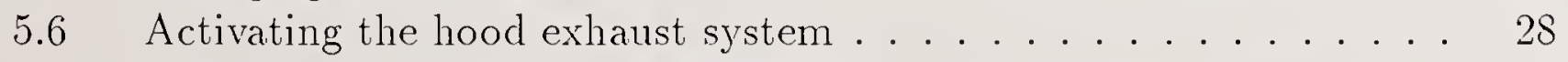

5.7 Gas analyzer calibration (Zero/Span) . . . . . . . . . . . 29

5.8 Setting the flow rates for the exhaust and for the soot sampler . . . 38

5.9 Checking the orifice flow constant . . . . . . . . . . . 39

6 Preparative procedures 41

6.1 Sample preparation .................... 41

6.2 Preparing the specimen holder . . . . . . . . . . . . . . . . . 43

6.3 Use of special sample holder equipment . . . . . . . . . . 43 
6.4 Preparing weighed soot filters $\ldots \ldots \ldots \ldots \ldots \ldots$

6.5 Recording pre-test data . . . . . . . . . . . . . . . 45

7 Running tests 46

7.1 General . . . . . . . . . . . . . . . 46

7.2 Checking gas analyzers, sampling lines, filters . . . . . . 46

7.3 Checking the cold trap . . . . . . . . . . . . . 47

7.4 Checking the exhaust duct flow . . . . . . . . . . . 47

7.5 Setting the soot mass flow controller . . . . . . . . . . . 47

7.6 Setting the cone heater orientation and height $\ldots \ldots \ldots \ldots 47$

7.7 Checking the load cell . . . . . . . . . . . . . . 48

7.8 Setting up the desired flux of the cone heater . . . . . . . . . 49

7.9 Computer program setup and starting the test . . . . . . . 50

7.10 Ignition . . . . . . . . . . . . . . . . . 52

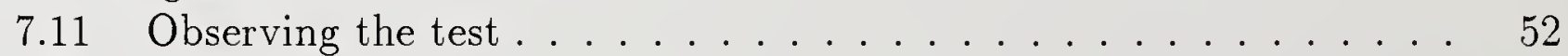

7.12 End of test ..................... 53

8 Daily shutdown procedures $\quad 55$

9 Test report $\quad \mathbf{5 7}$

9.1 Computer-generated standard reports . . . . . . . . . 57

10 Weekly calibration procedures $\quad 58$

10.1 Checking the calibration of the electronic mass-flow controller . . . 58

10.2 Checking system calibration with PMMA . . . . . . . . 59

11 Less-frequent calibration procedures $\quad 61$

11.1 Calibrating the heater thermocouples to actual heat flux values . . . 61

11.2 Gas burner checks, 5 and $10 \mathrm{~kW}$ level . . . . . . . . . . 62

11.3 Checking the operating flux gauge against the reference gauge . . . 62

11.4 Checking the laser smoke photometer . . . . . . . . . . 63

11.5 Setting the gas analyzer flow rates . . . . . . . . . . . 64

11.6 Determining the gas analyzer time offsets . . . . . . . . 66

11.7 Setting the oxygen analyzer response time . . . . . . . 67

11.8 Checking analyzer D-to-A operation . . . . . . . . . . 67

11.9 Load cell damping factor adjustment . . . . . . . . . . . 68

11.10 Set-up of the controller for the soot sampler . . . . . . . . 68 
11.11 Calibrating the exhaust flow controller . . . . . . . . . . 69

11.12 Calibrating the exhaust flow rate indicator . . . . . . . . . 70

11.13 Calibrating the smoke photometer . . . . . . . . . . . . 71

11.13.1 NBS version electronics . . . . . . . . . . . . . . 72

11.13.2 SSDC version electronics . . . . . . . . . . . . . 74

11.14 Checking the calibration of the orifice plate pressure transducer . . 80

12 Regular maintenance $\quad 81$

12.1 Electric contacts cleaning . . . . . . . . . . . . . . . . 81

12.2 Memory refreshing for the temperature controllers . . . . . . . . 81

12.3 General cleaning of the instrument . . . . . . . . . . . . . 81

12.4 Maintenance of the heat flux gauge . . . . . . . . . . 85

13 Troubleshooting and repair $\quad 87$

13.1 General . . . . . . . . . . . . . . . . . . . . 87

13.2 Computer program . . . . . . . . . . . . . . . . 88

13.2.1 Errors in the operating software ........... 88

13.2.2 Errors in the generated data printouts . . . . . . . . 88

13.3 Data system and system voltmeter . . . . . . . . . . . . 89

13.4 Electronic components . . . . . . . . . . . . . . . . . . 90

13.5 System check with the orifice flow constant . . . . . . . . . . 90

13.6 Methane calibration system . . . . . . . . . . . . . . 92

13.7 Exhaust system blower and indicator . . . . . . . . . . . . 93

13.7.1 Mechanical speed check-out . . . . . . . . . . . 93

13.7.2 Checking the zero flow condition . . . . . . . . . . 94

13.7.3 Flow rate checking with $\mathrm{CO}_{2} \ldots \ldots \ldots \ldots 9$

13.7.4 Troubleshooting the exhaust system . . . . . . . . . 95

13.8 General gas analyzer problems . . . . . . . . . . . . . . 96

13.9 Oxygen measurement system . . . . . . . . . . . . . . . . . . . 97

13.10 Thermocouples . . . . . . . . . . . . . . . . . . . . 100

13.11 Pressure transducer . . . . . . . . . . . . . . . . . . . . 102

13.12 System checking with additional gas analyzers . . . . . . . . . 103

13.13 Heat flux gauge . . . . . . . . . . . . . . . . . . . 105

13.14 Cone heater . . . . . . . . . . . . . . . . . 106

13.14.1 Heater troubleshooting . . . . . . . . . . . . 106

13.14.2 Winding a heater element . . . . . . . . . . 108

13.14.3 Heater replacement . . . . . . . . . . . . . . 108 
13.15 Load cell testing . . . . . . . . . . . . . . . . . . . 109

13.16 Laser smoke photometer . . . . . . . . . . . . . . . . . . 109

13.16.1 Alignment of the laser smoke photometer . . . . . . . . . 110

13.16.2 Troubleshooting of the photometer . . . . . . . . 113

13.17 Soot sampler . . . . . . . . . . . . . . . . . . . . 116

13.18 Cold trap . . . . . . . . . . . . . . . . . . 117

\section{List of Tables}

1 Typical oxygen and flow values . . . . . . . . . . . . . 92

2 Typical flow rates at specified fan shaft speeds . . . . . . . . . . 93

3 Mass yields for reference materials . . . . . . . . . . . . . . . . . . 104

4 Molar relationships for reference materials . . . . . . . . . . . . . . 104 


\section{Introduction}

In 1982 the National Bureau of Standards (NBS) developed a new type of apparatus for making bench-scale rate of heat release measurements. Rate of heat release was then beginning to be seen as a key factor in describing the flammability of materials, products, and assemblies. Laboratory instruments for measuring the rate of heat release had already been available at that time for over a decade. These earlier devices, however, were either of a very simple design and subject to serious measurement errors; or, they were capable of good measurement accuracy, but were of extremely complex and costly construction.

During the late 1970 's an entirely new principle was discovered for making rate of heat release measurements. This was termed the "oxygen consumption principle." The method required very precise means of measuring oxygen concentrations; given such capability, however, it was shown that highly accurate rate of heat release measurements could be made without the greatly complex hardware required for earlier designs. A program was then started at NBS to develop a bench-scale rate of heat release test method which could serve as a standard laboratory test. The apparatus became known as the Cone Calorimeter (due to the conical shape of the heating element). It has been provisionally published by ASTM as P 190.

This Guide is intended to provide supplemental information on installation, setup, daily operational procedures, and also on maintenance and troubleshooting. It is assumed that the user has available the following documents:

- Babrauskas, V., Development of the Cone Calorimeter-A Bench-Scale Heat Release Rate Apparatus Based on Oxygen Consumption, Fire and Materials. 8, 81-95 (1984). Also issued as NBS Report NBSIR 82-2611 (1982).

- Proposed Test Method for Heat and Visible Smoke Release Rates for Materials and Products using an Oxygen Consumption Calorimeter (E-5 Proposal P 190), Annual Book of ASTM Standards, Vol. 04.07, pp. 1221-1237, American Society for Testing and Materials, Philadelphia (1986).

- Construction Drawings for the Cone Calorimeter. Available from the Center for Fire Research. National Bureau of Standards, Gaithersburg, MD 20899.

- The manufacturers' instruction manuals for all the analyzers, controllers, pumps, and other off-the-shelf devices that are incorporated into the Cone Calorimeter. 
The first two background documents give the theory behind the Cone Calorimeter, explain the design features of the apparatus, and provide the basic equations of rate of heat release calorimetry. The user must have these documents on hand, since the information given in them is not duplicated in the this User's Guide.

Since it is expected that future revisions of these operating instructions will not necessarily coincide with any revisions of the hardware details, the Figures illustrating the features of the apparatus are not incorporated into the Guide-whenever this document refers to drawings or Figures, the user should refer to the Construction Drawings for the Cone Calorimeter.

The user is assumed to be at least passably knowledgeable in the operation of ordinary analytical chemistry laboratory equipment, and to be well-versed in ideal gas law computations.

There is a large number of actual apparatus details which depend on the laboratory installation. These include the exhaust system switches, instrument control switches, zero and spanning valves, supplemental gas analyzers, etc. The Construction Drawings do not, and cannot, prescribe a mandatory location or configuration for such features. Since the present document was originally developed for training new personnel on the use of the original Cone Calorimeter at the NBS laboratories, such details are described in this Guide as they have been implemented at NBS. Since it became evident that the Guide could form useful guidance for users in other laboratories, it is being made generally available. The installation-specific details given in this Guide will, however, apply directly only to the NBS instrument.

This Guide is a somewhat lengthy document, since the NBS installation contains a very large number of optional features (soot measurement, additional gas analyzers, etc.); in many installations, lacking such supplemental equipment, the operating procedures will be substantially simpler.

\subsection{Customized guides}

It is expected that instrument manufacturers producing Cone Calorimeters will make available customized versions of the Guide, specific to their particular implementation. If such a customized version is available, you should not use this NBS in-house version.

A word-processor-readable form of this guide is also available from NBS on request. 
1.2 Sequence of events

The sequence of events listed below, in most cases, is not of specific importance. In those instances where the sequence is important, this fact will be pointed out.

1.3 User comments

Users finding difficulties with these procedures, or encountering anomalous conditions not described in the documentation are urged to contact the National Bureau of Standards. User comments are specifically invited, and will be incorporated into future editions of this Guide. Phone: (301) 975-6679. Future editions of this Guide will incorporate additional information and suggestions received from users.

3 


\section{Installation and initial set-up}

\subsection{Laboratory environment}

The apparatus has been designed to operate satisfactorily only in a draft-free environment. While adequate ventilation must be ensured, as described below, it is essential that there be no serious cross-drafts blowing through the test area. Such drafts will create combustion complications and non-uniformities.

\subsection{Services required}

1. Ventilation. A hood system is required which can (a) remove the maximum of $50 \mathrm{l} / \mathrm{s}$ from the exhaust stack, while being decoupled from it [that is, the Calorimeter exhaust stack should empty into a collection hood, rather than being directly plumbed into the building exhaust]; (b) remove any smoke drifting up due to specimen insertion or removal; and (c) allow burned specimens to be temporarily placed in a safe location. The requirement for a decoupled configuration is to avoid introducing pressure fluctuations from the building ventilation system or from the outside weather. In practice, thus, the actual rated capacity will have to be,possibly, ten times the maximum $50 \mathrm{l} / \mathrm{s}$ coming from the exhaust itself.

2. Electrical power. Electrical power providing $240 \mathrm{VAC}$ at the instrument must be available. If only a lower voltage, e.g., $208 \mathrm{VAC}$, is available, a boost transformer will be required. If nominal $240 \mathrm{VAC}$ mains are available, but actual delivered voltage is less, the user should expect to find that the rated $100 \mathrm{~kW} / \mathrm{m}^{2}$ irradiance capability may not be achieved. Thus, a boost transformer will be necessary in such cases also. The minimum current capacity required is at least $25 \mathrm{~A}$ for the heater, plus the total rating for the remaining devices and instruments. This, in general, will depend on the installation, although, for commercial instruments, the manufacturer should be able to provide a value.

3. Water supply. Water supply is necessary to cool the heat flux gauge and cold trap. This is a very minimal flow; a pressure regulator set at $250 \mathrm{kPa}(35 \mathrm{psi})$ should be provided if house pressure may undergo surges greater than this value.

4. Drain. A drain line is required to handle the water being provided. 
5. High-pressure air. A supply of clean, dry high-pressure air (approx. $700 \mathrm{kPa}$ ) is required to operate the air actuator for the spark plug. Also, a source of high-pressure air (with an air gun) is essential in clean-up.

6. Natural gas. This service is neither required nor used.

\subsection{Calibration and auxiliary equipment required}

1. Dry test meter. A dry test meter is an essential calibration tool, used for maintaining the accuracy of the electronic mass-flow controller. The mass-flow controller is the device used to control the flow rate of methane being delivered when the daily heat release rate calibration is done. Since it lacks intrinsic calibration, it must be regularly calibrated against a reference dry test meter.

The dry test meter must be calibrated for methane and sized so as to be capable of, at least, $25 \mathrm{l} / \mathrm{min}$ flows. It must also be equipped with pressure and temperature monitoring sensors having a precision of 1 part in 1000 , or better.

2. Digital voltmeter. A high-quality digital multimeter, with at least 5-1/2 digit resolution is required for calibration and troubleshooting purposes. This is in addition to the voltage measuring device(s) associated with the data acquisition system.

3. A precision voltage/millivolt source is optional, but can make troubleshooting much easier.

4. Reference heat flux gauge. In addition to the heat flux gauge used for regular calibration, it is required that the user possess a second, identical gauge, also accurately calibrated. The second gauge is to be used only for a monthly comparison against the operating gauge. Otherwise, it is to be kept in a safe storage location. The additional gauge is necessary because, otherwise, there is no means of detecting a change in the calibration of the operating gauge. Such a change may occur, over time, by itself, or may be provoked by a shortage of cooling water, excessive fluxes, or similar inadvertent incidents. Users expecting to have full-time testing operations should possess three gauges. This will allow one gauge to be sent back to the manufacturer for service.

5. Micro-balance. A balance for weighing soot filters is needed which has a resolution of $0.001 \mathrm{mg}$. The balance should be fitted with a special pan which is intended to support $47 \mathrm{~mm}$ or larger filters. 
6. Laboratory weights. A set of laboratory weights is required for checking the calibration of the load cell.

7. Specimen holder equipment. In addition to two each (minimum) of the horizontal and vertical orientation specimen holders, the user may need the following items:

- An edge frame, used for testing in the horizontal orientation, of wood products and other specimens whose edges need special protection against edge burning.

- A wire grid, used either inside the vertical specimen holder, or else in conjunction with the horizontal edge frame, which functions to restrain intumescing materials.

- A fabric specimen tensioning insert, used for testing fabric specimens over a dead air space; used in conjunction with the edge frame above.

Descriptions of all these items are given in the Construction Drawings.

8. Special tools for aligning and calibrating laser smoke photometer. For alignment, two main tools are desirable, as shown in Figure T2. The first is a metal rod, somewhat smaller than the I.D. of the beam tubes that are welded onto the sides of the exhaust duct. The second is a translucent plastic plug with a thin area in the center, used for inserting in place of a photodetector assembly (or at the end of the main photometer tube, farthest away from the laser). This plug is used as a target for aligning the laser beam. For calibration, the procedures will differ, depending on whether the photometer hardware is of the "original" or of the "new" design (details are given in the LESS-FREQUENT CALIBRATION PROCEDURES Chapter). For units of the original design, the user has to construct a filter-positioning device, which can be inserted into the beam inside the exhaust duct, once the front half of the exhaust duct is removed. This device must be able to position a filter nearly, but not quite perpendicularly to the laser beam. Two glass neutral density filters are required, typically at values of approximately 0.3 and 0.8 optical density ("OD") units, calibrated at the laser wavelength of $623.8 \mathrm{~nm}$. For units of the new design, filter positioning provisions are already incorporated into the photometer, thus, the user needs only to have a calibration filter already mounted in a filter holder which mates with the special filter slots. 
9. Vacuum cleaner. A shop vacuum cleaner is normally required to clean up the debris of specimen burning.

\subsection{Calibration samples}

The user should procure and regularly use the normal calibration sample for the Cone Calorimeter. This sample is PMMA (polymethylmethacrylate) cast sheet stock. It can be obtained as Polycast ${ }^{1}$, black, $25 \mathrm{~mm}_{\text {thick }}{ }^{2}$. [The prior manufacturer for these specimens had been Rohm \& Haas. They are no longer producing this plastic in the required thickness, and, therefore, Polycast is now specified as the supplier. The new data obtained from Polycast will not be identical to any old measurements obtained from Rohm \& Haas stock.] These samples are not prepared in the standard way, as described in ASTM P 190, but rather are to be prepared in the following special way:

Cut the specimens to be $100 \mathrm{~mm}$ by $100 \mathrm{~mm}$ in area. Obtain cardboard stock, approximately $0.5 \mathrm{~mm}$ thick. Prepare from the cardboard strips 25 $\mathrm{mm}$ wide by $100 \mathrm{~mm}$ long. Use a thin layer of adhesive to attach the strips to each edge of the specimens. Cure for at least 24 hours. The adhesive used must hold the cardboard strips firmly during the burning process. Note that no aluminum foil is used with these specimens, and that the protective paper sheets on the top and bottom faces of the plastic must be removed prior to testing. The purpose of the cardboard strips is to create a slow-burning condition at the edges. This allows the specimen regression rate at the edges to approximate that at the center.

The user should retain test data from previous PMMA calibration runs, and compare against those, when necessary in the process of troubleshooting. The flux values are normally chosen to be $25,50,75 \mathrm{~kW} / \mathrm{m}^{2}$. Note that since these calibration runs are for the purpose of diagnostic testing within one laboratory only, ASTM P 190 does not standardize this procedure.

\footnotetext{
${ }^{1}$ Certain commercial products and materials are identified in this document in order to adequately specify the experimental procedure. In no case does such identification imply recommendation or endorsement by the National Bureau of Standards, nor does it imply that the product or material identified is the best available for the purpose.

${ }^{2}$ Type Cellcast BK2025, from Polycast Co., 69 Southfield Avenue, Stamford, CT 06902. Telephone: (800) 243-9002.
} 


\subsection{Initial set-up steps}

1. Test all services described above to make sure they are operational. Doublecheck the values of all calibration gases.

2. Make sure that all the calibration equipment, described above, is available and functional.

3. Prior to placing the Calorimeter under the intended room-exhaust hood, turn on the hood and burn a small item in the place where the Calorimeter will stand. Make sure that all combustion products are adequately cleared, and that the air flow into the sample area is as symmetric from all sides as possible.

4. Roll in the Calorimeter and connect all the services. Turn on all the power switches. Turn on the temperature controller for the cone heater to the maximum value. Leave everything on for a while to make sure electric faults do not develop.

5. Turn off heater; leave on all the remaining power overnight. This will allow gas analyzers and other electronics to stabilize.

6. Check out the load cell, the smoke photometer and each gas analyzer provided with the system by using a strip chart recorder. It is important to verify at this stage that there is no electrical interference, ground loop problems, or other conditions which would result in interference being present on the instrument output. Turn the heater, the cold trap circuit, and the electric sparker on and off in doing this. The strip chart record should show a minimal, if any, noise associated with such switching transients. The outputs should all be correct, constant, and showing only an acceptable amount of thermal noise.

7. Hook up the data acquisition system. Check all channel assignments to make sure that the expected signal is showing up at each data channel. If using a PC-type computer with an analog-to-digital converter (ADC) board, instead of a system voltmeter, verify that (a) at least a 16-bit resolution (including sign bit) is available; and (b) the board uses reed relay, rather than solid-state, switching. Verify that the chosen range for each instrument is appropriate for its expected dynamic range. At NBS, for the basic instruments, the following ranges are required: 


\begin{tabular}{|l|l|}
\hline Oxygen analyzer & 0 to $2.5 \mathrm{~V}$ \\
Load cell & 0 to $1.0 \mathrm{~V}$ \\
Stack thermocouple & 0 to $50 \mathrm{mV}$ \\
Pressure transducer & 0 to $2.5 \mathrm{~V}$ \\
Laser smoke photometer & 0 to $5.0 \mathrm{~V}$ \\
Photometer thermocouple & 0 to $50 \mathrm{mV}$ \\
Soot mass flow indicator & 0 to $2.0 \mathrm{~V}$ \\
\hline
\end{tabular}

8. Set up and test out the computer programs to be used for data collection and reduction. With the program running, check that cold-junction compensation is being properly done for all thermocouple channels. Cold-junction compensation (and linearization) can be done by hardware, by software, or by a combination of both. Since the actual scanner equipment used can not only vary from laboratory to laboratory, but may also be changed to a different type within one laboratory, specific set-up steps cannot be given for general advice. The operator must make certain, however, once the hookup has been made and the data collection and reduction programs to be used have been installed on the computer, that the proper operation is checked out. To do this, prepare the computer software to output the necessary temperature channels (there will be at least two-the stack thermocouple and the smoke photometer thermocouple). Make sure the instrument has not been heated and all temperatures are at ambient. Measure the laboratory air temperature with a thermometer. Then scan the temperature channels on the data system and record their readings in degrees C. A reading close to that obtained from the room thermometer should be found. If not, adjust appropriate hardware switches on the data system, or correct the computer program routines. It may also be desirable to make a similar check at an elevated temperature, for which a boiling water bath can be used.

9. Put in all soot filters and turn on the sampling pumps to all analyzers, even if their outputs are not to be used, so room air will not be drawn backwards through one of the other analyzers and pumps and appear as a leak in the sampling line.

10. Roughly check the zero and span on each gas analyzer. Check that the load cell responds to weights. If any instruments are seen to be faulty, repair them before proceeding. 
11. Perform all the steps indicated in the Less-frequent Calibration ProceDURES Chapter, below. Steps which had been performed by the instrument manufacturer may not need to be repeated at this time.

12. Perform all the steps indicated in the WEekLy Calibration Procedures Chapter, below.

13. Perform all the steps indicated in the START-UP AND DAILY CALIBRATION PROCEDURES Chapter, below. An orifice flow constant in the range 0.040 to 0.046 will be obtained for a unit which is constructed exactly according to the NBS drawings. For units with different duct dimensions, different blowers, etc., a different orifice flow constant will be expected. Once it has been verified that all systems are fully correctly operational and that no leaks are present anywhere in the gas sampling system, the operator should record the constant obtained. Future calibrations which do not produce this constant, to within about \pm 0.003 , will indicate a need for troubleshooting and repair.

14. Once all is in good operation, it is desirable to procure some calibration PMMA material, burn it, and compare results to expected values (details are given in the WEEKLY CALIBRATION PROCEDURES Chapter). Once this is successful, it can be assumed that the installation is satisfactory.

\subsection{Calibration levels}

The standard calibration procedures, described in the START-UP AND DAILY CALIBRATION PROCEDURES Chapter, call for calibration at a $10 \mathrm{~kW}$ level. This level has been chosen because it represents a high heat output, but is not the maximum output detectable. Values up to approximately $20 \mathrm{~kW}$ can be recorded.

The $10 \mathrm{~kW}$ calibration level is chosen to avoid overheating the equipment. At this level, indefinite operation can take place, therefore, calibrations may be made in a deliberate and methodical manner. Extensive operation at the $20 \mathrm{~kW}$ level may result in some ductwork warpage. Heat release rate peaks in excess of $10 \mathrm{~kW}$ are rare; it is expected that they are accurately measured, however, since linearity studies have shown excellent linearity in the 0 to $12 \mathrm{~kW}$ region. 


\section{Spares and supplies}

The user will need to maintain certain supplies and spare parts for the Calorimeter. The needed items are listed here in three categories: (1) regular operating supplies. The quantities to be maintained will depend on the testing schedule being maintained. (2) Essential spare parts. (3) Spare parts which are less essential to a laboratory doing occasional testing, but which may be essential to a laboratory doing full-time testing.

Part numbers needed should be obtained from the data given in the Construction Drawings for the Cone Calorimeter, which is one reason why the user is urged to maintain a current copy of that document.

\section{Operating supplies}

- Calibration specimens of PMMA, as described in the previous Chapter

- Fuses for all instruments; thermal cut-out for $\mathrm{O}_{2}$ analyzer; $30 \mathrm{~A} \mathrm{I}^{2} \mathrm{t}$ ("sub-cycle") fuses for the cone heater power controller.

- Ascarite (unless not used since instead of scrubbing $\mathrm{CO}_{2}$, correction to the heat release rate formula is made using $\mathrm{CO}_{2}$ analyzer readings)

- Drying medium (Drierite or silica gel)

- $90 \mathrm{~mm}$ filters for heated and unheated soot filters

- $47 \mathrm{~mm}$ filters for soot mass sampler

- Floppy disks and tape cartridges for computer

- Ceramic fiber blanket, $13 \mathrm{~mm}$ thick, $65 \mathrm{~kg} / \mathrm{m}^{3}$ nominal density

- Aluminum foil (available as $0.025 \mathrm{~mm}$ thickness in USA and $0.040 \mathrm{~mm}$ in Europe)

- Stainless steel foil, $0.050 \mathrm{~mm}$ thick

- Wire grid mesh, if replaceable type wire mesh is used

- Glass wool, bulk, for backup filtering 
- Silicone sealant of the RTV (room temperature vulcanizing) type

- Span and zero gases for each gas analyzer (where nitrogen is used as the zero gas, it should generally be $99.99 \%$ minimum purity)

- Methane, $99.9 \%$ purity or better, for calibration

- Gas for leak-checking (use pure $\mathrm{CO}_{2}$ if a $\mathrm{CO}_{2}$ analyzer is available, else use pure $\mathrm{O}_{2}$ )

- Combustion air and fuel gases for hydrocarbon analyzer

\section{Essential spare parts}

- Overhaul kit for main sampling pump

- Brushes for exhaust blower DC motor

- Laser, for smoke photometer

- Op-amps (Precision Monolithics OP-07)

- Thermocouple signal module (Analog Devices 2B50A)

- Thermocouples for cone heater, stack, and smoke photometer

- Thermocouple connectors and wire, Type K

- Heater element for cone heater

- Ceramic fiber refractory gasketing material, $2.5 \mathrm{~mm}$ nominal thickness

- O-rings for soot filter assemblies

\section{Additional spare parts}

- Inside cone, stainless steel, for heater

- Orifice plate, for exhaust stack flow rate measuring 
- Power supply for laser

- Hydrocarbon analyzer spares: burner parts, capillaries, sample filter(s)

- Scanner box multiplexer cards

- Pyrex glass for enclosure, if enclosure glass is used

- Temperature controller for cone heater

- Infrared sources for all infrared gas analyzers

- Soot filter support screen, $90 \mathrm{~mm}$, for unheated holder

- Damping fluid for load cell, of several centistoke ratings (350 to 60,000 cS)

- Cold trap body (2 pieces) and Viton gasket 


\section{Data collection and analysis software}

The software operating instructions given below presume that data collection and analysis will be done on a Hewlett-Packard System 200 computer, using software as provided by NBS. With only very minor modifications the software will also work on System 300 computers. Users operating different computer systems will need to develop a guide suitable for their purposes.

At NBS the further development of the software for HP systems has now stopped. While fixes for noted bugs will continue to be provided, software development efforts will focus on IBM (or IBM-compatible) personal computer systems. The new version of the software will be designed so that data collection will be done using an 8088based (or better) PC with an IEEE-488 controller card, controlling the currently specified type of Hewlett-Packard voltmeter and scanner models. (See the Construction Drawings for a list of hardware which has been found to be satisfactory.) For data reduction, the existing software developed for the HP computers had the serious limitation that no reduced data files were stored and no database capabilities were provided. These functions require substantially higher computer power; thus, the software being developed for data reduction, database manipulation, and graphics presentation will only be developed for the more powerful members of the IBM PC or PS/2 families. This software will require computer models which are at least 80286 , and preferably 80386-based.

In the instructions below on how to enter data into the computer, the symbol $\mathrm{C}_{\mathrm{R}}$ will be used to denote pressing the "carriage return," or "enter," key. A carriage return is generally required after all text input, but is not required when pressing any of the "special" keys. Items which the user must enter, that is keyboard text or special labeled keys, are identified in bold-face type below.

\subsection{Data collection}

For any data system operations, the computer system should be fully powered up including the CPU, floppy drive, and hard disk drive; bootup will begin. Once the booting process has successfully loaded the Basic operating system, the message BASIC 4.0 READY will appear.

To run the data acquisition routines, type LOAD "CONAQU" $C_{R}$, then either type RUN $\mathbf{C}_{\mathbf{R}}$ or press the RUN key, to execute the program. You will be prompted to enter the date and time (in military, 24-hour form) in the format shown on the screen. Note that two integers should be typed for each space requested. For example, 
3:30 p.m. on May 19, 1987 would be entered as $\mathbf{5 / 1 9 / 8 7 , ~ 1 5 : 3 0 : 0 0 . ~ T h e ~ p r o g r a m ~}$ will decode this string into the correct date and time to be used in tracking test dates and elapsed times to ignition.

After typing the data, press $\mathbb{R}_{\mathbf{R}}$. The screen will then display 10 highlighted boxes on the bottom of the CRT screen (only 8 boxes possible for the System 300 computer). The pertinent choices are Calibrate and Run a Test. The highlighted areas represent the ten (eight) user-defined keys ("softkeys"), labelled k0-k9 (f1-f8) on the upper left of the keyboard. Now, to select the Calibrate option press the key $\mathrm{k} 0$.

\subsubsection{Calibrate}

The Calibrate option is used at the beginning of the day's testing to obtain the calibration factor necessary for calculation of the mass flow through the exhaust duct. The procedure is straightforward: After selecting this option, the program will first obtain baseline instrument readings. Then it will prompt you to insert a lighted methane burner into bracket provided for that purpose. Allow 3-4 minutes for the flame to stabilize and for the analyzers to register the incoming data. Then, press any key to take the calibration scan. The $\mathrm{O}_{2}$ analyzer, the pressure transducer, and the stack thermocouple are scanned, and the resultant calibration factor is displayed. If this factor is within the range considered normal for the Calorimeter being operated, proceed to run a test by pressing the softkey Run a Test. If the value of the calibration factor displayed is unacceptable, you may repeat this step as often as necessary to rectify the situation. To repeat, press Calibrate again, then any key to compute successive factors. If the calibration factor remains outside an acceptable range, consult the TROUBLESHOOTING AND REPAIR Chapter.

\subsubsection{Run a test}

The Run a Test procedure is as follows:

- Enter a file name to use for storing the data. At NBS we use the convention of TXXXX where XXXX represents successive integers, starting with 0001 for the first test that was logged in.

- You will then be prompted to enter test comments. The first line will be the title line for your test. The standard form consists of: 


\section{Sample material $\mathrm{xx} \mathrm{kW/m2} \mathrm{Hor.} \mathrm{[or} \mathrm{Vert.]} \mathrm{(XXXX)}$}

When you have finished this line, press $\mathbf{C}_{\mathbf{R}}$.

- You will now be asked to type the specimen weight in grams, then press $\mathbb{C}_{\mathbf{R}}$.

- The program will now prompt you to enter any additional pre-test comments you would like to make. You may enter anything you wish, but pre-test comments are limited to 5 lines. When you have finished entering comments, press $\mathrm{C}_{\mathbf{R}}$ on a line on which you have entered nothing else (a blank line).

- The screen will now exhibit a softkey labelled START, corresponding to key k0. You must wait at least 1 minute now for baseline data to be recorded. Any time after 1 minute has elapsed, the actual test can be started. When the sample is placed on the load cell, press the START key momentarily. Be sure not to hold it down.

- Immediately after you have pressed START, you will see that the softkey label for key k0 now corresponds to IGNITION. When you observe ignition, press key k0 again to now send an interrupt to the scanner telling it to temporarily stop collecting data and record the ignition time. (It is more important to correctly record the ignition time, than it is to take the next scan exactly on time.) The elapsed time to ignition will be shown on the screen and data collection resumes.

- After all signs of burning have stopped (or after a specimen was exposed for the length of time specified in ASTM P 190 and did not ignite), the test can be considered completed. Do not stop the test, however, without allowing 2 minutes of additional data collection past this point! (This allows suitable posttest baselines to be verified.) When ready to stop the data collection (but before removing the sample from the load cell) press key $\mathrm{k} 9$, which is labelled END. You will be asked to enter any post-test comments you may have. Again you may use up to 5 lines. When you have finished, you must again press $C_{\Omega}$ on a blank line to inform the computer that you have finished making post-test comments. The message will then be given that the computer is closing this data file. It is important that you do not use the keyboard at all until the screen display shows that this process is complete. 
- You may now run another test (Run a Test), calibrate again (Calibrate), or quit (END), by pressing the appropriate softkey.

\subsection{Data reduction}

The same data reduction software routine could be used with either one of the Hewlett-Packard computer systems. The procedure for analyzing test data is as follows:

- Press the PAUSE key, and then type LOAD "DATARED" $\mathbf{C}_{\mathbf{R}}$.

- Now type RUN $\mathbf{C}_{\mathbf{R}}$ or press the RUN key to execute the program.

- The prompt will be issued for you to enter the data file name to be analyzed. You should type TXXXX, which corresponds to the test number you desire to reduce, and then press $\mathbb{C}_{\boldsymbol{R}}$.

- The program will display the pre-test comments. Also, there will be a display showing the progress as each 40 scans of data have been read. When the data scan corresponding to the ignition time is encountered, the elapsed time to ignition will be displayed on the screen. When the entire test has been read into the raw data array, the program will display the post-test comments, and then it will display FINISHED READING TEST XXXX.

- Next, there will be a slight pause as the gas analyzer data are time-shifted by the time delay value. The length of this pause varies directly with the length of the test.

- Choices for the next step to be taken will now be highlighted in reverse video on the softkeys. These are DATA ANALYSIS, PRINT DATA, PLOT, READ NEW TEST, and EXIT. The first choice should always be DATA ANALYSIS.

- Once you press DATA ANALYSIS, the program will display a menu (first of the two principal menus that the data reduction program shows) of the parameters of the program. Each parameter is displayed with a selection number. The program will prompt you to enter the selection number identifying the parameter you want to change, or $\mathbf{0}$ to continue with the program execution. It is very important that you understand that the selection number of a parameter must be entered first to be possible to change it. 
- The procedure to change the parameters of the software is the following:

$\triangleright$ The menu will display what has been recorded as the calibration factor for this test. If this value is not correct, enter a $\mathbf{1}$ to enable changes to be made. The program, then, will prompt you to enter the corrected calibration factor. Type the correct value and press $\mathbb{R}_{\mathrm{R}}$. As soon as you do this, the new value will be shown in the corresponding place of this parameter in the menu.

$\triangleright$ Enter a 2 to be able to input the initial mass of sample. The program will prompt you to enter the initial mass of sample-type it and press $\mathcal{C}_{\mathbf{R}}$; the value will be shown on the screen.

$\triangleright$ Enter a $\mathbf{3}$ to be able to input the irradiance value used. The program will then prompt you to enter the value. Type in the value and press $\mathbf{C}_{\mathbf{R}}$. The value will appear on the screen.

$\triangleright$ Most of the tests are made in the horizontal orientation. Thus, the default value of the orientation has been chosen to be horizontal. If the present test was done in the vertical orientation, enter $\mathbf{4}$ for its selection number. The change will be make, and the word VERTICAL will appear now in the appropriate place for this parameter on the screen.

$\triangle$ As in the previous case, most of the tests are made using the nominal area of $0.01 \mathrm{~m}^{2}$ for the surface area of the sample. So, this value is used as the default value for the surface area, and is shown in the menu. If some area other than $0.01 \mathrm{~m}^{2}$ was used, enter 6 to enable changing the default value. The screen will show now the different choices of surface area that you have. The program will prompt you to enter the choice number of your surface area selection. If the value actually used is not shown, enter 5 in response. Now you will prompted to enter the new surface area value in units of $\mathrm{m}^{2}$; type it and press $\mathbb{R}_{\mathrm{R}}$. Once you have selected your area the new value will be displayed on the screen.

$\triangleright$ To change the general chemistry default constants-the oxygen consumption conversion factor or the fraction of carbon in fuel (the latter used only for certain special investigations) - enter 6 . The program will display a menu with several predetermined choices, and will prompt you to enter the selection number of your conversion factor. Enter the selection number. If your specific conversion factor is not shown, enter 8 . The program will prompt you to enter a name associated with this conversion factor; type 
it and press $\boldsymbol{C}_{\boldsymbol{R}}$. You will now be prompted to enter the new conversion factor, in units of $\mathrm{kJ} / \mathrm{kg} \mathrm{O} \mathrm{O}_{2}$ burned. Type the value and press $\mathrm{C}_{\mathbf{R}}$.

Then, the program will prompt you to enter the new value of the fraction of carbon in fuel; or hit $\mathcal{C}_{R}$ to use 0.6 , which is an arbitrary default value artificially set. After these new values are entered, they will be displayed on the screen.

$\triangleright$ The scale ranges for the gas analyzers in use vary only rarely. The menu will, next, show the customarily used ones as the default values. If any of those are not right, type 8 to be able to change it. The screen will then show a menu with the different gas analyzers identified, and the program will prompt you to enter the selection number pertinent to the analyzer whose range is to be changed. Enter your choice, and then you will be prompted to enter the new value of the gas meter range in ppm (or just hit $\mathbf{C}_{\mathbf{R}}$ to keep the old value). Type the value and press $\mathbf{C}_{\mathbf{R}}$. You will now be prompted to enter the value of the volts full-scale for the same analyzer (or hit $\boldsymbol{C}_{\mathbf{R}}$ to use the old value). Each time you change a value it will be shown in its corresponding place on screen. Once you have made all your changes, type $\mathbf{0}$ to continue. The screen will now show the principal menu with all the changes made.

$\triangleright$ If some of the parameters are still not correct, you can change them by repeating the steps above. When you have verified that everything is correct type $\mathbf{0}$ to continue.

$\triangleright$ The screen will now show the second principal menu, and the program will prompt you to enter the selection number of the parameter to be changed or $\mathbf{0}$ to continue. Mostly, it involves Yes/No questions, defaulted to the most common response.

$\triangleright$ The $\mathrm{H}_{2} \mathrm{O}$ analyzer is usually non-defective, so the first parameter of the menu is defaulted to ' $\mathrm{N}$ ' for a negative answer. Type $\mathbf{1}$ if the $\mathrm{H}_{2} \mathrm{O}$ analyzer was broken during this test. The program will verify this selection on the screen, and later in the computations will calculate an imputed value for the $\mathrm{H}_{2} \mathrm{O}$ readings, using the measured $\mathrm{CO}_{2}$ values and an $\mathrm{H}_{2} \mathrm{O} / \mathrm{CO}_{2}$ molar relation.

$\triangleright$ Usually, here at NBS, Ascarite is used to scrub out $\mathrm{CO}_{2}$ from the $\mathrm{O}_{2}$ line. Due to this, the second parameter is ' $\mathrm{Y}$ ' for an affirmative answer. If you did not use Ascarite to scrub out $\mathrm{CO}_{2}$ from the $\mathrm{O}_{2}$ line, the rate of 
heat release expression must be calculated including the $\mathrm{CO}_{2}$ terms. In that case, enter 2 to the prompt. The program will show an ' $\mathrm{N}$ ' in the corresponding place in the menu. Later, in the computations the switch to the pertinent heat release expression will be made.

$\triangleright$ The next question is whether or not the load cell was used for this test. In most tests, the answer is yes (the exceptions are gas burner tests). For such tests, enter 3 if you did not use the load cell. The program will then prompt you to enter the actual value of the mass rate used, or hit $\mathbf{C}_{\boldsymbol{R}}$ to use an arbitrary default value.

$\triangleright$ Entering item 4 toggles between "used" and "not used" answers for the Tapered Element Oscillating Microbalance (TEOM). [The TEOM is a research instrument currently being explored for use by NBS. Most other laboratories can ignore this item.] If the TEOM was used, the program will then prompt for the amount of soot collected in the filter, in grams. Type the value and press $\boldsymbol{C}_{\boldsymbol{R}}$. If you press $\boldsymbol{C}_{\mathbf{R}}$ without entering a value, the program will use the default value of 0 . grams.

$\triangle$ If you used TEOM, but the conversion factor for TEOM was not the default value of 100 micrograms per volt, enter $\mathbf{5}$. The program will prompt you to enter the new value of the conversion factor for TEOM. Type in the value and press $\boldsymbol{C}_{\boldsymbol{R}}$. The new value will be displayed on the screen.

$\triangleright$ Finally, if some of the parameters are not correct, you can repeat any of the steps above to change them. When you are sure that everything is correct, type $0 \mathrm{C}_{\mathbf{R}}$.

- At this point, the program is ready to begin the data reduction.

- The program will display its progress by showing on the screen the computations that are performed.

- When this display is finished, you have now finished the analysis of the data of your test.

- You can now obtain data outputs by pressing PRINT DATA. The program will ask you what kind of data report do you want to print. The options are LONG DATA FILE, COVER SHEET, REDUCE DATA, and RAW DATA. 
- You may obtain a complete listing of all the reduced data in engineering units by selecting LONG DATA FILE, or, only a summary of the reduced data by selecting COVER SHEET. The REDUCED DATA option is used to print columns of data from only certain, selected variables of the test. The RAW DATA option is, similarly, used to obtain the raw data read from the instruments, before conversion to species yields, etc.

- After all the desired tabular outputs have been generated, you can exit the print data menu by selecting EXIT PRINT.

- Now you can obtain plots of the data by selecting the PLOT option. The main graphics menu screen will then be presented. It consists of the following primary, pre-selected choices:

$\triangleright$ HT REL - HT COMB provides for a combined plot, with the heat release rate on the left $\mathrm{Y}$-axis and the heat of combustion on the right Y-axis.

$\triangle$ EX AREA - M DOT provides for a combined plot, with the smoke extinction area on the left $\mathrm{Y}$-axis and the specimen mass loss rate on the right $\mathrm{Y}$-axis.

$\triangleright \mathrm{CO} 2$ - $\mathrm{H2O}$ provides for a combined plot, with the $\mathrm{CO}_{2}$ yields on the left $\mathrm{Y}$-axis and the $\mathrm{H}_{2} \mathrm{O}$ yields on the right $\mathrm{Y}$-axis.

$\triangleright$ OTHERS provides for an auxiliary selection menu for additional preselected choices. The software routines creating this menu have been designed to allow it to be customized to accommodate current experimental data presentation needs.

$\triangle$ SINGLE Y-AXIS and DOUBLE Y-AXIS provide for user assembled special plots. Selecting the option SINGLE Y-AXIS enables you to choose the reduced data that will be assigned to the left $y$-axis, and which will then be shown in the graph as a function of time. Selecting the option DOUBLE Y-AXIS enables you to choose separate reduced data variables that will be assigned to the left $\mathrm{y}$-axis and to the right $\mathrm{y}$-axis, with both shown on the same graph as functions of time.

- Once you have selected the reduced data that are to be plotted, the program will display a secondary menu with the following choices for the softkeys: SELECT 


\section{DATA, GRAPH TITLE, X RANGE, Y RANGE, PLOT CRT, PLOT PLOTTER, PARAMETERS, and EXIT CHOICES.}

- For the GRAPH TITLE option, the first line of the plot title is defaulted to the test title which was entered during the data collection. If you wish to use this default value, press $\mathbf{C}_{\mathbf{R}}$ when prompted for the first line of the test title. Conversely, you may enter a first line of your choice at this time. You are, in either case, then requested for a second line for each graph. At NBS our convention for the second line on the plot title has been the following:

$$
\text { Mo }=\mathrm{xx} . \mathrm{x} \mathrm{g} ; \mathrm{Mf}=\mathrm{xx} \cdot \mathrm{x} \mathrm{g} ; \mathrm{T} \text { Ign. = xx.x s; date }
$$

where the Mo and the Mf are the initial and final sample mass, respectively.

- Each of the variables which may be plotted has associated with it a certain default scale value. You may wish to preview the plot by pressing the PLOT CRT softkey and observing if the scaling is correct. If not, then choose the $\mathbf{X}$ RANGE or Y RANGE choices to alter the maximum and minimum values for the $\mathrm{X}$ and $\mathrm{Y}$ axes, and to determine the number of tick marks to be used. When plots of the DOUBLE Y-AXIS type are selected, you will be prompted separately to enter values pertinent to the left and to the right axes.

- The option PARAMETERS is used to show a list of the current parameters values of the graph. This option gives a listing only; you cannot alter parameters by using this softkey.

- The option PLOT PLOTTER is used to actually draw the curve(s) on the plotter.

- Once you have finished drawing a data plot, you can either re-plot the same data using different RANGE values, or you can exit to the main graphics menu by pressing EXIT CHOICES.

- When finished with all plots for a given test, exit the graphics routine by pressing EXIT GRAPHICS.

- If you want to re-analyze the data from the test, but only for a specific number of scans, press the DATA ANALYSIS key. The program will show a menu with the current ignition and end times for this test. Choices will then be presented for the range of test times to be analyzed. 
- When you have finished all the printing and plotting of data for one test, you may reduce and print/plot the data from another test by selecting the READ NEW TEST option that appears on the main menu, or finish the execution of the program by pressing EXIT. 


\section{$5 \quad$ Daily start-up and calibration procedures}

The steps below are predicated on the assumption that the Calorimeter has been shut down in the prescribed manner the previous day and no problems were noted in any of the equipment. Maintenance and troubleshooting are described in later Chapters. In each case, the expected result for each action taken is described. If the unexpected does occur, some troubleshooting and corrective action will be necessary.

The order of the steps indicated in this Chapter should be followed unless there are specific reasons to the contrary.

Note that there are mandatory calibration procedures to be followed on a weekly basis. If a week, or more, has elapsed since the last time these calibrations were performed, these weekly calibrations must also be performed before testing is done. In such a case, the user should complete the daily start-up procedures, but before any testing is actually started also complete the necessary weekly calibrations (see the WEEKLY CALIBRATION PROCEDURES Chapter). There are also additional calibration procedures which are done on a less frequent or as-needed basis. Those are described in the LESS-FREQUENT CALIBRATION PROCEDURES Chapter.

\subsection{General}

The power switches are part of a group of four toggle switches (MAIN, WATER, PUMP, HEATER) located on the front of the Calorimeter bench which control the electrical power to the various components of the apparatus.

- Turn on the MAIN power switch.

The MAIN toggle switch controls the power to the pumps and blowers on the apparatus. It does not turn off any of the analyzers. It can be used to shut down the main electrical power quickly in an emergency.

- Turn on the WATER power switch.

The WATER switch opens a solenoid valve on the water line allowing water to flow to the cold trap and the flux gauge. It also supplies electrical power to the power supply for the thermoelectric cold plates. The MAIN switch must be on before there is power to the WATER switch. The thermoelectric cold plates are the heart of the cold trap. They cool the inside of a box full of glass beads. The sample gas going to the oxygen, $\mathrm{CO}_{2}$, and $\mathrm{CO}$ analyzers passes over and 
around these beads causing the water vapor in the gas to condense on the beads. This condensed water is drained each day before starting that day's run.

- Turn on the power to the heated sample lines.

The circuitry in the total hydrocarbons analyzer controls the heating of the main heated sample line and the heated soot filter. The main power switch for the analyzer in normally left on all the time. This switch is a pushbutton switch with the notation PWR. If this switch is not pushed in, then do so.

There are two heater switches, labeled SAMP and DET. They denote the heaters in the sample line + filter and the heaters in the detector base of the analyzer, respectively. The normal operating temperature for both the detector base and the sample line + filter is $175^{\circ} \mathrm{C}$. Turn both of these on, by pushing them in. It takes about 20 minutes for the sample lines, filter and detector base to heat up to the $175{ }^{\circ} \mathrm{C}$, which is why the analyzers that do not require the heated lines will be calibrated first in the procedures below.

- Turn on the power to the $\mathrm{HC} \ell$ analyzer, if it is to be used.

This analyzer is highly stable and warms up quickly, thus it is normally turned off at the end of the day. If turned on now, it will be ready to calibrate by the time the calibration sequence reaches it. If it is desired to calibrate the $\mathrm{HC} \ell$ analyzer only, then allow 20 minutes for it to come up to operating temperature.

- Check that the power to the supplementary heating line is on.

\subsection{Checking the cold trap temperature setting}

The cold trap temperature is regulated by a controller and a thermocouple. The normal operating temperature of the cold trap will depend on the type of cold trap that is used. For a thermoelectric trap constructed according to the Construction Drawings, this value is $0^{\circ} \mathrm{C}$. For traps of other designs, a minimum temperature will have to be established which does not lead to trap freezing. Each day, before the first test is run, a check should be made on the cold trap temperature to make sure it is within the right range. This temperature may need adjusting depending on the sample burned. Samples which liberate a lot of water vapor throughout a long test may cause the cold trap to freeze up and block off the flow of gas to the analyzers. If 
this should occur, raising the controller's temperature setpoint up a few degrees will solve this problem.

\subsection{Changing the drying and $\mathrm{CO}_{2}$ removal media}

The drying agent is always necessary and is either Drierite or silica gel. The $\mathrm{CO}_{2}$ scrubbing medium is not necessary if a system has been implemented whereby readings from a $\mathrm{CO}_{2}$ analyzer are used in an appropriate form of the rate of heat release equation. At NBS Drierite and Ascarite, respectively, are used for these functions. They are located in plastic tubes next to the oxygen analyzer. The Drierite is on the right and the Ascarite is on the left.

1. The Drierite cartridge uses $\mathrm{CaSO}_{4}$ to remove any residual moisture which may be left after passing through the cold trap. At least some fresh (indicating) Drierite is mixed in any regenerated (white, non-indicating) Drierite to give a visual indication of when the Drierite is saturated and needs replacing. The indicating Drierite is blue when it is fresh and becomes pink as it gets saturated. One should always check the color in the tube before starting a test to be sure there is enough active Drierite to complete the test. All the gas going to the oxygen, $\mathrm{CO}_{2}$ and $\mathrm{CO}$ analyzers passes through the Drierite.

2. The Ascarite is used to scrub out the $\mathrm{CO}_{2}$ in the gas stream going only to the oxygen analyzer. Ascarite is $\mathrm{NaOH}$ on a clay filler. The color of fresh Ascarite is a light brown. As it absorbs $\mathrm{CO}_{2}$, the color changes to white. Excess water in the gas stream will cause the individual grains to fuse together and may even cause a solid plug to develop and block the gas flow. Always check the analyzer rotameters before starting a test to be certain that the Ascarite is not blocking the gas flow. It is important to correctly replace the Ascarite on the left and the Drierite on the right in their holders. If they do get reversed the $\mathrm{CO}_{2}$ reading will be wrong. 


\section{PRECAUTION}

Because Ascarite is a strong base, care must be exercised in handling it. It is recommended that rubber gloves be used for handling Ascarite to avoid skin irritation. Also, Ascarite spilled on the apparatus can damage it. Avoid spilling any of it on the equipment-clean it up promptly with water if you do.

\subsection{Draining the condensed water from the cold trap}

The cold trap condenses water from the gas sample line. When the Calorimeter is shut down at the end of the day's testing, the power is turned off to the cold trap. This causes the water which was previously frozen to the glass beads to melt and drip down into a collection tube. At the bottom of this tube is a large ball valve. This valve is opened and a cup placed below it to collect the water. Once all the water is drained out, simply turn the valve 90 degrees to close it. Discard the collected condensate.

\subsection{Changing the soot filters}

1. The $\mathrm{O}_{2}, \mathrm{CO}_{2}$, and $\mathrm{CO}$ sampling line has a non-heated $90 \mathrm{~mm}$ soot filter in it. This filter prevents soot from getting into the pump and the analyzers. This filter is located on the bench just to the right and back of the four previously mentioned toggle switches. This filter must be changed as often as necessary. Some samples burn clean enough to allow the same filter to be used for several tests. Other samples burn so dirty that the filter will only last through one test. Of course, never change any of the filters while running a test. When a new filter is inserted, make sure that it is firmly seated and that there are no leaks around the edge. If there is any evidence that soot has blown by the filter, the backup filter (fiberglass wool stuffing) must be taken out of the line and renewed.

2. The sampling line going to the water vapor, hydrocarbon, and $\mathrm{HC} \ell$ analyzers is a heated line. In this line is a heated $90 \mathrm{~mm}$ soot filter. This filter should also be checked between tests and changed as required. The filter is located 
inside a large stainless steel canister at the back of the bench. To change the filter, turn the lever on top of the canister and lift the top of the canister. The top will pivot on its hinge and expose the filter. At the start of the day, before the sampling line heaters have been turned on, the canister will be cold, but after the analyzer has been operating this canister will be hot! If a new filter is needed, make sure that it is seated concentrically and is not off to one edge.

3. There is one other filter on the apparatus; this is the soot sampler. This filter is located in a holder found on the front top rail of the Calorimeter bench. This filter collects a fraction of the soot flowing down the main duct. The type of filter used here is critical; the user should not deviate from the type of $47 \mathrm{~mm}$ Teflon-coated glass filters recommended in the Construction Drawings. This filter is carefully dried and weighed before and after each test to determine the exact mass of soot collected. This filter is placed in the holder just before the start of the test. At all other times a blank of solid Teflon is placed in the filter holder to block the flow through this line. Before inserting the weighed filter at the start of an actual test, one should also wipe out the holder to remove any residual soot and blow out the sampling line with high pressure air to remove any loose soot from the previous test.

\subsection{Activating the hood exhaust system}

[This description is pertinent only to the Calorimeter located in Polymers Bldg, Room A-350 at NBS; other users will need to develop similar procedures.]

1. There are two main components in the hood exhaust system. One component is the hood and damper in the room with the Calorimeter. The other is the fan and afterburner in the attic of the building. Both systems must be turned on before burning anything in the Calorimeter. To activate the damper and hood in the Calorimeter room, go to the control panel located in the back corner of the room and find the row of five knobs. Set the far left knob to AUTO. Ignore the two knobs marked SUPPLY-MANUAL and EXHAUST-MANUAL as they are only active when the far left knob is in the MANUAL mode. Set the knob marked FAn to MEDium. Set the knob marked Damper to AFterburner-CONE. The hood in room A-350 is now set.

2. The afterburner-fan system must be activated by going to room B-359 in the other corridor of the building, where the control panel for the afterburner is 
located. On this panel there are three lights, an on-button, an off-button and a timer knob. One of the lights should always be on. This is the FUME FAN CONTROL light, which is blue. It shows electrical power is available. To activate the afterburner-fan system, the timer knob must be first set to the expected number of hours needed for the system to run.

Next press the ON button. This should cause a green light to come on immediately below the title FUME FAN RUNNING. A few seconds later the light below the title FUME FAN + PRESSURE DIFFERENTIAL should come on, indicating the system is functioning properly. A tag showing which room is using the system must then be hung on the hook provided. This tells other users of the system who is using the afterburner system and prevents someone from accidentally turning the system off. The hood system is now set to run a test.

\subsection{Gas analyzer calibration (Zero/Span)}

There are two racks of analyzers. One rack contains those analyzers which do not require a heated sampling line: $\mathrm{O}_{2}, \mathrm{CO}_{2}$, and $\mathrm{CO}$. The other rack contains the analyzers supplied from the heated sampling line: water vapor, total unburned hydrocarbons $\left(\mathrm{CH}_{x}\right)$, and $\mathrm{HC} \ell$. The procedures described below are directly applicable only if the following makes of analyzers are used: a Servomex $\mathrm{O}_{2}$ analyzer, $\mathrm{MSA} \mathrm{CO}_{2}$ analyzer, Thermo Environmental Instruments $\mathrm{CO}$ and $\mathrm{HC} \ell$ analyzers, Scott total unburned hydrocarbons $\left(\mathrm{CH}_{x}\right)$ analyzer, and $\mathrm{MSA} \mathrm{H}_{2} \mathrm{O}$ analyzer. Users in other laboratories who are not using the identical manufacturers' analyzers will have to develop their own calibration procedures.

A wall chart is maintained identifying the location and the purpose of each of the calibration gas cylinders. In performing the calibrations, use this chart to make sure that the correct cylinder is being used.

In doing the calibrations below, it must be emphasized that, if the flows to any gas analyzer are not identical in the zero, span, and sample conditions, a correct calibration will not be achieved! It is assumed that all the analyzer flow rates were previously set up correctly, as described in the Chapter on LESS-FREQUENT CALIBRATIONS. During daily calibration, however, the operator should check that the flow rates, as indicated by the appropriate rotameter, are identical during zeroing, spanning, and sample running. If necessary, correct the flow rates by adjusting the pressure regulator on the zero or span gas cylinder. 
- Setting the correct ranges on the analyzers.

The $\mathrm{CO}_{2}$ and the water vapor analyzers do not have any range adjustment, but are fixed at $5 \%$ and $10 \%$ maximum, respectively.

The $\mathrm{O}_{2}$ analyzer has a range switch, but this should never be changed. The correct setting is for the $0-25 \%$ range.

The $\mathrm{CO}$ analyzer has numerous range setting possibilities. It is important to note that the $\mathrm{ppm}$ reading on the meter on the front of the $\mathrm{CO}$ analyzer will read correctly over the whole instrument range, regardless of the range switch settings, but that the analog voltage output to the data acquisition system will be pegged out if too low a range is specified. The three typical ranges most often used are zero to $1,000,2,000$, and $5,000 \mathrm{ppm}$. These correspond to the range switch settings of 6,7 , and 8 respectively. Both halves of the switch should be set to the same value, i.e., for range 6 , the range switch should be set to 66 . To double-check the range selection, use the STAT button; make sure to push RUN when finished. If during a test it is noted that over-range errors are detected, the test should be re-run with a higher range setting. This analyzer also has a response time switch. Make sure that TIME is set for 00 .

The hydrocarbons analyzer also has numerous range settings possible. Set the range button to the appropriate range. Often the $1000 \mathrm{ppm}=10$ volts full scale range is used. Again, if during a test it is noted that over-range errors are detected, the test should be re-run with a higher range setting.

The hydrogen chloride analyzer has a range adjustment of the same type as the $\mathrm{CO}$ analyzer. This analyzer will not be used at all for specimens which do not contain chlorine molecules. For those that do, some calculations may be helpful beforehand to determine an appropriate value for the maximum expected $\mathrm{HC} \ell$. The ranges most commonly used will be zero to 200,500 , and $1000 \mathrm{ppm}$, which correspond to range switch settings of 5,6 , and 7 , respectively. Verify also that the response TIME switch is set at 00 .

- Zeroing the $\mathrm{O}_{2}, \mathrm{CO}_{2}$, and $\mathrm{CO}$ analyzers.

These analyzers are calibrated as a group because the solenoid valves to the zero and span cylinders are hooked together in a group.

1. Set the SAMPLE-ZERO- $\mathrm{CO}_{2} / \mathrm{CO}-\mathrm{SPAN} \mathrm{O}_{2}$ switch, located below the oxygen analyzer, to ZERO. This opens the nitrogen gas line to the $\mathrm{O}_{2}$ and $\mathrm{CO}_{2}$ analyzers. 
2. Push the RUN button located on the $\mathrm{CO}$ analyzer once. A red light should come on below the word zERO. This opens the nitrogen gas line to the $\mathrm{CO}$ analyzer. (A red light should always be flashing above the word RUN on this analyzer.)

3. Turn on the $\mathrm{N}_{2}$ cylinder and check the rotameters on the $\mathrm{O}_{2}, \mathrm{CO}_{2}$, and $\mathrm{CO}$ analyzers. The desired flows to these instruments are: 2 cubic feet/hour for the $\mathrm{CO}_{2}$ analyzer; $1 \mathrm{LPM}$ for the $\mathrm{CO}$ analyzer; and " 4 " on the rotameter for the $\mathrm{O}_{2}$ analyzer. The flow to the $\mathrm{O}_{2}$ analyzer seldom needs adjustment because it is controlled by a mass flow controller, which makes necessary flow corrections over a broad range of inputs. If adjustment is required to the flow to the $\mathrm{O}_{2}$ analyzer, a potentiometer just below and to the left of the $\mathrm{O}_{2}$ analyzer regulates the setpoint of the mass flow controller. A pair of banana jacks is provided on the rear of the instrument rack to read out the flow rate being supplied by the oxygen mass flow controller. For the correct flow rate $(225 \mathrm{~m} \ell / \mathrm{min})$ an indication of 1.27 volts should be seen. If required flows are not obtained, one must first check the pressure regulator on the $\mathrm{N}_{2}$ cylinder and the knob of a valve below the $\mathrm{CO}_{2}$ analyzer's rotameter.

There is no separate adjusting valve in the gas line to the $\mathrm{CO}$ analyzer. There is, instead, a restrictor orifice within the analyzer itself. The flow rate valve on the $\mathrm{CO}_{2}$ analyzer will change the flow to the $\mathrm{CO}$ analyzer. It must then be adjusted so that there is adequate flow to the $\mathrm{CO}$ analyzer also.

4. With the $\mathrm{N}_{2}$ flowing at the proper rates to the analyzers, their respective outputs must be set to zero. Using the digital voltmeter, plug it into the patch panel plug labeled $\mathrm{O}_{2}$. The voltmeter should read very close to zero volts. If it does not, the red knob on the left behind the small gray door of the $\mathrm{O}_{2}$ analyzer must be turned to obtain a true zero. Next, move the voltmeter plug from the $\mathrm{O}_{2}$ plug to the $\mathrm{CO}_{2}$ plug on the patch panel. The voltmeter should again read zero. If not, adjust the ZERO knob on the $\mathrm{CO}_{2}$ analyzer until it does. This may be difficult to set precisely to zero, since there is some analyzer noise at that level. For zeroing the $\mathrm{CO}$ analyzer, it is sufficient to use the digital meter on the face of the analyzer. This meter reads directly in ppm. Again, the desired output is zero. If the meter is not reading zero ppm (or, more precisely, within $1 \mathrm{ppm}$ of a 0 ppm reading), 
then the three small thumbwheels below the word ZERO must be turned to get the zero output.

This completes the zeroing of the $\mathrm{O}_{2}, \mathrm{CO}_{2}$, and $\mathrm{CO}$ analyzers. Turn off the $\mathrm{N}_{2}$ gas cylinder.

- Spanning the $\mathrm{CO}_{2}$ and $\mathrm{CO}$ analyzers.

This is similar to zeroing them with a few differences. The span gas for the oxygen analyzer will be room air. A nominal value of $20.95 \%$ oxygen is assigned to room air. With the recent introduction of the FTIR spectrometer into the lab, and its associated purging with nitrogen, it is important to be sure that the lab is well ventilated before assuming that the $\mathrm{O}_{2}$ concentration is $20.95 \%$.

1. Set the SAMPLE-ZERO- $\mathrm{CO}_{2} / \mathrm{CO}-\mathrm{SPAN} \mathrm{O}_{2}$ switch located below the oxygen analyzer to $\mathrm{CO}_{2} / \mathrm{CO}$. This opens the $\mathrm{CO}_{2} / \mathrm{CO}$ span gas line (note that a single calibrated cylinder mixture is used which contains both $\mathrm{CO}$ and $\mathrm{CO}_{2}$ gases) to the $\mathrm{CO}_{2}$ and $\mathrm{O}_{2}$ analyzers only.

2. Push the RUN button located on the $\mathrm{CO}$ analyzer once. A red light should come on below the word SPAN. This opens the span line to the $\mathrm{CO}$ analyzer. The red light should still be flashing above the word RUN on this analyzer, just as before.

3. Turn on the $\mathrm{CO}_{2} / \mathrm{CO}$ span gas cylinder. Check chart on back wall of lab for proper location of this cylinder. $\mathrm{CO}_{2} / \mathrm{CO}$ span gas should now be flowing to the $\mathrm{O}_{2}, \mathrm{CO}_{2}$, and $\mathrm{CO}$ analyzers. Be sure the flows to the analyzers are the same as those shown for the zero gas. If not, adjusting the cylinder pressure regulator and the knob of the valve on the $\mathrm{CO}_{2}$ line will bring them back into their proper flows.

4. With the $\mathrm{CO}_{2} / \mathrm{CO}$ span gas flowing at the proper rates to the analyzers, their respective outputs must be set to the proper values. Using the digital voltmeter, plug into the patch panel plug labeled $\mathrm{CO}_{2}$. Determine that the proper reading on the voltmeter is being obtained for the current calibration gas cylinder. This value is arrived at by knowing the certified $\mathrm{CO}_{2}$ level in the span gas cylinder and using a curve supplied by the analyzer manufacturer. If the voltmeter does not give this value, then adjust the SPAN knob on the $\mathrm{CO}_{2}$ analyzer. The patch panel (analog) output of the $\mathrm{CO}$ analyzer will depend on which range the analyzer is set on. On the lower ranges, the span gas concentration used can cause the voltmeter to 
peg out at 10.0 volts, which is wrong. Thus, to be able to use any desired range, it is desirable, instead, to rely on the front-panel meter on the CO analyzer. The value indicated should be exactly the ppm value of the calibration gas cylinder. If not, the span thumbwheels on the analyzer must be adjusted to get this value.

This completes the spanning of the $\mathrm{CO}_{2}$ and $\mathrm{CO}$ analyzers. Turn off the span gas cylinder and let gas bleed out of lines.

- Spanning the $\mathrm{O}_{2}$ analyzer.

To span, set the SAMPLE-ZERO- $\mathrm{CO}_{2} / \mathrm{CO}-\mathrm{SPAN} \mathrm{O}_{2}$ switch, located below the $\mathrm{O}_{2}$ analyzer, to SAMPLE. This selects normal sample atmosphere to be drawn into the analyzer. Turn on the toggle switch labeled PUMP.

Push the RUN button located on the CO analyzer once. This closes the span valve and opens the sample line. The only light on the analyzer should be the one flashing above the word RUN. The $\mathrm{O}_{2}, \mathrm{CO}_{2}$, and $\mathrm{CO}$ analyzers are now receiving room air by way of the duct from the Cone through the filter, pump, cold trap, Drierite, and Ascarite. The oxygen analyzer should be reading 2.0950 volts with the digital voltmeter plugged into the $\mathrm{O}_{2}$ plug on the patch board. If the voltage is different from this, use the right hand red span knob located behind the gray door on the $\mathrm{O}_{2}$ analyzer to set the correct voltage.

Since, at this time, room air will be flowing through several other analyzers, it is convenient to check that their background readings are correct. The CO analyzer should be reading background $\mathrm{CO}$, which is almost zero. The $\mathrm{CO}_{2}$ analyzer should be reading the background $\mathrm{CO}_{2}$, which is typically about 400 ppm. This completes the zeroing and spanning of the $\mathrm{O}_{2}, \mathrm{CO}_{2}$, and $\mathrm{CO}$ analyzers.

Note that even though a SPAN $\mathrm{O}_{2}$ position is provided on the selector switch, this position is not used in daily calibration. The purpose of this switch position is to make available an additional level of $\mathrm{O}_{2}$ for troubleshooting purposes. Typically, a cylinder of $17 \%$ oxygen is connected to this position and is used only in case of suspected malfunctions of the oxygen measuring system.

- Water vapor analyzer calibration.

Plug in (back of the analyzer rack) the heated-head sampling pump which is used for the water vapor analyzer.

Using the 10-point temperature indicator, check that the heated extension sample line which goes from the total hydrocarbons analyzer to the water vapor 
analyzer has been equilibrated to the right temperature $\left(60^{\circ} \mathrm{C}\right.$ to $100^{\circ} \mathrm{C}$ range $)$. (The heater and heater controller for this line are normally always "on.")

To zero the analyzer, first turn on the nitrogen cylinder. Then push the button marked zERO just below the hydrocarbon analyzer. Nitrogen gas should be flowing through the water vapor analyzer's rotameter at $2.0 \mathrm{\ell} / \mathrm{min}$. If not, adjust the flow by adjusting the regulator on the nitrogen cylinder. Plug the digital voltmeter into the plug marked $\mathrm{H}_{2} \mathrm{O}$ in the patch panel. With the nitrogen flowing, the meter should read zero volts. If not, then open the blue door on the water vapor analyzer and adjust the ZERO knob to obtain zero volts. Turn off $\mathrm{N}_{2}$ cylinder.

To span the analyzer, propylene gas will be used, which is flammable. Thus, to avoid risk of explosion, verify first that the room exhaust hood and afterburner are running. Leave the digital voltmeter in the $\mathrm{H}_{2} \mathrm{O}$ plug. Turn on the propylene cylinder (which is used as the span gas, making use of a slight propylene $/ \mathrm{H}_{2} \mathrm{O}$ spectral interference). Push the SPAN button next to the ZERO button. The water vapor analyzer rotameter should again read $2.0 \ell / \mathrm{min}$. If not, adjust flow with cylinder regulator. The digital voltmeter should read 0.64 volts. If not, adjust the SPAN knob behind the blue door to get the $0.64 \mathrm{~V}$ reading. Turn off the propylene cylinder and push the SAMP button. To set up for sample gas flow, the $\mathrm{H}_{2} \mathrm{O}$ sample pump has to be plugged in. This is plugged in at the rear of the instrument rack, behind the analyzer. Check that the sample line and filter for the hydrocarbon analyzer must be also be on, so that the sample lines and filter (which serves the $\mathrm{CH}_{x}, \mathrm{H}_{2} \mathrm{O}$, and $\mathrm{HC} \ell$ analyzers) are hot. (The sample lines must be hot, or else the water vapor will condense and wrong water vapor reading will result.) The temperature is checked on the meter on the face of the total hydrocarbons analyzer.

The water vapor analyzer is now ready to run.

- Total unburned hydrocarbons analyzer calibration.

1. Using the temperature indication position of the front-panel meter, check that the detector base and sampling lines have reached $175^{\circ} \mathrm{C}$.

2. Turn on the combustion air high-pressure cylinder (which is "hydrocarbonfree air" but is not the same physical cylinder as in the zeroing step below). The combustion air pressure gauge should read 25 psi. If not, adjust the combustion air pressure regulator (the black knob below the combustion 
air pressure gauge) to get this 25 psi setting. Next, turn on the hydrogen/helium combustion gas cylinder. No pressure should be recorded on the fuel pressure gauge until the IGN button is pushed. Push the IGN button and check the fuel pressure gauge. It should read 23 psi. If not, adjust the fuel pressure regulator (the black knob below the fuel pressure gauge) to obtain this reading. The mode select switch should be in the SAMP position, which should give a pressure of $1.15 \mathrm{psi}$ on the sample pressure gauge and a bypass flow of 2.5 liters per minute. With all these conditions met, the FID burner should ignite, and the light over the IGN button should come on within a minute or two. If not, see the manufacturer's troubleshooting instructions. When the light does come on, push the ON button. The ionizing flame should now be burning and the detector should be ready for zeroing and spanning. Sometimes the light above the IGN button will go out, indicating the flame has gone out. If this happens, push the IGN button, and when the light does go on again push the ON button. If the flame repeatedly extinguishes, see the manufacturer's instructions for corrective procedures.

3. To zero the analyzer, turn on the high-pressure cylinder of hydrocarbonfree air (note this is not the same cylinder as the combustion air cylinder) and press the mode select button ZERO. With the zero gas flowing at the same pressure and bypass flow as the sample gas span flow (1.15 psi, $2.5 \mathrm{\ell} / \mathrm{min}$ ), adjust the zero pot to yield a zero volts output on the digital voltmeter.

4. To span the analyzer, turn on the span gas cylinder (which can be either methane in air or methane in nitrogen) and press the SPAN button. With the span gas flowing at the same pressure and bypass flow as the sample gas (1.15 psi, $2.5 \ell / \mathrm{min}$ ), adjust the span pot to yield an appropriate value commensurate with the range setting and the concentration of methane in the span gas. For example, with the range set at $1000 \mathrm{ppm}=10$ volts and the methane in the span gas certified as $521 \mathrm{ppm}$, then the expected output from the analyzer would be 5.21 volts. It is useful to switch back and forth between the zero and span gasses several times to be certain both are in adjustment. With the zero and spans set, press the SAMP button and make sure the sample flow is at the proper pressure and flow $(1.15$ psi, $2.5 \ell / \mathrm{min})$. Then turn off the zero and span cylinders. Do no turn off 
these cylinders before switching to the SAMP flow as this may cause the flame to go out. If this happens, then the calibration must be re-started.

5. There are also certain subtle conditions related to the optimization of the analyzer using the methane in nitrogen and the methane in air which are discussed in the manufacturer's literature. If there are difficulties in getting correct answers despite the above steps being performed correctly, re-check the manufacturer's instructions to be sure that this optimization was accomplished correctly during initial installation.

- Hydrogen chloride analyzer calibration.

This analyzer is set up and used only if materials are to be tested which are chloride-containing.

The hydrogen chloride analyzer calibration is carried out in a similar fashion as the $\mathrm{CO}$ analyzer. The instruments are manufactured by the same company and have essentially identical controls. The most significant difference is due to the highly corrosive nature of $\mathrm{HC} \ell$ when mixed with moist air. Since such rapid corrosion does not occur in the calibration system if the $\mathrm{HC} \ell / \mathrm{N}_{2}$ mixture is kept completely dry, certain steps are given below for this reason. All the zero, span, and run solenoids referred to in the calibration steps below are located in and activated by controls on the analyzer.

1. It must be remembered that the $\mathrm{HC} \ell$ analyzer shares the same heated sample line as the hydrocarbon and water vapor analyzers. This common line must be heated to above $175^{\circ} \mathrm{C}$ to ensure the proper functioning of these analyzers. The hydrocarbon analyzer has the control circuits which maintain the temperature of this line. Therefore, the hydrocarbon analyzer must be turned on, even if no hydrocarbon data are desired. The pumps in both the hydrocarbon analyzer and the water vapor analyzer must be on to prevent back-flowing of air into the sampling line, which will distort the $\mathrm{HC} \ell$ concentrations.

2. To zero the analyzer, start by pushing the RUN button once. A red light should come on below the word ZERO. This opens the nitrogen gas line to the analyzer. (A red light should always be flashing above the word RUN.) Our particular $\mathrm{HC} \ell$ analyzer has been modified to turn off the sampling pump and open a bypass solenoid to divert the zero and span around the idle pump when either the zero or span gas valve is open. 
3. Turn on the $\mathrm{N}_{2}$ cylinder and check the rotameter on the analyzer. The desired flow is 1 LPM. Adjust the $\mathrm{N}_{2}$ cylinder regulator to obtain this flow. Wait a minute or two to give the flow a chance to purge any impurities from the analyzer.

4. With a suitable flow of $\mathrm{N}_{2}$ established, read the digital front-panel meter. The meter should read zero ppm. If the output does not read zero (within $\pm 1 \mathrm{ppm}$ ), adjust the output by turning the three thumbwheels below the word ZERO until a zero output is obtained. This completes the zeroing operation. Turn off the nitrogen cylinder.

5. Spanning the analyzer is similar to the zeroing operation with a few special steps. Start by pushing the RUN button once. A red light should come on below the word SPAN. This opens the span gas line and keeps the pump off as well as maintaining the pump solenoid bypass open. The red light above the word RUN should still be flashing.

6. At this point one would normally turn on the span gas cylinder, but due to the corrosive nature of $\mathrm{HC} \ell$, a special procedure must be taken. The $\mathrm{HC} \ell$ span gas regulator is equipped with special nitrogen purge fittings to allow the regulator to be purged after each use. It is best if the nitrogen cylinder used for this is separate from the one normally used as the zero gas. To do the purging, the nitrogen cylinder is opened and the $\mathrm{N}_{2}$ gas is allowed to flow through the $\mathrm{HC} \ell$ regulator and line to the analyzer. The objective is to clear the lines of any moisture which may have accumulated from the air. The lines should be purged with nitrogen for about 10 minutes. A good indication of the effectiveness of this purging is to watch the output of the front-panel meter. The output should initially rise as any residual line $\mathrm{HC} \ell$ is swept into the analyzer by the $\mathrm{N}_{2}$ gas and then fall back to zero as the line clears of water and $\mathrm{HC} \ell$.

7. Once the lines have been purged, turn off the $\mathrm{N}_{2}$ cylinder, and then turn on the $\mathrm{HC} \ell$ span gas. Set the regulator on the span gas cylinder to get 1 LPM through the analyzer's rotameter. With the span gas flowing through the analyzer at the proper rate, check the front-panel meter. The meter should read the span gas concentration within $1 \mathrm{ppm}$. If not, adjust the span thumbwheels until the proper value is obtained.

Note that, just as for the $\mathrm{CO}$ analyzer, the electrical output signal from this analyzer is not auto-ranging, even though the digital meter on 
the analyzer front panel is auto-ranging. Thus, the correct range to be used must have been verified properly.

8. This completes the spanning operation. Turn off the $\mathrm{HC} \ell$ span gas and allow it to bleed down to zero flow. Again turn on the $\mathrm{N}_{2}$ cylinder hooked up the $\mathrm{HC} \ell$ line and purge through the regulator, lines and analyzer with $\mathrm{N}_{2}$ until the meter reads back down to a few ppm. This procedure will clear the lines and regulator of the $\mathrm{HC} \ell$. (In the presence of water from the air, any residual $\mathrm{HC} \ell$ can form aqueous hydrochloric acid, and this would greatly reduce the life of the regulator and associated parts.) Turn off the $\mathrm{N}_{2}$ gas.

9. This completes the zeroing and spanning of the $\mathrm{HC} \ell$ analyzer. To set the analyzer for normal operation, push the RUN button one more time. The only light now on on the analyzer should be the one flashing above the word RUN. The analyzer is now drawing its sample from the Cone Calorimeter's main duct.

\subsection{Setting the flow rates for the exhaust and for the soot sampler}

1. Check that the exhaust system has been turned on (see above) and is exhausting air properly.

2. For normal testing, where room air is to be used as the combustion air, set the Cone Calorimeter exhaust control blower on CONSTANT VOLUME. In this mode the motor speed is held constant and the mass flow through the duct is allowed to change as the gas temperature changes. The other exhaust control mode for the blower is the CONSTANT MASS MODE. In that mode, the motor speed is varied by a servo loop in order to keep the mass flow in the duct constant as the temperature of the gas in the duct changes. The CONSTANT MASS MODE must be used for tests where a Pyrex enclosure is used on the Cone Calorimeter and where a controlled atmosphere is being supplied from the bottom of the unit.

3. Check the Calorimeter exhaust flow rate indicator meter. This should read 30.0 grams per second; adjust the manual flow rate setting knob, if need be.

4. The soot sampler flow rate is adjusted next. This is the most convenient time to do that, since the exhaust system is cold and the main exhaust duct mass flow 
rate is not varying. Set the soot sampler to the PROPORTIONAL MODE switch position. Set the proportional-mode flow setting control knob to an appropriate setting depending on the sootiness of the sample - 1/500 of the main duct flow is the typical setting. [This ratio has to be determined by determining what $1 / 500$ of the exhaust duct flow would be, which is $30 / 500=0.060 \mathrm{~g} / \mathrm{s}$ for normal operation, and then setting to that desired value.] The soot sampler has a range from approximately $1 / 200$ to $1 / 1000$ of the main duct flow. For sootier samples, a lower sampling fraction should be chosen.

\subsection{Checking the orifice flow constant}

[The instructions below presume that the weekly calibration of the electronic mass-flow controller has been made successfully, as described under LESS-FREQUENT CALIBRATION PROCEDURES, below.]

1. Make sure that the exhaust system flows have been correctly set up, as described above, and that no ventilation difficulties are observed.

2. Turn the methane gas flow switch to the down position, insert the calibration burner in place, and set the mass flow controller valve setting (located below the burner) on the front of the machine for its correct $10 \mathrm{~kW}$ value, typically = 412 .

3. Set up the computer for the calibrations as described in the DATA COLLECTION AND ANALYSIS Chapter.

4. During the baseline value check, recheck the oxygen analyzer reading to be sure it is 2.0950 volts. If it has drifted slightly, it should be readjusted. Experience has shown that if such a slight drift occurs, it is most typically associated with the zero, rather than the span, end of the scale. Thus, to readjust, turn the zero knob on the analyzer. If the oxygen analyzer reading has shifted significantly, find the reason for this sudden shift and correct it before proceeding.

5. Turn on the methane gas calibration cylinder (make sure that the gas is of $\geq$ $99.9 \%$ purity).

6. With the calibration burner in place, strike a match. Flip the gas-flow toggle switch to the horizontal position. This will allow the methane gas to flow. Ignite the gas; make sure a steady flame is established. 
7. Let the test flame burn for 3 to 4 minutes, then depress the appropriate button on the computer.

8. Obtain the orifice flow constant. If the actual value is substantially different from the reference value established for the instrument during its initial set-up ( 0.040 to 0.046 for the NBS unit), consult the TROUBLESHOOTING AND REPAIR Chapter.

9. Turn off the methane gas at the gas cylinder. Allow all gas in the line to burn off, then turn off the toggle switch. (Failure to bleed the line may cause the burner to leak methane during a test.) This procedure is now finished. 


\section{$6 \quad$ Preparative procedures}

The following procedures are done as needed to assure adequate preparation for actual testing.

\subsection{Sample preparation}

1. Conditioning. The manner in which samples are prepared can have a very significant effect on achieving reproducible and valid output from the Cone Calorimeter. Hygroscopic samples should be conditioned in an environment of $50 \%$ relative humidity $( \pm 5 \%)$ and $23^{\circ} \mathrm{C}\left( \pm 3^{\circ}\right)$ until a stable specimen weight is reached. If nonstandard environmental conditions are used in preparing the sample (such as oven drying), these conditions must be documented and included in the comment section of the test data file. Conditioning of some samples and, especially, oven-drying can shrink the specimen size; thus, it is preferable to condition first, and cut to size afterwards.

2. Determining the exposed surface area. The exposed surface area of the sample is an important parameter in data analysis, and must be well known. For consistency in conducting tests, it is, therefore, desirable to have all the samples conform to this $0.01 \mathrm{~m}^{2}(100 \times 100 \mathrm{~mm})$ surface area dimension after all sample conditioning has been completed. With those sample holders which have an edge lip, the area exposed to heating at the start of the test is $0.008836 \mathrm{~m}^{2}$ $(94 \times 94 \mathrm{~mm})$. A correction for this is not normally made, since it is assumed that shortly after burning starts, the surface recedes somewhat, exposing the whole $0.01 \mathrm{~m}^{2}$ specimen. The use of the wire grid, when used to restrain intumescing samples, is also assumed not to reduce the nominal exposed surface area.

For certain cases, it may not be possible to test $100 \times 100 \mathrm{~mm}$ samples, and a different geometry may be necessary, for instance, a circular specimen. Within reason, it is possible to take care of this deviation by entering the actual specimen's surface area, when asked that question by the computer program. Excessive liberties, however, should not be taken with the specimen size, since it has been shown that both the ignition time and the rate of heat release could become somewhat changed. These effects are not expected to be detectable for area changes of $<50 \%$. 
3. Preparing the specimen to the correct thickness. In all cases, sample thickness must be determined during the sample preparation. Where the sample being tested is supplied in a standard thickness of less than $50 \mathrm{~mm}$ thick, it is a simple matter to determine and record the sample thickness. (See the caveat about very thin samples in $\$ 6.3 .3$ of ASTM P-190). In instances where the product is made up of several different layers totaling greater than $50 \mathrm{~mm}$ in thickness, the test protocol will usually specify some means of how the thickness should be proportioned. The procedure that was actually used should then be reported in the test Report.

For some applications, the test protocol being used will specify that thin layers, ones less than a certain number of mm thick (which would be difficult to section), should be used in full-thickness, whereas the remaining, thicker layers should be depth-sectioned so that the ratio of their depths in the test specimen resembles the ratio in the product.

When composite specimens are encountered, very likely special means of edge protection will have to be used. This is especially true if some layers serve a protective function. In the case of upholstered furniture samples, for example, the procedures which have normally been used at NBS involve initially cutting the fabric, plus any protective interliner layers, to a size of $200 \times 200 \mathrm{~mm}$. From this piece, a square of $50 \times 50 \mathrm{~mm}$ is removed from each corner. The resulting cruciform-shape covering is then laid over the padding material, and the four sides folded down. Finally, after the specimen has been weighed (see below), the covering material is stapled at a $45^{\circ}$ angle at the bottom edge.

Composite specimens may also present special problems if the layers need to be bonded together. A careful note should be made in the test report of any necessary bonding procedures.

4. Weighing and final preparation. Once the actual arrangement of the sample has been completed, the sample is weighed. This should be done before any pins or staples are used to assemble the various layers or pieces together. Weigh only the sample, record this weight, and enter it when the computer program asks for the sample mass. The completed sample is then wrapped in one layer of heavyduty aluminum foil, leaving the appropriate surface exposed. Stainless steel foil may need to be substituted for the aluminum foil where high temperatures or specimen reaction chemistry destroy the shape or integrity of the aluminum foil or allow the sample to spill out or off the load cell. Be sure to note in the test 
comments the use of the stainless steel foil instead of the aluminum foil. The sample is now ready to be placed in the appropriate sample holder. Note: The wrapping with aluminum foil is not done for the case of the standard PMMA calibration specimens.

5. Non-uniform products. The case of specimens which are non-homogeneous in the thickness dimension has been considered under the thickness measuring procedure above. Some products, further, exhibit non-uniformities in the direction(s) parallel to the thickness. In such cases, the testing protocol established for the particular test series will usually include a specification describing how many different specimens are needed and where they should be taken from. An example of a product with such non-uniformities would be an upholstered chair where the seat and back constructions are different.

\subsection{Preparing the specimen holder}

For the horizontal specimen holder, the specimen is placed on top of a layer of ceramic fiber blanket, which is placed into the holder. The total thickness of the blanket should be 13 to $20 \mathrm{~mm}$. The actual thickness will depend on the weight of the specimen and on the age and condition of the blanket. The blanket should be replaced if it is contaminated with specimen melt or residue.

For the vertical specimen holder, the specimen is directly backed by at 13 to 20 $\mathrm{mm}$ thickness of ceramic fiber blanket. At least one layer of rigid ceramic fiber board is then placed in back of the ceramic fiber blanket layer. The thickness of rigid board to be used will depend on the thickness of the specimen. The complete assembly, when mounted in the holder, must fit snugly, but without forcing.

\subsection{Use of special sample holder equipment}

In addition to the normal horizontal or vertical sample holders, three other accessory devices may be needed for special testing. These are (a) the horizontal holder edge frame, (b) the wire grid, and (c) the fabric tensioning insert.

The horizontal holder edge frame is used for testing in the horizontal orientation: those composite specimens where edge burning is anticipated, all wood specimens, and any other specimens where experience shows that its use is necessary to prevent unrepresentative edge burning. The edge frame must also be used if it is desired to test in the horizontal orientation using either the wire grid or the fabric 
tensioning insert. The edge frame is equipped with two thumbscrews, located near the bottom edge. To use, place the specimen on top of the refractory fiber pad on the specimen holder. Place the edge frame on top of the specimen. Check that it fits snugly against the top of the specimen, but do not force down. Tighten the two thumbscrews against the edge of the horizontal specimen holder to achieve a rigid connection.

The wire grid is used primarily for intumescing or delaminating materials. It is normally used in the horizontal orientation in conjunction with the edge frame; however, it can also be used in conjunction with the standard vertical specimen holder. The wire grid can be either a permanent fixture, constructed as specified in the Drawings, or else expendable wire mesh grid, of the specified spacing, can be used. In the horizontal orientation, place the specimen on the specimen holder, place the wire grid on top, then place the edge frame on the assembly. Check that the frame fits snugly against the top of the wire grid, and that the wire grid is snug against the top of the specimen. Tighten the two thumbscrews against the edge of the horizontal specimen holder to achieve a rigid connection. In the vertical orientation a separate edge frame is not needed, and the wire grid is simply placed first into the holder, before loading the specimen.

The fabric tensioning insert is used in conjunction with the horizontal edge frame for testing fabrics and films that need to be tested over a dead air space (it is not intended to be used in the vertical orientation). The fabric specimen is cut with about a $25 \mathrm{~mm}$ extra border around its four edges. It is then placed over the tensioning insert. The horizontal edge frame is then forced on top, until it is fully seated. The assembly is then placed on top of the horizontal specimen holder, creating a dead air space underneath the sample. Finally, the thumbscrews are used to secure the assembly.

\subsection{Preparing weighed soot filters}

A micro-balance is required for this, as specified above. The $47 \mathrm{~mm}$ soot filter discs used in the soot sampler must have a tare weight accurately determined before starting of test. The discs should be identified by writing a serial number on them and placed in a desiccator for at least 24 hours (to lose moisture). After 24 hours, the filters are to be weighed and the weight recorded. The filters are then replaced into the desiccator until needed for testing. 
6.5 Recording pretest data

Information to be recorded in the laboratory notebook should include the mass of the specimen (excluding any aluminum foil, pins, staples or other fasteners not normally associated with the sample), its thickness, and its area (if nonstandard). It is also desirable to record the thickness and the mass of the separate layers of composite samples. The identity of material, if known, and any other distinguishing or unusual characteristics of the material should be recorded. The mass information on the soot filters to be used should be recorded, along with the serial numbers which have been assigned to them.

45 


\section{Running tests}

\subsection{General}

At this point, it is assumed that the operator has a fully-operational apparatus, and has followed all the steps of the DAILY START-UP AND CALIBRATION PROCEDURES and of the PREPARATIVE PROCEDURES.

The running of routine tests is covered by the ASTM P 190 document. The user should consult this for instructions, which are not repeated here. A few additional points on equipment operation are given below, however.

\subsection{Checking gas analyzers, sampling lines, filters}

The actual running of the test can only be carried out after the analyzers have been properly set up, including the zeroing and spanning of all the gas analyzers. The gas analyzers should all be set in the "run" mode and drawing air from the main exhaust duct of the Calorimeter. Before each new test, check if the flows through the analyzers are at the same level as was used in the calibration of these analyzers; this should also be occasionally checked during the course of each test to ensure that they are not dropping due to clogged filters or icing of the cold trap. If during a test the analyzer flows do fall, replace the filters (after the end of the test) and check the waste regulator to be certain it is set correctly. The waste regulator may also be adjusted during a test run to restore the proper flow setting on the gas analyzers. Always start the day's first run with clean filters and look at them after each run, replacing as necessary. Visual inspection of the filters is generally a good indication of clogging (some materials, however, seem to produce sticky deposits on the filters which restrict the flow, even though the filter does not look particularly dirty). Cold trap freeze-up can also be a cause of low flows to the analyzers. If ice plugging occurs, turn off the power to the cold trap and allow ice to thaw, then drain the water from the collection tube.

Check the temperature of the heated lines to verify that they are at the correct temperature. Also, check that all the sampling pumps are running, even if a particular analyzer is not being used (this ensures that no room air is drawn back through these idle pumps and appear as a leak in the sampling system). Check the Ascarite and Drierite to be certain that there is enough to complete the test. 
[Note that it is not permissible to change filters, Ascarite, or Drierite during a test. Thus, if it is discovered during the course of test that any of these are clogged or used up, the test must be re-run.]

\subsection{Checking the cold trap}

Check the cold trap temperature to be sure it is at the desired setpoint.

\subsection{Checking the exhaust duct flow}

The exhaust system can be operated in either a constant mass or constant volume mode. For running of routine test, it will be assumed that only the constant volume mode is used.

The exhaust duct flow is usually set at $30 \mathrm{~g} / \mathrm{s}$ (cold). Remember that the duct flow will drop after the heater is turned on. Do not readjust the warm flow back up to a $30 \mathrm{~g} / \mathrm{s}$ rate.

For non-routine testing, it is possible to use a different main duct flow setting without adversely affecting any of the results. It may be desirable to use a lower setting if detailed gas analysis measurements are to be made on a specimen where a very small heat release rate is expected. Remember to increase the flow back to the $30 \mathrm{~g} / \mathrm{s}$ range for subsequent tests. The instrument can safely measure heat release rate values up to $2000 \mathrm{~kW} / \mathrm{m}^{2}$ only if there is sufficient duct flow to provide adequate cooling and prevent metal warpage and possible ductwork damage.

\subsection{Setting the soot mass flow controller}

The soot sampler should be set at the desired fraction of the main duct flow. The soot filter itself should not yet be placed in the filter holder but retained in the desiccator until just before the actual start of the test. This will help minimize the amount of atmospheric moisture trapped on the filter. Clean out the upper filter holder bell with a soft tissue and blow out the sampling line with 100 psi air before inserting the new filter.

\subsection{Setting the cone heater orientation and height}

(This should, if at all possible, be done with the heater cold, otherwise gloves have to be worn, and the operation becomes more difficult.) 
Set the required orientation, horizontal or vertical. In the vertical sample orientation, the sample to heater distance is fixed by the holder; the operator should, however, verify that the cone heater height is correct. The height is correct when the center of the opening of the cone corresponds to the center of the specimen's face.

In the horizontal orientation, the operator has to check before each test that the correct cone-to-specimen spacing is maintained, and will have to re-adjust the heater height when specimens of different thickness are tested. If the heater is cold, to set the proper height of the cone heater above the specimen's exposed face, place the sample on the horizontal sample holder pan, which is resting on the load cell, and crank the cone up or down until a $25 \mathrm{~mm}$ spacing between the top of the sample and the lower surface of the cone's base plate is obtained. If necessary, it is possible to set this spacing when the cone is hot. To do this, place the empty holder on the load cell and measure the spacing above the top of an imaginary specimen with a ruler. This should be done first on the bench by measuring the distance from the top of the specimen holder's lip to the top of the specimen, as it actually sits on the (now compressed) refractory blanket. This measurement must be added to $25 \mathrm{~mm}$, and the total distance then measured from the holder's lip when it is placed under the cone. When running the test, some final adjustment may be necessary in this cone/sample spacing. This correction should be made as soon as possible after the start of the test to help minimize the time the sample is exposed to the wrong flux. This positioning correction should be very small or ideally not required at all. Significant errors in this spacing (greater than $4 \mathrm{~mm}$ ) should be cause for aborting the test and correctly readjusting the spacing and rerunning the test.

When testing in the horizontal orientation, remember to have available a second, empty (no specimen, but with a refractory blanket) specimen holder, which will be kept on top of the load cell whenever possible that the heater is on, except during running a test or while using the heat flux gauge.

\subsection{Checking the load cell}

The load cell must be checked before each test.

1. Insert the sample holder that is going to be used for the test. Next, ensure that the load cell will not be bottomed out at its mechanical stop at the start of the test, nor topped out at the end of the test. (This adjustment must be checked each time that either the sample orientation is changed, or a heavier sample is to be tested than the one last checked out on the same sample holder.) To 
check, place the correct sample holder (horizontal or vertical) on the load cell platform and read the panel meter, then gently push up on the load cell with your finger. The panel meter reading should drop visibly when thus pushed. Repeat for the bottoming-out check by putting on both the holder and a weight equal to the heaviest sample to be tested. Note the panel meter reading. Gently push down on the holder and make sure that the reading increases. If one or the other readings does not change, then the load cell has hit one of its stops. At this point one must adjust the mechanical zero control on the load cell. To adjust, insert a $1 / 8$ " hex wrench in the hole marked ADJUST in the load cell body. If the load cell reads a high positive number and does not respond when you press down on it, the load cell is bottomed out, turn the hex wrench clockwise, so that the meter reads 10.0 grams \pm 3.0 . For fine adjustments, use the electrical zero knob. If the load cell reads a negative number, and when you push up on the cell it does not change, insert the hex wrench and turn it in the counterclockwise direction until it reads 10.0 grams \pm 3.0 grams. There are 250 turns available, so do not be surprised if you have to turn the wrench many revolutions before any change is noted on the meter. For fine adjustments, use the electrical zero knob.

2. Adjust the load cell electric zero adjustment knob (located above water vapor analyzer) to read 10.0 grams. Place a known calibration weight on the sample holder, then check the load cell output. This should read the known weight plus 10.0 grams. This checks out the calibration of the load cell electronics. If this reading is wrong, adjust the scale factor by turning the pot located behind the meter face.

3. The electrical zero potentiometer (fine zero) will be set before each specimen is burned, by adjusting so that with the empty specimen holder placed on the load cell, the output reads exactly 0.0 grams. (This setting is important so that the operator could properly monitor the test; however, any errors in adjusting this knob do not show up as errors in the computer output.)

\subsection{Setting up the desired flux of the cone heater}

This procedure will only be necessary if changing to a different heat flux or orientation from the previous test.

A calibration table should be available for this purpose, as described under the LESS-FREQUENT CALIBRATION PROCEDURES. The table will contain both the heater 
temperatures corresponding to various common irradiance fluxes and the corresponding millivolt outputs for the flux gauge. To set up the heater, turn on the toggle switch labeled HEATER and adjust the controller to the desired temperature by holding in the button on the controller marked SETPOINT and simultaneously pressing the up or down arrow, as appropriate, to raise or lower the displayed setpoint. Once the controller's setpoint is adjusted to correspond to the value referenced in the look-up table, the final adjustment should be made with the flux gauge in place under the cone. The flux gauge holder is designed so that inserting it into the mating holder on the cone it will automatically position the flux gauge $25 \mathrm{~mm}$ from the bottom of the cone and directly at the center of it. Periodically this position should be checked to be certain the hardware has not been bent or misaligned. The output from the flux gauge is fed through to a plug on the patch plug board marked FLuX. By plugging in a digital voltmeter, the millivolt output of the flux gauge can be determined. The final tuning of the cone heater can be accomplished by adjusting the controller setpoint temperature to produce the expected millivolt output from the flux gauge. Be sure to give the controller time to stabilize and overcome the thermal lag associated with the heating elements.

Note: The heat flux gauge will be typically rated at less than $110 \mathrm{~kW} / \mathrm{m}^{2}$ maximum output; leaving it exposed under the heater for long periods of time at higher than rated fluxes can damage it or cause the calibration to change or degrade.

Special warning: The heat flux gauge will lose its correct calibration if the flat black coating of its sensing face is damaged. This coating is rather easily damaged if the face is struck against any other metallic object. The operator should establish a safe-keeping position for the gauge where it can be placed and rested without the danger of contact with its sensing face.

\subsection{Computer program setup and starting the test}

It is assumed that the calibration check has been run and that the orifice calibration constant is within its normal operating range. By pressing the Run test softkey on the computer, the actual test data acquisition routine will be able to begin. The program first asks various questions regarding the test (test number, title of the sample, weight of the sample and information on the ranges of certain analyzers). Most of the data required to answer the questions should have been recorded in the $\log$ book when the sample was prepared. The test numbers are assigned sequentially and always begin with the letter "T". If you try to use a test number which already exists, the screen will show an error message. When all the set-up questions have been 
answered, the computer screen will show only two active softkeys on the keyboard. One key will say START and the other will say END.

Before you press this start key, make one last visual check of all the following systems and correct as necessary.

1. Afterburner exhaust system on (green light on).

2. Exhaust hood on (check control panel flow meter).

3. Cone exhaust fan on (motor speed control panel meter reads $25-30 \mathrm{~g} / \mathrm{s}$ ).

4. Cold trap indicated temperature (look at controller output, normally $0^{\circ} \mathrm{C}$ ).

5. Check heated lines and filter (touch line and filter quickly).

6. Check flow meters on $\mathrm{O}_{2}, \mathrm{CO}_{2}, \mathrm{CO}$ analyzers (should read 4,2 , and 1 respectively).

7. Check flow meters on $\mathrm{H}_{2} \mathrm{O}$ and $\mathrm{CH}_{x}$ analyzers (should read 1.9 and 3 respectively).

8. Check output on $\mathrm{CO}$ analyzer (should read less than $1 \mathrm{ppm}$ ).

9. Check range setting on $\mathrm{CO}$ analyzer (should agree with computer input).

10. Check $\mathrm{CO}_{2}$ analyzer output (should read very slightly above zero).

11. Check $\mathrm{CH}_{x}$ analyzer output (should read close to zero).

12. Check range setting on $\mathrm{CH}_{x}$ analyzer (should agree with computer input).

13. Check $\mathrm{H}_{2} \mathrm{O}$ analyzer output (should read typically 0.5 to $2 \%$, depending on the room air $\mathrm{RH})$.

14. Check $\mathrm{HC} \ell$ analyzer output (should read less than $1 \mathrm{ppm}$ ).

15. Check range setting on $\mathrm{HC} \ell$ analyzer (should agree with computer input).

16. Check laser smoke meter output (should read 0.000).

17. Check soot sampler fractional flow setting (should agree with computer input).

18. Now, place weighed $47 \mathrm{~mm}$ soot filter into filter holder. 
19. If a blank sample holder is in place on the load cell, then the panel indicator can be verified for a plausible weight indication.

20. Check controller on cone heater (setpoint temperature and actual temperature should agree).

21. Check oxygen analyzer out with DVM (should read 2.09500 volts).

If all these systems check out, you are now ready to actually run the test. Start by turning on the sparker transformer. If running in the horizontal orientation, remove the blank sample holder from the load cell, using insulated gloves or pliers. Place the prepared specimen on, or into, its sample holder, place the holder on the load cell and immediately press the START softkey on the computer keyboard. (The softkey label will then change from START to IGNITION at that point.) Insert the sparker arm. Check the height of the sample below the cone; adjust as necessary.

\subsection{Ignition}

The presence of ignition is observed next. This may require some experience on the part of the operator, since the ignition event to be recorded is a sustained ignition, rather that a brief, non-sustained flash. When ignition is observed, press the IGNITION softkey. Now the computer will only show an END softkey. Turn off the sparker power and remove the sparker arm.

Note: Some materials have a propensity for intumescence, bubbling up, or bowing up. In each case, this can interfere with the operation of the sparker. If such problems are experienced, it will usually be necessary to re-run the test, using the wire grid (Fig. C15) to hold the specimen in place. In extreme cases, even the use of the wire grid may not be sufficient to prevent interference with the sparker. In some cases, successful ignition may still be achieved if the sparker is used in a location closer to the edge, rather than in the normal location at the centerline. In more severe cases, it is sometimes possible not to use the sparker and, rather, to ignite with a propane torch. Such procedures, however, definitely fall into the category of non-standard testing, and should be documented as such in the test report.

\subsection{Observing the test}

Soon after starting the test, the operator should take a look at the reading on the load cell indicator, to make sure that a value fairly close to the actual specimen mass 
is seen. If an implausible reading is seen, the test should be stopped and the load cell re-adjusted or repaired.

The burning specimen should be observed during the entire course of the test. The operator should look for:

- pieces falling off

- dripping

- excessive swelling (the specimen should not swell so much as to foul any metal portions of the apparatus)

- explosive spalling

- any other anomalous behavior.

If any of those are observed, an appropriate note must be recorded.

The operator should also observe that pyrolyzed matter is not accumulating on the heater coils. This is very rarely a problem, but has been noticed with certain types of silicone specimens tested in the vertical orientation. If such residue is building up upon the coils stop the test. The test is to be stopped by turning off the 240 $\mathrm{VAC}$ power to the heater. If testing is continued with such buildup occurring, the heater coils will, very likely, overheat and burn out at the place where the buildup has occurred.

The operator should periodically observe the rotameters on the gas analyzers to see that flow rates are not dropping. The oxygen analyzer should also be periodically observed to see that plausible values are being shown. Occasionally, it is worthwhile to see that the cone heater temperature controller is in good control. The controller will register a positive deviation of a few degrees when ignition occurs. This deviation should rapidly diminish, however, and values close to the setpoint should be seen during most of the test. If a systematic offset is seen, the controller settings should be checked and re-adjusted, as explained in the instruction manual supplied with the controller.

Caution: Make sure not to blow upon the specimen during testing. Such an action will put anomalies into the heat release rate curve.

\subsection{End of test}

The test is normally ended when all signs of combustion have ceased, with the possible exception of a very small, continued mass loss. The end has not yet been reached if 
there is any flaming or any visible pyrolysis or smoking. Some types of specimens may show an extended period where there is no flaming or active smoke being emitted, but there is still a char matrix which is glowing and losing mass at a very slow rate. Normally, it is considered acceptable to stop a test when that state has been reached. In specific cases, however, the preferences of the sponsor of the test should be considered. The operator should use good judgement to make sure that a test is not stopped short where the combustion has entered a non-flaming stage, but, where there is an amount of combustible material still unconsumed which will flare up at a later time. If in doubt, the test should be continued longer than necessary rather than risk stopping it too quickly. Make sure now that 2 additional minutes of test data are collected after the end of combustion has been declared.

Now press the END softkey to end the data acquisition process.

Remove the specimen holder (using gloves or pliers!), and place in a chemical exhaust hood to cool down. The hood is necessary so that any remaining degradation products do not enter into the habitable laboratory space. Take the specimen out of the holder, so that the holder would cool off faster for re-use. Note that each test must be run with a cold holder, so that at least two holders will always be necessary. Check the holder and the ceramic fiber blanket for any residues. If necessary, clean the holder and replace the blanket.

If testing in the horizontal orientation, place a blank specimen holder under the cone heater, in order to avoid excessive heating of the load cell.

Remove the $47 \mathrm{~mm}$ soot filter, and place in desiccator.

Type into the computer program the post-test comments, which will normally consist of any observations of specimen behavior made during the test.

The following day the soot filters are weighed and the weight is recorded. This delay in weighing the filters gives them some time to lose some of their water. 


\section{Daily shutdown procedures}

The prescribed shutdown does not turn everything off. The $\mathrm{O}_{2}, \mathrm{CO}_{2}, \mathrm{CO}$, and $\mathrm{H}_{2} \mathrm{O}$ analyzers are left on constantly. Other devices are also left on: the pressure transducer/transducer power supply, smoke meter electronics, and the data acquisition system. This is done to keep the electronics stable and avoid an excessive warm-up period the following day. The detector cells in the various analyzers are also kept at a slightly elevated temperature to prevent the condensation of water in them. It should be noted that, even though the analyzers are left on, no gas is flowing through them except during zero/spanning and testing. Some of the analyzer manufacturers do recommend a dry $\mathrm{N}_{2}$ purge be run through the analyzer when the analyzer is not being used. All the manufacturers recommend purging their analyzers before turning their power off for long-term storage. We do not employ an overnight purge in any of our analyzers and have yet to see any deleterious effects. We do, however, purge the entire gas sampling system with room air for about 10 minutes after the last test of the day so the analyzers and lines will not sit overnight with residual combustion gasses in them.

1. Continue running the analyzers and the sampling system for about 10 minutes after the end of the last test.

2. After room air has been run through the analyzers, turn off all the pumps: Turn off the toggle switch marked PUMP. Unplug the water vapor sampling pump. Push the button marked PUMP on the hydrocarbon analyzer; the button should then be in the "out" or off position. The $\mathrm{HC} \ell$ analyzer can also be turned off as it has a fairly quick warm up time and this will turn off its internal pump.

3. Turn off all gas cylinders-do this by turning off the cylinder valve at the top of the cylinder; do not turn off the regulator outlet valve nor the regulator control handle. Normally all the gas cylinders except for the hydrogen/helium and the air cylinders feeding the hydrocarbon analyzer would have been turned off once their spanning and zeroing was finished. Double-check, especially, that all combustible gas cylinders have been properly turned off. The special precautions in shutdown and purging of the hydrogen chloride cylinder have been covered under DAILY START-UP AND CALIBRATION PROCEDURES, above, which should be consulted.

4. Turn off the Calorimeter exhaust. Do not do this before all smoke has been fully cleared out from the apparatus. Shutting off the exhaust with a smoky 
atmosphere still present may lead to smoke particulates being deposited on the optics of the smoke photometer.

5. Turn off the power for the photometer laser (but not for the associated electronics).

6. Turn off the soot sampling system.

7. Turn off the Cone heater. The toggle switch marked HEATER does this.

8. Turn off the toggle switch marked WATER. This stops the water flow to the cold trap and cuts the electric power to the thermoelectric cold plates.

9. Turn off the toggle switch marked MAIN. Note that this switch will not shut off those circuits which power the gas analyzers or those electronic devices which need to always stay on.

10. Turn off the room exhaust hood above the Cone by turning the knob marked FAN to " 0 ". This knob is located on the control panel in the back corner of the lab.

11. Turn off the laboratory exhaust system by turning off the timer in Room B-359 and pressing the OFF button to shut down the afterburner fan. Remove the tag and replace on its hook.

12. Turn off the digital voltmeter.

13. Turn down the brightness of the computer screen.

14. Be sure all samples which have been tested are extinguished.

This completes the shutdown procedure. 


\section{Test report}

The basic requirements for the test report are given in the ASTM document P 190 . Most of the numerical data are obtained directly from the data reduction using the computer software. Other items are normally entered in the comment lines on the test data file. Only a limited amount of information, however, can be incorporated into those comment lines. Thus, it is the responsibility of the operator to maintain a supplementary laboratory notebook, where deviations from standard procedure, additional test conditions established for a particular test series, problems of equipment malfunction, and similar data are recorded. The operator is responsible for verifying that the data entered into the computer test file and the information recorded in the laboratory notebook for each test include each item mandated by ASTM P 190 , in addition to the operator's noted observations during test and the necessary supplemental data.

For most applications, especially for research and development, significantly more numerical test data will need to be tabulated than is the minimum specified in $\mathrm{P}$ 190. For this purpose, the Construction Drawings include an example computergenerated test report. Before designing their own report format, users should consult this example report. While additional information is always easy to add, it is strongly advised not to omit any data tabulations shown in this example for which the user possesses the necessary instrumentation. It is much easier to cope with a superfluity of data than it is to have to re-generate tests because now-needed data are missing.

\subsection{Computer-generated standard reports}

A large enough number of data items are associated with Cone Calorimeter testing, that data management has to be addressed systematically. For the last few years, NBS has been working on developing a standard report format. An example of the current standard report format is found in the Construction Drawings. The present reports are being generated by the Hewlett-Packard computer system. With the ongoing migration to IBM computer equipment, the report format will be changed, but not changed drastically. What will change much more is the actual management of the reduced data. At the moment, reduced data are not stored at all, only raw data being stored. With the IBM system, extensive provisions are being made to store the reduced data in a format which constitutes a user-friendly database, with fully integrated graphics capabilities. Information about the new formats will be made available as the software development effort progresses. 


\section{Weekly calibration procedures}

There are some essential procedures which must be accomplished on a weekly basis. They are sufficiently time-consuming so that their use daily would unnecessarily slow down testing. If when they are accomplished it is discovered that an error was present, it will usually be necessary to discard the test data generated after the time of the last good calibration. Thus, extending the calibration interval to more than 1 week would be imprudent.

\subsection{Checking the calibration of the electronic mass-flow controller}

For daily calibrations, the settings of the electronic mass-flow controller are very stable; nonetheless, since the electronic mass-flow controller is not intrinsically calibrated, its readings must be checked against a reference method weekly, according to the procedure below.

- Turn on the exhaust system; set the flow rate for $30 \mathrm{~g} / \mathrm{s}$.

- Insert the calibration burner in place and strike a match. Flip the methane-flow toggle switch to the horizontal position. This will allow the methane gas to flow. Ignite the gas.

- Check the methane flow rate by clocking the required (indicated) liters of methane in a one minute time period. This is done with a dry test meter calibrated for methane. For typical laboratory conditions where the absolute pressure of the methane, monitored inside the dry test meter, is $108.1 \mathrm{kPa}$ and the corresponding temperature is $293 \mathrm{~K}$, a flow rate of 16.92 liters of methane (indicated) per one minute is required. The above flow rate then represents a $10 \mathrm{~kW}$ rate of delivering methane. If laboratory temperatures or line pressures are different from above, then the required volumetric flow rate will have to be recomputed, using the basis of $50.0 \times 10^{3} \mathrm{~kJ} / \mathrm{kg}$ as the net heat of combustion of methane. This gives the following required actual gas flow rate, $\dot{V}$ to obtain the $10 \mathrm{~kW}$ rate of methane:

$$
\dot{V}=16.76\left(\frac{101.3}{P}\right)\left(\frac{T}{273}\right) \quad \ell / \min
$$


where $P$ is the gas pressure in the test meter $(\mathrm{kPa})$, and $T$ is the gas temperature (Kelvins) in the test meter.

- Adjust the potentiometer setting the level for the electronic mass-flow controller to a new setting if the desired flow rate is not obtained.

- Note: With newer versions of the data acquisition software, it is not necessary to deliver exactly $10 \mathrm{~kW}$ for calibration purposes. A different $\mathrm{kW}$-value may be delivered, if that value is accurately known and is entered into the program when the relevant question appears on the screen. If a value different than $10 \mathrm{~kW}$ is used, a note must be saved which records what potentiometer setting corresponds to what flow level. The $\mathrm{kW}$ rate for an arbitrary (indicated) volume flow rate of methane is computed from:

$$
\dot{q}=0.597\left(\frac{P}{101.3}\right)\left(\frac{273}{T}\right) \dot{V} \quad \mathrm{~kW}
$$

\subsection{Checking system calibration with PMMA}

The basic check of the stability of the various measurement systems is the test burn made with PMMA. To do this, use a PMMA calibration specimen, prepared as described in the INSTALLATION AND INITIAL SET-UP Chapter. Set up the Calorimeter for normal operation in the horizontal orientation, with an irradiance of $50 \mathrm{~kW} / \mathrm{m}^{2}$. Burn the specimen and record the data as for a normal test. Once reduced, the test data are then examined for:

- Heat of combustion (test avg.)

This should be in the range of 24.0 to $24.9 \mathrm{MJ} / \mathrm{kg}$.

- Ignition time

This should be $24.0 \pm 2 \mathrm{~s}$.

- Average heat release rate

Over the time period from ignition to $900 \mathrm{~s}$ past ignition, the average rate of heat release should be $620 \pm 20 \mathrm{~kW} / \mathrm{m}^{2}$.

- Specific extinction area (test avg.)

This value should be $110 \pm 8 \mathrm{~m}^{2} / \mathrm{kg}$. 
- Soot yield

This should be $0.0104 \pm 0.0014(\mathrm{~kg} / \mathrm{kg})$.

- $\mathrm{CO}_{2}$ yield (test avg.)

This value should be $2.20 \pm 0.15(\mathrm{~kg} / \mathrm{kg})$.

- CO yield (test avg.)

This value should be $0.0060 \pm 0.0010(\mathrm{~kg} / \mathrm{kg})$.

- $\mathrm{H}_{2} \mathrm{O}$ yield (test avg.)

This value should be $0.72 \pm 0.03(\mathrm{~kg} / \mathrm{kg})$.

- Total hydrocarbons yield (test avg.)

This value should be $0.0010 \pm 0.0005(\mathrm{~kg} / \mathrm{kg})$.

If any of these values do not conform to the expected ones, further troubleshooting and repair must be done; see the Chapter devoted to these procedures. 


\section{Less-frequent calibration procedures}

\subsection{Calibrating the heater thermocouples to actual heat flux values}

(This procedure is normally done once monthly.)

In the normal operation of the calorimeter, the correct setting of the heat flux can be quickly attained if one knows the temperature of the thermocouples which give the desired heat flux. To do this, it is necessary to first generate calibration tables of heater temperatures vs. heat flux to the sample. Separate tables are to be made for the horizontal and for the vertical specimen orientations. To make these calibration tables, insert the flux gauge in its holder, being certain the center of the flux gauge is at the center of the cone and exactly $25 \mathrm{~mm}$ from the bottom of the cone heater plate. (By this reference is meant the bottom of the over-all heater retaining plate, which is illustrated in Fig. C2.)

Note that for this calibration step, NO specimen holder or specimen blank is to be used.

Select the desired-horizontal or vertical-orientation. With the flux gauge set up, turn on the fan to the typical $30 \mathrm{~g} / \mathrm{s}$ and increase the temperature setpoint on the controller for the cone heater until the millivolt output of the flux gauge (converted to $\mathrm{kW} / \mathrm{m}^{2}$ by using the flux gauge calibration) shows the appropriate reading. Be sure to give the controller enough time to stabilize before recording the temperature. When complete, the procedure should generate the heater temperatures which correspond to flux readings starting from $10 \mathrm{~kW} / \mathrm{m}^{2}$ to $110 \mathrm{~kW} / \mathrm{m}^{2}$ in $10 \mathrm{~kW} / \mathrm{m}^{2}$ increments plus three intermediate values of 25,35 , and $75 \mathrm{~kW} / \mathrm{m}^{2}$. Now perform the same calibration steps for the other orientation.

With these tables, it becomes a easy matter to get a particular flux simply by setting the controller temperature to the temperature corresponding to the desired flux from the lookup table. It is important to realize that the temperature of the thermocouples in the cone heater will not give the exact flux but only a close approximation. It is always necessary to use the flux gauge to set the final flux. This may require setting the controller's setpoint temperature a few degrees higher or lower than what was originally calibrated for the lookup table. This slight variation in temperature $v s$. heat flux is to be expected as the thermocouples age and shift their position due 
to expansion and contraction of the heating element. If any major variations develop in these ratios, this is a sign of possible trouble and should be investigated. See the TROUBLESHOOTING AND REPAIR Chapter for further details.

\subsection{Gas burner checks, 5 and $10 \mathrm{~kW}$ level}

(This procedure is normally done once monthly.)

The heat release calibration is normally highly linear and no linearity corrections need to be applied. In some cases, however, it is possible to have a problem, such as a line leak that shows up at certain temperatures and not at others. Such a malfunction would introduce a non-linearity into the calibration. Thus, periodically it is desirable to check the performance at another level, specified as the $5 \mathrm{~kW}$ level in $\mathrm{P} 190$. The check involves using the normal methane gas calibration burner. Since a steady-state reading alone may not indicate certain potential anomalies, it is desirable to record a complete square-wave test at each chosen level. Often, it is desirable to go in 1 $\mathrm{kW}$ steps from 1 to $10 \mathrm{~kW}$. To perform this calibration, first do the normal daily calibration at the $10 \mathrm{~kW}$ level, then progressively introduce other, known burner flow rates. (Do not rely on assumed linearity for the potentiometer setting the mass flow controller. This linearity can be poor, especially at the lower end of the scale. Instead, use the dry test meter to first calibrate the potentiometer for each different methane flow level.) To obtain square-wave shapes, first light the burner outside the Calorimeter hood, and keep it there temporarily. Start the data acquisition system as if running a test, but do not introduce the burner; instead, wait for about 4 minutes. During this time, baseline, $0 \mathrm{~kW}$ data will be recorded. Now, quickly introduce the burner from the outside to underneath the hood. The burner does not have to be pushed into its normal calibration slot. Record at least 4 minutes of data. Quickly pull out the burner to outside of the hood. Record at least 4 minutes of baseline data. If additional levels will next be run, reset the flow controller to a different level, and repeat the procedure. The reduced test data should show clean square waves and good agreement $( \pm 5 \%)$ for all plateau levels.

\subsection{Checking the operating flux gauge against the refer- ence gauge}

(This procedure is normally done once monthly.) 
The calibration of the operating gauge is to be checked against the reference gauge at several fluxes. Typically, fluxes of $25,50,75$, and $100 \mathrm{~kW} / \mathrm{m}^{2}$ are used in checking. It is not important that these exact values be chosen, but it is essential that the cone heater be operating properly, and that a true equilibrium be reached at each calibration level. The temperature controller must have reached a constant temperature, and must also show nearly zero deviation on the deviation scale. The two gauges should be inserted one after the other, making sure that the reading is again fully equilibrated. Readings should agree to within $2 \%$ over the entire range. If the operating gauge is found to disagree with the reference gauge by a constant factor (to within a $2 \%$ spread) over the whole flux range, then a new calibration factor (units of $\left[\mathrm{kW} / \mathrm{m}^{2}\right] / \mathrm{mV}$ ) is established for the operating gauge, and the gauge used with the new factor. If the operating gauge cannot be brought to within a $2 \%$ agreement over the entire range by the use of a single, new factor, then the gauge must be rebuilt or replaced.

Repeated warning: Do not under any circumstances use the reference gauge as the daily-use gauge-this will destroy the capability of having a reliable standard.

\subsection{Checking the laser smoke photometer}

(This procedure is normally done once monthly.)

To perform a routine laser smoke meter check, first remove the end from the photometer tube. Insert the translucent plastic plug specified under CALIBRATION AND AUXILIARY EQUIPMENT NEEDED section above. A clean, well-centered laser beam image should be seen. No glow should be seen in the area surrounding the laser image. There should also be no "streamers" of light visible. If any of these are present, cleaning or re-alignment are necessary; see the TROUBLESHOOTING AND REPAIR Chapter. If the optics are visibly satisfactory, then the filter readings with a neutral density filter can be verified. This will be a very abbreviated version of the calibration procedure described below as CALIBRATING THE SMOKE PHOTOMETER. Zero the front panel control, then using one or two of the neutral density filters, verify that the expected reading is obtained. If the expected reading is not obtained, then the full calibration procedure will have to be done. 


\subsection{Setting the gas analyzer flow rates}

(This procedure is normally done only when changes or additions are made to the gas analysis system.)

The procedure for the oxygen analyzer adjustment, below, must be checked first if there are any flow difficulties with the other unheated line $\left(\mathrm{CO}, \mathrm{CO}_{2}\right)$ analyzers, since the waste regulator flows are set up in that step.

- Oxygen analyzer.

The oxygen analyzer is sensitive to two quantities: (1) the inlet pressure, and (2) the back-pressure to the analyzer. The response will not be satisfactory unless both are properly adjusted. Additional gas analyzers, if used, are also sensitive to both these pressure. However, since much greater resolution is required of the oxygen analyzer than of the $\mathrm{CO}, \mathrm{CO}_{2}$, etc., analyzers, only the inlet pressure to these remaining analyzers is controlled.

For the Servomex oxygen analyzer, the requirements are that a backpressure of approximately $1 \mathrm{psig}(7 \mathrm{kPa})$ be maintained at the outlet. The exact value is not critical, as long as it is not changing due to clogging, malfunctions, etc. Thus, a throttling valve is fitted at the outlet, so a back pressure could be applied. To adjust this valve, connect a manometer with one end open to room air and the other end connected to a T-fitting between the analyzer's outlet port and the throttling valve. Put in some preliminary setting of the inlet flow controller to achieve approximately an indication of " 4 " on the front-panel rotameter. Adjust the throttling valve until the proper pressure indication is obtained on the manometer. Remove the manometer.

Further back-pressure throttling valve calibrations, can be accomplished more easily by making use of the electric pressure-measuring module fitted to the Servomex analyzer. This reading is not the outlet port reading, but the detector cell reading, which is slightly higher. If the correct inflow is established on the front panel rotameter, and the correct back-pressure exists, then the electric pressure-module signal will be uniquely related to the desired absolute pressure to be maintained at the outlet port. To check that this gives in the vicinity of a 1 psig drop, it can be compared to the room barometer. This electrical reading is found across terminals marked "P" and " $0 \mathrm{~V}$," accessible once the front cover of the analyzer is opened. This output is scaled at $0.333 \mathrm{~V} / \mathrm{psia}(0.0476 \mathrm{~V} / \mathrm{kPa})$. 
Thus, to check the proper setting of the throttling valve, convert this voltage to an absolute pressure reading, and subtract the barometer reading. This will give a "gauge" drop across the throttling valve, approximated to the extent that the cell pressure was substituted for the outlet pressure. If the correct reading for this operation was recorded during initial setup, it should now be possible to use this reading to re-set the throttling valve to its correct position.

The inlet pressure is not adjusted directly; rather, the inlet flow is controlled. The correct flow setting for the Servomex analyzer is obtained when the front panel rotameter reads " 4 ." Two controls are available for adjusting the flow rate: the waste regulator and the flow controller. Their settings interact, so the adjustment must be done methodically. First, the oxygen analyzer flow controller is set to its wide-open position, while simultaneously increasing the waste flow being diverted out the waste regulator, so the rotameter remains on-scale. Leave the waste regulator in such a position that the flow-controller is wide-open and the rotameter reads "5." Now, decrease the flow-controller setting to obtain a reading of " 4 ." The flow-controller will now be within its control range and will not be pegged out.

- Water vapor analyzer.

Since all of the plumbing associated with the water vapor analyzer has to be heated, the analyzer does not have a front panel flow rate adjusting valve. Instead, a dump valve has been fitted to the supply line, to allow a variable rate of bypass flow. This valve is located as a part of the solenoid zero/span/sample switching arrangement; it has a big black knob accessible at the center of this assembly from the back of the instrument rack. To adjust, vary this setting until the correct front-panel $\mathrm{H}_{2} \mathrm{O}$ rotameter reading is achieved. Note that if other gas analyzers in the heated-analyzer rack are put in or removed from service, flow rate variations will be seen. Thus, it is important, once the desired analyzers have been put on-stream, to verify that the flow rate to the water vapor analyzer is identical during the zeroing, spanning, and sample running steps.

- Other gas analyzers.

The other gas analyzers, if used, also require additional flows. For each analyzer, in turn, make sure that its controller is not pegged out. To do this, increase the setting on the flow-controller pertinent to that analyzer and see 
that some further flow increase is possible. If this is not true, cut down on the amount of bypass flow being diverted out the waste regulator, so that this does hold. When all the remaining gas analyzers are so checked out, this step is complete.

\subsection{Determining the gas analyzer time offsets}

(This procedure is normally done only when changes or additions are made to the gas analysis system.)

The response of the thermocouple, stack pressure transducer, and the load cell are fast enough that they are assumed to occur without a time offset. The gas analyzers, however, show a significant time offset, and this has to be corrected by time-shifting the data appropriately. These values will be different for each analyzer and each installation, and depend on the analyzer itself, the pumps, and the flow paths. There is not any one "standard" offset time; times less than $45 \mathrm{~s}$ are reasonable.

To determine the appropriate offset time, the instrument must be fully operational. Since the flow rates established through the gas sampling train, including adjustments to the waste regulator will affect the time offset, it is essential that the analyzer flow rate adjustments must be successfully completed before the time offsets are determined.

Start the data system. Then light the calibration burner while holding it outside of the hood, so that the flame is vented into the room hood, not into the Cone Calorimeter collection hood. Quickly thrust the burner under the Calorimeter hood. Allow about 10 minutes to reach a steady state. Remove the burner by quickly pulling out manually. Extinguish the burner once it is outside of the Calorimeter hood. Collect another few minutes of data points. Shut off the data system.

The offset for each analyzer is now determined by trial-and-error, adjusting the offset in steps equal to the scan interval. The data analysis software should be programmed to specify some fixed, arbitrary, mass loss rate (the burner, unlike a solid specimen, obviously does not show a load cell indication). Now reduce the data and examine the heat release rate, the "kg CO/ $\mathrm{kg}$ fuel," and similarly the values from the other gas analyzers. The correct value for each analyzer will be that time offset which indicates the closest to a square-wave shape, both on the rise and on the fall, for each particular gas. (The reason that, with an incorrect offset, non-square-wave shapes will be indicated on the reduced data columns is that there will then be a 
relative time error between the gas channel reading and the stack thermocouple + $\Delta \mathrm{P}$ readings.)

This procedure can always be double-checked using a stopwatch and a stripchart recorder. The correct offset time will be somewhat greater than the time required to the first signs of pen deflection, but less than the $50 \%$ rise point.

\subsection{Setting the oxygen analyzer response time}

[This feature is available only on the Beckman unit. The operation needs only to be performed at the time of initial installation.]

The Beckman oxygen analyzer incorporates an electrical circuit whereby the intrinsic response of the detector is speeded up by electrically adding a certain fraction of the signal's derivative to the signal itself. To adjust, hook up a stripchart recorder to the analyzer's output. Provide a three-way valve which permits changing the supply to analyzer over from one gas cylinder to a second one quickly. Select two different $\mathrm{O}_{2} / \mathrm{N}_{2}$ mixtures, and make sure stripchart response is on-scale. Set the cylinder pressure regulators to values which will give identical flow rate rotameter indications for both cylinders. Now cut over quickly from one cylinder to the other and back. If the response shows an overshoot, decrease the response time control, otherwise, increase it. Determine by trial-and-error the setting which corresponds to barely detectable overshoot. This constitutes the optimum setting of the response time control.

\subsection{Checking analyzer D-to-A operation}

(This procedure is normally done only when difficulties are experienced with the gas analyzers.)

The gas analyzers made by Thermo Environmental Instruments have microprocessor controlled linearization. Thus, their output is intrinsically digital and must be converted back to an analog signal for use by the data collection system. Since the direct digital output, as indicated on the front-panel meter, is used in spanning and zeroing, it is essential to know that the analog output corresponds exactly to the digital output. The manufacturer provides a simple procedure to check this operation of the D-to-A converier. Follow the instructions in the Thermo Environmental manual for the steps to be taken. 


\subsection{Load cell damping factor adjustment}

(This procedure is normally done only after completing any needed repairs to the load cell.)

To adjust the damping, hook up a stripchart recorder to the output of the load cell. Run the recorder at a high chart speed to be able to observe the timing. Check the cell to ensure that it is in its dynamic range (see the DAILY START-UP AND CALIBRATION Chapter above). A mass in the range of a typical sample is gently placed on the load cell (at NBS, a weight of $200 \mathrm{~g}$ is typically used) and thirty seconds or so later it is gently removed. The output of the stripchart is observed. The ideal shape of the trace would be a square wave with sharp corners. The rise and fall times should be such that $90 \%$ of the rise (or fall) is typically achieved in $3 \mathrm{~s}$ or less. If the cell does not have enough damping the stripchart will show an overshoot of the final value.

Increase the damping on the cell until the overshoot just disappears and a square corner is obtained. Then, turn on the exhaust blower and verify that the damping as initially set is still effective in controlling the inevitable vibration associated the exhaust system. If the load cell output is noisier than when the test was first conducted, then more damping may be required. For further information on the load cell, see the manufacturer's instructions.

\subsection{Set-up of the controller for the soot sampler}

(This procedure is normally done only after any repairs have been performed to the soot sampling system. Refer to Fig. E5 in the Construction Drawings for identification of parts.)

1. The needed thermocouple input $(\mathrm{T} / \mathrm{C})$ may come from an actual thermocouple, or from a voltage source. If a voltage source is used, make sure that presence of the electrical cold junction module is taken into account. The pressure transducer signal will normally be supplied by a test voltage source.

2. Warm up the unit overnight. Obtain a DC millivoltmeter which can read to $\pm 0.1 \mathrm{mV}$.

3. Set trim pots R18, R29, using the normal procedure of shorting together the op amp inputs and setting for minimum output. 
4. To set stage gain of $10 \times$ for the $2 \mathrm{~B} 50 \mathrm{~A}$ module:

- apply an equivalent of $400^{\circ} \mathrm{C}$ as the $\mathrm{T} / \mathrm{C}$ input

- set R22 to read $0.164 \mathrm{~V}$ at test point TP1

- check that $25^{\circ} \mathrm{C}$ on $\mathrm{T} / \mathrm{C}$ gives $0.010 \mathrm{~V}$ at $\mathrm{TP} 1$

5. Set up OP- $07 \mathrm{AH}$ to gives $10 \times$ gain and to change ${ }^{\circ} \mathrm{C}$ to ${ }^{\circ} \mathrm{K}$ :

- apply $400^{\circ} \mathrm{C}$ to $\mathrm{T} / \mathrm{C}$

- set $\mathrm{R} 1$ to give $2.799 \mathrm{~V}$ at TP2

- check that $25^{\circ} \mathrm{C}$ on $\mathrm{T} / \mathrm{C}$ gives $1.212 \mathrm{~V}$ at $\mathrm{TP} 2$

6. Calibrate the reference voltage on the 433J module:

- apply $10 \mathrm{~V}$ to the $\Delta \mathrm{P}$ input

- apply $25^{\circ} \mathrm{C}$ to $\mathrm{T} / \mathrm{C}$ and make sure $\mathrm{TP} 2$ reads $1.212 \mathrm{~V}$

- adjust R2 to get $10.000 \mathrm{~V}$ at TP3

- apply $400^{\circ} \mathrm{C}$ to $\mathrm{T} / \mathrm{C}$

- check that TP3 gives $6.58 \mathrm{~V}$

7. Calibrate the soot sampler mass flow rate [front panel trim pot R23]:

- set the manual front-panel flow rate control (R4) near full-scale

- insert a calibration dry test meter in series with mass flow controller; connect the vacuum source

- adjust R23 for correct reading, based on the dry test meter reading (taking into account corrections for pressure and temperature).

\subsection{Calibrating the exhaust flow controller}

(This procedure is normally done only after any repairs have been performed on the exhaust flow control system.)

The exhaust flow control system comprises the following components: 
- the flow rate indicator

- the signal conditioning circuitry that derives a flow rate signal from the stack thermocouple and pressure transducer (this circuitry is physically located in the NBS instrument in the soot mass controller box, and is brought out of the exhaust flow control box through a Lemo plug).

- the millivolt controller

- the motor speed controller

The calibration of the exhaust flow rate indicator is given in the next section below; the calibration of the circuitry delivering the pressure and temperature information is covered in the section SET-UP OF THE CONTROLLER FOR THE SOOT SAMPLER.

The millivolt controller's operation is very similar to that of any 3 -term temperature controller. The controller is to tuned so that (a) there is no oscillation of the output, and (b) the offset error between the desired setpoint and the achieved output is at a minimum. For further details, consult the manual for the Time-Trol millivolt controller or any textbook on the operation of industrial temperature controllers.

The motor speed controller has a number of factory adjustment points on the chassis, however, none of these should be changed. In case of malfunction, see the TROUBLESHOOTING AND REPAIR Chapter.

\subsection{Calibrating the exhaust flow rate indicator}

(This procedure is normally done only in connection with repairs to the exhaust flow indicator.)

The front-panel meter showing the exhaust flow rate $(\mathrm{g} / \mathrm{s})$ provides the normal way of setting up the instrument exhaust flow for a test. This meter is not used in the data acquisition, as the data acquisition system utilizes the pressure transducer and thermocouple readings directly. Without the front-panel indicator, however, it would be difficult to set a desired flow rate before start of test. The meter readout is derived from the pressure transducer and the thermocouple, and then computed electronically. There are various ways to calibrate this meter. The simplest way is to utilize a known methane flow and determine the orifice coefficient as for normal operation. Once this coefficient has been determined, the adjustment of the meter 
consists of computing the flow using the orifice flow formula and the data supplied by the pressure transducer and thermocouple. The orifice coefficient must fall within the expected normal tolerances for this to be a plausible setting.

Since the exhaust flow rate indicator is electrically coupled in the NBS installation to the soot mass flow controller, it is required that the soot mass controller be calibrated first. Thus, if the soot sampler controller calibration has not yet been done (see above), that procedure must first be completed.

1. Verify that a correct zero reading is obtained. Block the main duct with a cap to ensure that no flow is actually going through the duct (the canopy exhaust system or other convective currents can sometimes induce a small flow). With zero flow established, check that the meter reads exactly zero. If zero is not obtained, either the zero-pot on the pressure transducer has not been set properly (see instructions below), or there is some circuit failure. Fix the relevant problem and continue.

2. Determine the orifice plate orifice flow constant by using the standard procedure, as given above.

3. Make sure that the flow rate indicator meter has had its decimal point wired such that at full scale a reading of 199.9 is shown.

4. Set the upscale pot. This is front panel trimpot R7, as shown on Fig. E4. Remove the cap blocking the duct. Operate the fan in the constant volume mode, setting the fan at a moderate speed. Using the output from the thermocouple, pressure transducer, and the newly developed orifice plate coefficient, compute the flow through the duct and set the trimpot $\mathrm{R} 7$ to indicate this flow. The equation is:

$$
\dot{m}=C \sqrt{\Delta P / T} \quad \mathrm{~kg} / \mathrm{s}
$$

It is convenient to convert this to the front panel readings of $\mathrm{g} / \mathrm{s}$, by multiplying by 1000 . Note that $\mathrm{T}$ is in degrees Kelvin.

\subsection{Calibrating the smoke photometer}

(The complete procedure given here is normally done only when repairs have been made to the smoke photometer.) 
Among the various laboratories using Cone Calorimeters, slight differences exist both in the mechanical construction of the photometer and in the signal electronics used. For the mechanical construction, the "original" version used only one beamsplitter and did not make any special provision for special slots for the insertion of neutral density filters. The "new" version has both photodetectors arranged in a symmetrical fashion, so that two beamsplitters are used. This version also incorporates two permanent slots for neutral density filters, one in front of the laser, the second in front of the main beam detector. For the signal conditioning electronics, the version as originally published by NBS will be referred to as the "NBS" version, while the later version designed by SSDC, Inc., will be referred to as the "SSDC" version. Certain instructions below will be given in specific variants, for the "original," and for the "new" mechanical arrangements, and also for the "NBS" and the "SSDC" electronics.

If a re-calibration of the signal electronics is necessary because of observed irregularities in photometer operation, it should be presumed that a mechanical re-alignment will need to be done. This should be done first, using the procedures described in the TROUBLESHOOTING AND REPAIR Chapter.

\subsubsection{NBS version electronics}

(See Fig. E6 for adjustment points.)

1. Turn on the electronics overnight. Do not turn on the laser.

2. Short together terminals $2-3$ on OP-07. Set R4 for zero output. Remove the shorting wire.

3. Attach a voltmeter to test point TP1. Set R1 and R2 at mid-scale. Turn on the laser. The procedure at this point will depend on whether the smoke photometer unit has a filter-holder slot provided in front of the laser (new version) or not (original version). If it does not, the natural oscillatory behavior of the laser will have to be relied on. If the laser has warmed up enough in trying to do the steps below so that the oscillations diminish, turn it off for a couple minutes, then turn it back on. If a filter-holder slot is provided, all that is necessary is to open the cover exposing that filter-insertion opening which is located in front of the laser, and repetitively put in and take out a neutral density filter (precise value is unimportant) into the slot. In either case, monitor TP1 for laser ripples, or for fluctuations as the filter is pulled in and out manually. Either one 
effectively changes the laser output power. When the procedure below has been successfully accomplished, the circuit will be balanced out so that laser output power fluctuations will have no effect on the extinction coefficient indication.

Slowly adjust $\mathrm{R} 1$ for minimum ripple. Adjust $\mathrm{R} 2$ for minimum ripple. By successive adjustment of $\mathrm{R} 1$ and $\mathrm{R} 2$ it should be possible to obtain a condition where the laser fluctuations (or filter insertions) have no effect on the TP1 reading. If either $\mathrm{R} 1$ or $\mathrm{R} 2$ are pegged and ripple still exists, the log amp may be damaged or has excessive offset current; in that case replace the log amp. When finished, close up and secure the filter-holder opening (new version only).

4. Check that the output voltage and the panel meter indication track correctly. The reading on the panel meter should be exactly $10 \times$ the output voltage, as measured at the main patch panel with a digital voltmeter. If the decimal point is wired incorrectly in the panel meter, re-wire correctly.

5. Procure a high quality glass neutral density filter, with a value in the range of $\mathrm{OD}=0.3$ to 0.8 , calibrated at the $\mathrm{HeNe}$ wavelength $632.8 \mathrm{~nm}$. For the new version photometer, this will be already mounted in a special filter-holder which slides directly into the second, calibration filter-holder opening, located in front of the main beam detector. Without a filter in place, set R3 (front panel zero) and R5 at midpoint. Adjust R14 for zero output. Insert the filter. To do this using the new version photometer merely requires opening the cover on the calibration filter-holder opening and inserting the filter. The filter-holder has a special locating pin so that it can only be inserted one way. For the original version photometer, the filter must be inserted into the beam using a rigid positioning device, which can hold it at several degrees off beam-perpendicular. (Inserting the filter into the exactly perpendicular position would result in multiple reflections and an incorrect calibration. The angle of offset should be just enough to ensure that none of the re-reflections are coming back along the centerline.) To insert the calibration filter into an original version photometer, it is necessary that the exhaust duct section which is in front of the section on which the photometer is mounted be removed. Also remove the ring sampler. Since the user's calibration stand will probably not have filter-locating devices to make sure the filter is only inserted one way, the user should be careful to verify each time that the filter is being put in with the shinier surface towards the laser. 
6. The output should be $k=O D \times 2.302 / L$, where $O D$ is the optical density of the filter actually being used, and $L$ is the inside diameter of the exhaust duct at the location of the photometer. Thus, with typical values as used, $k=0.3(2.303) / 0.114=6.06 \mathrm{~m}^{-1}$ might be computed. Adjust the slope control, $\mathrm{R} 5$. (If there is not enough range available in R5, then R7 must be changed slightly; do not push R7 to the extremes of its range.) Repeat adjustments of R14 and R5, alternately removing and inserting the filter, until correct readings are being obtained both for the zero OD and the filter OD conditions.

7. Repeat the above step at least two more times to check the repeatability of the filter insertion.

8. For the new version photometer, remove calibration filter, and close up the cover for the opening. For the original version photometer, remove the filter holding device, then re-install the ring sampler and the front exhaust duct section. Check carefully that the ceramic fiber gasket is not damaged and that there are no leaks.

9. In normal operation, only R3 needs to be trimmed for zero. However, since the design does not incorporate windows on which soot could be deposited, any adjustments needed between tests should be very slight.

10. With laser off, the reading is indeterminate. With light path fully blocked, the reading is pegged at maximum output (which is greater than the $20.00 \mathrm{~m}^{-1}$ range of the indicator).

\subsubsection{SSDC version electronics}

(See Fig. E7 for adjustment points.)

1. The SSDC electronics box has two switches, one labeled RUN/CAL CMR, and the second RUN/CAL SLOPE. ("CMR" denotes common-mode rejection.) Each has a red LED associated with it. There are also, adjoining, five adjustment potentiometers: ZERO, GAIN, SLOPE, CMR, BAL.

2. The procedures described in this section assume that a completely new or repaired unit has to be calibrated. If the purpose of calibration is because the photometer had to be disassembled for making mechanical repairs only, then, 
upon re-assembly, an abbreviated calibration procedure can be followed. In that case, only the zero and slope control adjustments will normally need to be made.

3. To start calibration, make sure power to the electronics is turned on. Make sure that power to the laser is turned on and that the laser is operating.

Make sure that the thermal enclosure for the electronics box is firmly in place. Place the RUN/CAL CMR switch in the CAL CMR position. Let the system warm up for at least 1 hour.

4. Adjusting the balance control. [This will only need to be done at the time of the original installation, or after internal repairs to the SSDC electronics box.] The first step will be a balancing of reference resistances. Using the specified DVM, connect the positive lead to edge card pin 5. Set the meter for autoranging of resistance. The following must be done quickly (to avoid heating of resistors due to measuring currents). The operator must familiarize himself with the remainder of this step before proceeding.

Place the RUN/CAL CMR switch is in the RUN position.

Connect the negative lead of the DVM to edge card pin N. (This pin is located on the lower face of the circuit card only. Note that the alphabet starts with 'A,' but skips the letters G, I, O, and Q.) Record the stable resistance reading.

Connect the negative lead of the DVM to edge card pin S. (Also on lower face.) Adjust the BAL control to achieve a resistance value equal to the reading recorded above, within $\pm 25 \Omega$.

Disconnect the DVM.

5. Adjusting the CMR control. This control is used to balance the gain of the two log channels. The setting is internal to the electronics box only, therefore the light exposure conditions to the system detectors are not important for this step.

Place both switches in their CAL positions.

Adjust the CMR control for an extinction coefficient reading of zero.

6. Preliminary zero control adjustment. Next, the ZERO control on the electronics box will be adjusted; this is the coarse zeroing control, the fine zero 
being the front panel knob normally used in daily testing. (This coarse zero will also be adjusted later, under the slope calibration procedures.)

Place both switches in their CAL positions.

Set the front panel (fine) zero knob at its midpoint.

Record the reading of the extinction coefficient. The reading must be stable and within $0.000 \pm 0.020$.

Place the RUN/CAL SLOPE switch in the RUN position.

Adjust the (coarse) zero control to achieve the previous reading above to within \pm 0.010 . Repeat by trial-and-error, if necessary.

Place both switches in their RUN positions.

7. Adjusting the gain control. This is the gain adjustment on the final, outputstage buffer amplifier. It is normally set for unity gain. It can, however, be used as an additional gain stage for systems which would require a non-standard output level.

Place the RUN/CAL CMR switch in the RUN position; place the RUN/CAL SLOPE switch in the CAL position.

Adjust the SLOPE control to obtain an extinction coefficient reading of $-17.000 \pm 2.000$. Make sure the reading is stable to within $\pm 0.100 /$ minute. Record the reading.

Place the RUN/CAL SLOPE switch in the RUN position. Adjust the GAIN control until same reading is obtained as was obtained on the previous step, to within \pm 0.010 .

When this is completed, the gain will now be set to an accuracy of $\pm 0.01 \%$.

Place both switches in their RUN positions.

8. Final zero control adjustment. Once the buffer gain has been set, the ZERO control must again be re-checked.

Make sure that both switches are in their RUN positions and that both filter insertion ports (new version only) are closed. Set the front panel (fine) zero control knob at its midpoint.

Adjust the (coarse) zERo control to obtain a panel meter display within $0.000 \pm 0.050$. Do not attempt to use the coarse ZERO to achieve a closer zeroing; set as close to zero as possible with the fine zero knob. 
9. Adjusting the slope control. This control is the basic adjustment necessary to ensure that system extinction coefficient readings are properly calibrated with regards to neutral density filters. Special precautions have to be taken in this procedure to allow for the fact that photodetectors do heat up slightly from the laser beam energy itself; they heat up rather quickly, but cool down slowly. To perform this step, all of the preceding steps in the calibration sequence should have been successfully completed.

The user should have two neutral density calibration filters in the range of 0.3 OD to 0.8 OD. Verify the actual value of the neutral density calibration filters to be used by checking the manufacturer's calibration chart, reading off from the chart at the $632.8 \mathrm{~nm}$ wavelength. Convert this value into extinction coefficient $(k)$ units by taking $k=O D \times 2.303 / L$. Here $L$ is the inside diameter of the exhaust duct, with typical values being $L=0.114 \mathrm{~m}$ for the NBS units, and $L=0.1095$ for the Custom Scientific Instruments units. The 2.303 is needed to convert from base-10 to natural logarithm units. Record this theoretical $k$ value for the filters being used.

The operations below will be described for one filter. When properly adjusted, a check with the second filter should indicate no re-tuning to be necessary. Significant disagreement between the filters suggests a defective filter.

The SLOPE control adjustment is difficult because of the interaction between the SLOPE and the ZERO controls. The interaction is such that changes to the slope control setting have a greater effect on the meter indications at the zero end of the scale than at the top end. (To increase the effective meter reading, the SLOPE control is adjusted in the CW direction.)

Open the filter insertion slot cover and insert the calibration filter (new version). Note that the filter holder has a locating pin so that it cannot be inserted in the incorrect orientation. For the smoke photometer hardware of the original version, it will be necessary to dismantle the exhaust duct section which is ahead of the photometer duct section. Also, remove the ring sampler. The user is to have on hand a rigid calibration stand, which can be installed inside the duct. This calibration stand must be able to hold a neutral density filter slightly off-perpendicular with respect to the laser beam. The angle must be small, but sufficiently off-perpendicular that re-reflections do not come back into the detectors. Since the user's own calibration stand will probably not have filter-locating devices to make sure the filter is only inserted one way, the user 
should be careful to verify each time that the filter is being put in with the reflective surface towards the laser.

After 10 minutes record the filter reading (which should be stable to within \pm 0.010 /minute), using the front panel meter. Quickly remove the filter holder, and close the port cover. After one minute record the zero reading. Subtract the zero reading from the filter reading. Subtract this corrected reading from the expected theoretical $\mathrm{k}$ value to obtain a difference-error reading.

Re-insert the filter. After 10 minutes, record the display reading. Adjust the SLOPE control for the panel meter to indicate a new value, equal to halfway between the expected reading plus (or minus, depending on the sign of the error) half the difference-error. (It has been found empirically that convergence is quicker if half of the expected correction, rather than the full amount, is made each time.) Let the reading equilibrate, then record this new reading. Perform the zero reading, after removing the filter, as before. Perform the differenceerror calculation on this new reading, then repeat the adjustment. Repeat this procedure until the difference error becomes less than $0.5 \%$ of the filter reading.

Example. A nominal 0.8 OD neutral density filter is used and is found to have an actual OD of 0.79 from the chart. The formula above would indicate that a $k$ reading of 16.615 is expected. The filter is inserted into the filter port in front of the main beam detector. After 10 minutes, the display reads +19.615 . The filter is removed and the port is closed. After one minute the display reads +1.000 . Take the difference between the two readings. The corrected value is then $19.615-1.000=18.615$. The difference-error is $16.615-18.615=-2.000$. Since the error is negative, the slope must be reduced. If the reading were positive, the slope would be increased. The suggested amount of adjustment is $1 / 2$ the error, $(1 / 2) \times 2.000=1.000$. Do not adjust the controls yet. Re-insert the filter. Wait 10 minutes. The display reads +19.500 . Adjust the SLOPE control to achieve a reading of $18.500 \pm 0.050$. Wait one minute. The meter reads 18.510. Remove the filter and close the port. Wait one minute. The meter reads 1.800 . Subtracting the two readings, $18.510-1.800=16.710$. Repeat the procedure until $16.615 \pm 0.080$ is achieved.

If necessary, re-adjust the front panel zero.

Make sure main beam detector filter port is closed (new version). For the original version, remove the calibration filter holding device; re-install the ring sampler and the section of duct which was removed. 
10. Checking for adequate CMR and proper reference beam compensation. The purpose of the reference beam detector circuitry is to make sure that signal fluctuations are not caused by laser power changes. The photodetectors must be linear and well-matched, and the electronics circuit must be exhibiting good CMR for proper compensation to be observed.

The compensation must be well-done, since otherwise the smoke signal could be obscured by the common-mode signal. For example, a typical test specimen may show an extinction area of $100 \mathrm{~m}^{2} / \mathrm{kg}$. Under normal volume flow rates, this equates to approximately a $10 \%$ level change at the main beam detector. If the laser showed a maximum $5 \%$ instability, and if the system had no commonmode rejection capability, an error of $50 \%$ could be expected. To reduce the error to, say, $1 \%$ under these conditions, would require that a CMR ratio of $50: 1$ be achieved.

Original version: Turn off laser power for at least 5 minutes. Turn laser back on. When laser starts back up, there will be a cyclic output fluctuation for about 1 hour. If the circuit is properly operational, the output should be stable to within about $0.010 /$ minute. Over the span of 10 minutes the total change should not exceed 0.040 .

New version: This version has a second filter holder opening, located in front of the laser. For convenience, use the same filter as was used in the previous calibrations. Open the laser filter holder port, and insert the filter into the port. After 10 minutes, the reading should be stable (within 0.005/minute). Adjust the front panel zero knob to achieve $0.000 \pm 0.005$. Remove the filter holder and close the port cover. After one minute record the new reading. This reading will be used to determine the compensation efficiency. The sign of this reading $(+$ or -) is the opposite of the true sign of the compensation. The CMR ratio can be directly computed numerically. For example, if an 0.8 OD filter is inserted into the laser port, then with no common-mode rejection capability, a reading would be obtained which would be identical to that obtained by inserting the same filter into the main detector port. Thus, a value of $k=16.83$ would be indicated. If the system is in good alignment and adjustment, however, and the $0.8 \mathrm{OD}$ filter is inserted into the laser port, then a reading of $k=0.340$ would indicate a 50:1 CMR rejection ratio. Under optimal conditions, the SSDC electronics can show rejection ratios which are in excess of 100:1. 
If the results of this inspection do not meet the expected accuracy, recheck the BAL and CMR setting steps above; also, consult the TROUBLESHOOTING AND REPAIR Chapter, if necessary.

11. Checking linearity (optional). In some cases, it may be desirable to check the linearity of the photometer circuit. This should be done only after all the steps above have been successfully completed. Several calibrated filters must be available for this; the user is cautioned that it may be very difficult to obtain filters of OD less than about 0.1 that have a sufficiently accurate manufacturer's calibration. The procedure is similar to that described for slope control adjustment, above, except that no adjustments are made. Instead, a graph is made up plotting expected photometer responses against measured ones. Systematic deviations from a straight line on this plot would suggest that maintenance or adjustment is needed.

\subsection{Checking the calibration of the orifice plate pressure transducer}

(This procedure is normally done only after any needed repairs have been made to the transducer.)

1. Zero check. The pressure transducer should be checked periodically for drift in its zero. This is easily accomplished by disconnecting the lines which go to the pressure ports above and below the orifice plate. This should leave both pressure ports of the transducer exposed to an equal pressure of room air. In this condition the output should read zero volts. If not, adjust the zero trim pot on the transducer to yield zero volt output on the transducer. Once this is set, adjust the offset-balance pot on the $10 \times$ gain amplifier/smoother to make its output also equal to zero.

2. Full-scale check. The full-scale indication normally does not show any drift. If a problem is suspected, it can be checked by connecting the transducer in parallel with a water manometer and applying a relevant pressure difference. The presence of a correct output should be checked both at the output terminals of the transducer and after the signal has passed through the $10 \times$ gain amplifier/smoother. 


\section{Regular maintenance}

\subsection{Electric contacts cleaning}

Erratic electric operation can result unless electric signal contacts are clean. This is especially important for thermocouple and other millivolt-level lines, and also for high impedance circuits. An example of the latter is the detector circuit for the laser smoke photometer. Both the Lemo connector and the actual detector should periodically be plugged out and sprayed with a very thin layer of a contact cleaner/preservative, such a Cramolin [Red] Spray. Do not use Cramolin "Special" spray, which is a preservative only, lacking a cleaner. Cramolin spray is made by Caig Laboratories. Other proprietary products are available; however, note that it is not adequate to use a conventional electric contact cleaning spray.

\subsection{Memory refreshing for the temperature controllers}

The Barber-Colman temperature controllers used on the cone heating element and the thermoelectric cold trap must have their electronic memory refreshed at least annually. It only takes a few moments to perform the refreshing. Failure to perform this refreshing will result in the memory being lost. If the memory is lost the unit must be sent back to the factory to be repaired! Listed below is the procedure for refreshing the memory of the model 560 controller.

1. Press the SETUP key once.

2. Hold the DISPLAY key in and momentarily press the SETUP key.

3. Release the DISPLAY key.

4. Press and hold the SETUP key for one second or more. Do not interrupt power to the controller for 20 seconds.

5. After this $20 \mathrm{~s}$ wait is over, the procedure is finished.

\subsection{General cleaning of the instrument}

1. Cleaning interval

The apparatus, because of its intended use, will always collect a certain amount of dirt, soot, and ash. Some of this material will inevitably be deposited 
on the inside of the ductwork and sample lines. This material should regularly be removed by brushing and vacuuming. All safety precautions regarding potentially toxic or carcinogenic dusts should be carefully observed when cleaning the ductwork. The interval between cleaning will largely depend on the nature and amount of material burned; typically, every two to three months. Production type testing with very sooty samples may necessitate a much more frequent clean out interval. Normally a modest amount of soot in the duct will not affect the performance of the apparatus unless it reduces the inside diameter of the orifice plate or blocks the beam on the laser. The daily calibration check will give an indication of the condition of the orifice plate. A gradual drift in the orifice constant will be noted as soot accumulates on the orifice plate.

\section{Laser smoke photometer cleaning}

Soot deposited on the optics of the photometer can cause measurement errors. Unfortunately, this error is often undetectable by using neutral density filters alone; thus, it is essential that a regular cleaning program be followed. Before cleaning the photometer itself, it is a good idea to inspect and clean the main exhaust duct, especially in the area near where the photometer tubes are attached. Within the smoke photometer itself, if only a modest soot accumulation has occurred, it is sometimes possible to blow it out without disassembly. Using a high-pressure air hose nozzle, direct the air stream into each of the 4 small purge air entry holes. (These holes are located on the outside of the photometer barrel, about 1/5-way away from the exhaust duct.) The necessary frequency of cleaning will depend entirely on how much testing is being done and on how sooty are the specimens. If this cleaning is not done regularly, then soot buildups can occur. This may require a complete disassembly of the photometer. If disassembled, after re-assembly an optical re-alignment will generally be needed. Instructions are given in the TROUBLESHOOTING AND REPAIR Chapter.

In normal operation, the exhaust blower causes a small flow of room air to be drawn down the photometer tubes, keeping the soot from entering them. If the blower has been inadvertently left off, or is turned off too soon after the test, or if the fire produces so much smoke as to overwhelm the collection hood and fan, then soot may be forced into the tubes leading to the laser and the detectors. By careful setting of the exhaust control, however, the operator can minimize the need for such major cleaning tasks. 


\section{Inspection port}

The original ductwork design required that the section of duct between the sampling ring and the collection hood be removed to view or clean the ductwork. The current version of the ductwork has a viewing and clean-out port on the square section of the collection hood and this will greatly simplify the inspection of the duct. This port must be sealed tightly when operating the instrument. The port is most useful in viewing the accumulation of soot and not as effective as a clean-out port. It is possible to use a long extension pipe on a vacuum cleaner to remove accumulated soot in the duct from this port, but doing an effective job requires the removal of sampling ring, duct section and the orifice plate sections. With these pieces removed, good access is available for brushing and vacuum cleaning.

4. Specimen area

Frequent cleaning is necessary for the area around the sample holder and the load cell platform. Material falling off the sample during testing tends to accumulate in this area and may interfere with the load cell readings. Vacuuming will normally eliminate any problem. At the same time, check that the aluminum foil protecting the Marinite heat shield has not been moved so as to bind on the load cell.

5. Gas sampling system

The sampling ring and associated lines which connect it to the various analyzers require periodic cleaning. The usual indication of clogging is the need to readjust the waste regulator repeatedly to maintain the proper flow to the analyzers or-in the case of the hydrocarbon, water and $\mathrm{HC} \ell$ analyzers-by a drop in the rotameter readings on each of these analyzers. Cleaning of these lines consists of disassembling the various sections of tubing and blowing them out with 100 psi air, working from the analyzer end of the line toward the sampling ring. Do not direct high pressure air into the any of the analyzers and remember to vent the dirt and soot to a safe place. The sampling lines between the Drierite and the analyzers generally remain quite clean, due to the filtering action of the glass fiber plugs used to retain the Drierite in the tube. The lines most susceptible to clogging are those from the sampling ring to the main soot filter. The flow controllers, being downstream of the Drierite, will only very rarely require any cleaning, as will the analyzers. Consult the specific analyzer 
manufacturer's instruction manual for details on cleaning the measuring cell and possible recalibration.

The soot filters in the gas sampling lines are expected to be changed after every test or as often as necessary to ensure an adequate flow to the analyzer throughout a run. Also, it is necessary to check the screens supporting the filter elements periodically-if these show some soot accumulation, they should be carefully cleaned with a solvent. To minimize any blow-by, the support screens must be completely flat and free of any residue buildup. They must be handled very carefully to avoid any damage; if they are no longer flat, they must be replaced.

The back-up fiberglass packing filter should be replaced whenever leakage from the main sampling filter is noted. A thorough solvent cleaning of the affected area should then also be done.

The diaphragm and seat in the dump regulator also collect soot and tars, so periodic disassembly and cleaning are required; the frequency will depend entirely on the tarriness of the materials being tested.

6. Soot sampling system

A final area where regular cleaning is required are the soot sampling lines and pump. Certain of these lines are cleaned out after every test. Specifically, the soot sampling probe, sampling line, and upper half of the filter holder on the soot sampler should be blown out with 100 psi air and the upper half of the filter holder should be wiped out with a tissue. This is to ensure that no soot from a previous test will be carried over to the next test. The rest of this system should also be cleaned periodically. The screen supporting the filter tends to condense tarry materials, which should be removed with an appropriate solvent whenever it seems to be dirty or is restricting the flow. Under the screen, in the lower part of the filter holder, a glass fiber packing is usually kept as a secondary filter. This secondary filter should be changed as often as it becomes dirty. The condenser tubing leading to the mass flow controller can be cleaned with an appropriate solvent or can be replaced with a new piece of copper tubing as its condition dictates. The mass flow controller will also eventually condense vapors in its valve body and sensor unit. This unit should periodically be disassembled and cleaned with a solvent compatible with its O-rings and seals. Check the manufacturer's instructions for proper disassembly and approved cleaning fluids. Once the unit has been cleaned and reassembled it must be checked with the 
dry test meter to ensure the calibration is still correct (see the relevant section above).

7. Various pumps

There are several sampling pumps in a typical Cone Calorimeter system, which will include the main sampling pump for the oxygen analyzers, but may also include several additional pumps for different gas analyzers, and a pump for the soot sampler (if central vacuum is not used). Pump cleaning or maintenance is usually necessary when a flow rate drop is noted or, in case of the soot sampler vacuum, the normal maximum flow through the filter cannot be achieved. The usual problem with these small pumps is flapper valves tending to get coated with soot and tars, preventing them from sealing properly. Follow the manufacturer's recommendations on how to disassemble and clean these parts.

8. Miscellaneous effects

Cleanliness of the duct has little or no effect on the heat release rate value because the soot has only the smallest affinity for the oxygen in the duct. Certain other gasses which may be of interest, such as $\mathrm{HC} \ell, \mathrm{HBr}, \mathrm{HCN}$, can be more reactive with soot. In studies where these gasses will be under investigation, the level of soot deposition in the ductwork should at least be recorded and recognized as a possible source of error.

\subsection{Maintenance of the heat flux gauge}

With reasonable care in handling and positioning, the flux gauge should need to recoated only very occasionally. Recoating is needed when the flat black coating over the center sensing area of the gauge becomes chipped, abraded, or discolored (i.e., gray instead of black). Any such visible defects will cause the coating to lose its intended value of the radiant absorptivity, and, thus, to shift in calibration. The gauge need not be recoated if only the coating along the outside edge of the gauge becomes damaged, since that does not correspond to the active sensing area.

To recoat the gauge, first strip off the old coating by gently rubbing the surface of the gauge with a soft cloth with a little acetone on it. The Medtherm Model GTW-732-485A gauge is a Schmidt-Boelter type gauge, which is relatively hardy and can withstand a modest amount of rubbing, nonetheless no abrasive type cleaners should be used. If you are using a Gardon type flux gauge, which uses a thin-foil 
sensor, be especially careful during the stripping of the coating not to press on the foil. If the coating does not come off by using acetone, then other solvents can be used. Methyl-ethyl-ketone or a mixture of xylene and toluene are stronger solvents but present a greater health concern for the user.

With the old coating removed, the new coating must be applied in a smooth and uniform layer. The easiest way to recoat the gauge is to hold it by the water cooling tubes in one hand and spray a light coat from about 20 to $25 \mathrm{~cm}$ away. Let this first coat dry to the point of losing all its gloss and then turn the gauge 90 degrees and apply a second coat. This technique will reduce the chance of spraying an excessively heavy coating on the gauge. If you have not masked the water and electric lines, wipe the overspray off them before the paint fully dries. The recommended coating can be purchased from Medtherm Corp. in spray cans. The coating must be fully dried before using the gauge or recalibrating it. The coating can be dried by leaving it overnight at room temperature, or by drying in an oven at about 65 to $120{ }^{\circ} \mathrm{C}$ for 15 minutes.

The final step in recoating is to recalibrate the gauge against the reference gauge. This completes the recoating procedure. 


\section{Troubleshooting and repair}

The purpose of this Chapter is to help the user diagnose and solve any problems arising out of the Calorinieter operation. Also included are certain instructions for assembly and disassembly, where the steps to be taken are not obvious. Since this document is not a textbook on scientific instrument repair, it is assumed that the user already has basic experience in the repair of gas analyzers, load cells, and other laboratory instruments.

It is assumed here that all the commercially supplied analyzers $\left(\mathrm{O}_{2}, \mathrm{CO}_{2}, \mathrm{CO}\right.$, etc.) have been set up and are working according the manufacturer's specifications. If any of these analyzers are malfunctioning, see the troubleshooting section of the manual supplied with the particular analyzer. Analyzer malfunctions will usually be spotted in the process of spanning and zeroing the individual analyzer, or, possibly, when problems are encountered while trying to obtain the orifice calibration constant.

\subsection{General}

- Erratic specimen burning during the last few minutes of a test.

Such behavior can often be due to drafts blowing non-uniformly across the specimen. Observe the surface of the specimen as it is nearing the completion of its combustion (this is easier to observe during horizontal orientation tests). When the specimen is burning out, the material should be disappearing uniformly over the entire face. If one portion of the specimen's face is consumed before the remaining ones, the cause may be a draft blowing across the specimen.

Make sure that any glass [by which we mean Pyrex, or other suitable glazing] enclosure panels around the Cone are symmetrical, that is, there may be a complete enclosure on all four sides, panels on two opposing sides, or no panels at all. Any other arrangements will lead to unsymmetrical air patterns. Make sure that there are no other unsymmetrical objects nearby blocking out large areas of air flow. Finally, check out and remedy any draft problems associated with the laboratory ventilation system.

- Incorrect, very high values indicated for effective heat of combustion.

If a non-ambient combustion atmosphere test was used for the test, incorrect values of the heat of combustion can be attributed to malfunctions or incorrect 
setting of the exhaust constant-mass flow mode. An error will be seen if either (a) constant-volume (instead of constant-mass) mode was erroneously selected, or (b) a malfunction of the motor speed controller or its associated millivolt controller has occurred.

\subsection{Computer program}

\subsubsection{Errors in the operating software}

It is always wise to hand check several points of the computer-generated data to be doubly sure when using a new or different data acquisition system or any time changes are made in either the acquisition or data reduction programs. There is almost a limitless number of ways in which software errors can masquerade as hardware errors. Thus, if a malfunction shows up for the first time after a new version of one of the computer programs has been installed, troubleshooting the computer code should be the first step.

Some extremely vexing problems can arise if thermocouple cold-junction compensation is not properly done. This can include very obscure difficulties which arise if temperature correction voltages are mistakenly applied to non-thermocouple channels! The proper setup of data scanner channels should be verified carefully each time any data scanner equipment is replaced or repaired. (The correct setup procedures are different for each manufacturer and even each model.)

Users outside of NBS should periodically check with NBS to make sure that they are working with the latest version of the software, which should contain the most up-to-date bug fixes.

\subsubsection{Errors in the generated data printouts}

- Printout errors in the cumulated results

Sometimes a condition is observed that data on the printouts appear plausible on a time-step by time-step basis, but give all zeroes for cumulated values. This is most often due to failure to have the specimen properly seated on the load cell before pressing the start key. As a result, the first mass value recorded is negative, and this invalidates all further calculations which require the use of the initial specimen mass. The simplest solution is to re-run the test correctly.

- Values for one or more data channels are very low 
For most data channels, the reduced data value which is reported is obtained by subtracting the baseline (time $0^{-}$) value. If the values for the baseline were not correctly stored, the reduced data will be defective. Check the software and the hardware to make certain that a correct baseline interval is being stored. Such errors might also arise from improper test starting procedures. Repeat the test once the problems have been corrected.

- Square-wave burner tests do not give square-wave results

Using the calibration burner for a square-wave test is one of the simpler and more general diagnostic techniques for the Cone Calorimeter. The expected heat release rate output is, of course, of square-wave shape. A serious spike at either end of the plateau will, most likely, indicate that the oxygen analyzer offset time has not been properly determined. See the pertinent section in the LESS-FREQUENT CALIBRATION PROCEDURES Chapter. The yield data from the remaining gas analyzers should, again, show a square-wave response. If not, similar corrections must be made. A more shallow hump or depression to the response curve can, most likely, suggest an improperly functioning stack thermocouple. Thermocouple troubleshooting is described below.

\subsection{Data system and system voltmeter}

- General voltmeter problems

When setting up the Calorimeter, the user should have available a good quality and reliable digital voltmeter to ensure that the acquisition system is really recording the correct voltages from the instruments. Incorrect operation of the scanner input can be an extremely frustrating problem if not identified as such early. Very general-looking errors, such as all zeroes for all output, or the first or last scan always a garbage value, etc., are often attributable to miscommunicated settings sent to the system voltmeter, or an improper hookup of the hardware. If such general faults are found which affect more than one data channel, then this is the place to start troubleshooting. The user must note that if using the software as directly obtained from NBS, the operation will not be right if his voltmeter or scanner are not the identical model number as used at NBS. Thus, it should be verified that the various IEEE-488 bus commands being used are, in fact, the ones pertinent to the voltmeter and scanner physically present in the system. 
- Stair-stepping on the data channels

Results are sometimes observed which show a "stairstep" effect. Since most burning specimens will not show this type of degradation behavior, an artifact is presumed. This artifact is usually either due to the use of an A-to-D converter of an insufficient number of bits, or because a data channel was improperly configured with the wrong gain or range. The solution is to fix the gain scaling, or to use a better A-to-D converter.

\subsection{Electronic components}

The most common source of failures with electronic circuits is the failure of active devices, i.e., op-amps and analog signal modules. Problems which are determined not to be interconnect or data system problems, and which manifest themselves as

- greatly drifting output, or

- output equal to the value of the plus or minus power supplies,

are very likely due a failure of an active device. This can be circuit-traced by examining the inputs to each stage, and then determining if the output is correct for the given input.

In general, there should not be any analog instrument outputs, nor any outputs from intermediate stages, which are nearly equal to the supply rails, i.e., either +15 VDC or -15 VDC. Such a measurement should be an immediate suggestion that some component failure has occurred. When circuit-tracing, as usual, proceed from the input end, apply within-range inputs, and then keep checking intermediate outputs until you have worked your way to the final device output stage.

The user should keep on hand spares which include the common OP-07 op-amps, and, possibly, certain other analog signal modules, since the easiest verification of actual failure is by component substitution.

\subsection{System check with the orifice flow constant}

As mentioned earlier, the simplest and quickest check of the Calorimeter is the orifice flow constant check. This check does not verify all of the analyzers, only the $\mathrm{O}_{2}$ analyzer, but it does check the integrity of the gas sampling system, thermocouple, orifice plate, and pressure transducer circuits. This test, even though somewhat limited, should always be performed at least daily. Then, as necessary, other, more 
complex, tests can be performed using certain well-characterized, reference test materials, which can be used to give an indication of the proper functioning of other analyzers, soot and smoke measuring devices, and other systems which might be hooked up to the Calorimeter.

Again, it must be remembered that the orifice flow constant is computed in the data acquisition program, and any error in programming will, of course, yield an error which has nothing to do with a physical malfunction of the equipment. This is an unlikely source of error if the program has been working properly previously and has not been changed. It is always desirable to check the constant by hand if a specific malfunctioning device cannot be pinpointed. When the burner is being supplied with methane at a flow rate equivalent to $10 \mathrm{~kW}$, the relevant equation is obtained from the basic equation on the top of p. 18 of NBSIR 82-2611. The value of $\dot{q}$ here is 10 $\mathrm{kW}$, and the specific constant for methane, $12.54 \times 10^{3}$ is used instead of $13.1 \times 10^{3}$, giving:

$$
C=\frac{7.25 \times 10^{-2} \sqrt{\frac{T}{\Delta P}}\left[1.105-1.5 X_{O_{2}}\right]}{\left[0.2095-X_{O_{2}}\right]}
$$

where $X_{\mathrm{O}_{2}}$ is the oxygen concentration, $T$ is the stack temperature $(\mathrm{K})$ and $\Delta P$ is the stack orifice differential pressure $(\mathrm{Pa})$.

The easiest way to perform this check is to start with a cold instrument. Set up all the steps for a daily start-up. Make some provision to collect oxygen, thermocouple and pressure data every 1 minute, either on stripchart recorders, or using the data collection computer. Insert a burner, and turn it on to a $10 \mathrm{~kW}$ level. Record the data for 10 minutes. Determine the value of the orifice coefficient at each 1 minute interval. For an instrument constructed according to the current NBS documents, the value of $\mathrm{C}$ will be between 0.040 and 0.046 . The value pertinent to the user's machine should have been established and recorded during the initial set-up of the instrument. If the constant does not fall within the expected range (except for the first few readings, which might be somewhat further out), then it should be noted that one of three devices may be defective: the oxygen measurement system, the thermocouple associated with the orifice plate flowmeter, or the pressure transducer. Compare the table of values generated with the values in Table 1.

Keep in mind that the values recorded of all of these instrument channels can change dramatically if a different cold flow is chosen or the Calorimeter ductwork and fan have had a chance to heat up. However, the values under such conditions should correspond approximately to one of the later sets of readings. If only one 
Table 1: Typical oxygen and flow values

\begin{tabular}{|c|c|c|c|}
\hline $\begin{array}{c}\text { Time } \\
\text { (MIN.) }\end{array}$ & $\begin{array}{c}\text { OXYGEN } \\
\text { (vol. FraCt.) }\end{array}$ & $\begin{array}{c}\text { PressuRe } \\
\text { (PAsCals) }\end{array}$ & $\begin{array}{c}\text { TEMPERATURE } \\
\left({ }^{\circ} \mathrm{C}\right)\end{array}$ \\
\hline \hline 0 & 0.2095 & 152 & 22.4 \\
1 & 0.1724 & 73 & 212.0 \\
2 & 0.1701 & 67 & 238.0 \\
3 & 0.1684 & 66 & 261.0 \\
4 & 0.1671 & 64 & 276.0 \\
5 & 0.1665 & 63 & 283.0 \\
6 & 0.1656 & 63 & 300.0 \\
7 & 0.1652 & 63 & 302.0 \\
8 & 0.1648 & 61 & 309.0 \\
9 & 0.1643 & 61 & 316.0 \\
10 & 0.1640 & 61 & 318.0 \\
\hline
\end{tabular}

of the channels is showing significant deviation from expected readings, the device has been pinpointed. Conduct further troubleshooting by following the instructions pertinent to that device below. If all three readings are substantially off, then there are two possibilities: (1) the rate of methane being introduced is not $10 \mathrm{~kW}$; or (2) the duct flow rate is not $30 \mathrm{~g} / \mathrm{s}$.

Note that mis-setting the flow rate to a value other than $30 \mathrm{~g} / \mathrm{s}$ will not by itself cause an error in the orifice coefficient. However, if the value is mis-set, with an otherwise well-functioning instrument, all three channels of data will deviate from their reference values (even though the $\mathrm{C}$ is finally determined correctly). If there is, in addition, some other system fault, trouble tracing may get very difficult.

\subsection{Methane calibration system}

Errors in metering $10 \mathrm{~kW}$ of methane are very difficult to trace, since a redundant measuring system is not provided. If, for instance, a $95 \%$ purity cylinder is substituted for the required $99.9 \%$ one, this may be extremely difficult to detect. The errors here can be due to:

- wrong calibrating gas 
- defective or miscalibrated dry test meter

- defective temperature indicator on dry test meter

- defective pressure indicator on dry test meter

- errors in timing flow or in making required computations.

If the electronic mass flow controller setpoint changes suddenly, this should not simply be re-adjusted, but a cause should be sought. These controllers normally show very good long term stability; thus, a shift may well indicate some other component's failure, rather than an actual shift within the controller.

If required, error tracing consists of progressively substituting new gases, test meters, etc., in the list above.

\subsection{Exhaust system blower and indicator}

\subsubsection{Mechanical speed check-out}

If a stroboscopic tachometer is available, Table 2 provides some reference values to be used in determining if the flow calibration is approximately correct. This procedure should normally be done first, since trying to make electrical adjustments would not be useful if there is a motor or sheave problem.

Table 2: Typical flow rates at specified fan shaft speeds

\begin{tabular}{|c|c|c|c|c|}
\hline \multirow{2}{*}{$\begin{array}{c}\text { FAN SHAFT SPEED } \\
\text { (RPM) }\end{array}$} & \multirow{2}{*}{$\begin{array}{l}\text { DIFFERENTIAL } \\
\text { PRESSURE }\end{array}$} & \multirow{2}{*}{$\begin{array}{c}\text { STACK TEMP } \\
{ }^{\circ} \mathrm{C}\end{array}$} & \multicolumn{2}{|c|}{ FLOW THROUGH DUCT } \\
\hline & & & Calc. & Meas. \\
\hline 1000 & $0.42-0.43 \mathrm{~V}$ & 21.8 & 18.8 & 18.6 \\
\hline 1500 & $0.93-0.94 \mathrm{~V}$ & 21.8 & 27.9 & 27.6 \\
\hline 2000 & $1.68 \mathrm{~V}$ & 21.8 & 37.4 & 36.8 \\
\hline
\end{tabular}

The flow rates in the table above are given in $\mathrm{g} / \mathrm{s}$, not in $\mathrm{m}^{3} / \mathrm{s}$, as discussed in ASTM P 190, since the exhaust flow rate panel meter is calibrated in $\mathrm{g} / \mathrm{s}$. Note that the speed readings are taken on the fan shaft rather than on the motor shaft; thus they are not affected by the sheave ratio. An incorrect sheave ratio, however, may prevent the top limit of $50 \mathrm{~g} / \mathrm{s}$ from being reached. 


\subsubsection{Checking the zero flow condition}

Calibrations of the flow rate cannot be done successfully unless it is verified that the zero-flow condition corresponds to a $0.0 \mathrm{~g} / \mathrm{s}$ flow indication. To do this, shutting down the fan is not sufficient to create the no-air-flow condition needed. This must be checked by having the calorimeter cold, and then placing a cap on the exhaust duct opening, to make sure that there is no air flow induced by room currents. Under those conditions, the panel indicator should read exactly $0.0 \mathrm{~g} / \mathrm{s}$. If this reading is slightly off, adjust the zero-trim potentiometer on the body of the pressure transducer, until the panel meter reads 0.0 . This procedure will be successful only if there are no defective components; if a zero-flow error occurs due to equipment failures, see the troubleshooting discussion below.

\subsubsection{Flow rate checking with $\mathrm{CO}_{2}$}

The Chapter on LESS-FREQUENT CALIBRATION PROCEDURES gives instructions on routine calibrations of the exhaust flow rate indicator, if it can be assumed that the orifice calibration constant is correct. If this constant is also in question, an independent flow check is possible by using $\mathrm{CO}_{2}$ gas as a tracer. This requires having a $\mathrm{CO}_{2}$ analyzer, a cylinder of $\mathrm{CO}_{2}$ gas, and an accurate flowmeter for metering in the $\mathrm{CO}_{2}$. A baseline reading, $\mathrm{X}_{\mathrm{CO}_{2}}^{\mathrm{r}}$, (typically around $0.04 \%$ ) is obtained. The gas is introduced into the specimen hood at a known mass flow rate, $\dot{m}_{\mathrm{CO}_{2}}$. The same amount of $\mathrm{CO}_{2}$ should be recovered through the duct. Thus,

$$
\dot{m}_{\mathrm{CO}_{2}}=\dot{m}_{e x} \frac{44.0}{28.97} \frac{\left(X_{\mathrm{CO}_{2}}-X_{\mathrm{CO}_{2}}^{o}\right)\left(1-k_{r h}\right)}{\left(1-X_{\mathrm{CO}_{2}}^{o}\right)}
$$

To solve for the needed duct flow, $\dot{m}_{e x}$, it is also necessary to know the correction term, $k_{r h}$, which is the mole fraction of water in air at the given temperature and at the ambient relative humidity. This can be obtained from standard tables, and adjusts for the fact that $\mathrm{CO}_{2}$ is measured on a dry, rather than total, basis. It can also be gotten directly by reading the baseline value on the $\mathrm{H}_{2} \mathrm{O}$ analyzer, if that analyzer is in good calibration.

To adjust the flow indicator, use the front panel setscrew adjustment. Before doing this, however, make sure that the zero setting has been adjusted correctly; see above. 


\subsubsection{Troubleshooting the exhaust system}

Possible problem areas here include:

- Defective blower motor.

This will be manifested in a number of ways. If the brushes fail completely, then the motor will not spin. Check the electrical terminals first to see that the controller has not failed. The motor may show erratic behavior or propagate noise-both conditions also indicate the brushes should be checked. In rare cases, bearings or windings may burn up.

- Wrong blower sheaves.

Operation which is satisfactory in all respects except that the required maximum flow condition of $50 \mathrm{~g} / \mathrm{s}$ at $1800 \mathrm{rpm}$ cannot be reached (or, if excessively high maximum flow rates are seen) usually suggests that incorrect sheaves have been fitted. Check and replace, if necessary.

- Miscalibrated indicator.

The possibilities are an offset zero, or an erroneous on-scale reading. For checking the zero adjustment, see the pertinent section above.

To check the front-panel exhaust flow rate display, perform a calibration as given in the LESS-FREQUENT CALIBRATION PROCEDURES Chapter, or with alternative $\mathrm{CO}_{2}$ calibration method given above. If an error has been found, adjust the front-panel flow rate adjustment, as described in the Chapter on LESS-FREQUENT CALIBRATION PROCEDURES above.

- Failure of control electronics

Failures of the control electronics are rare. If the mass flow rate measuring signals are wrong, the orifice calibration constant will sometimes be affected; this is easy to detect during daily calibrations. The thermocouple signal, however, undergoes additional signal conditioning by means of the 2B50A circuit module (physically located in the soot mass controller box). For troubleshooting, it should only be necessary to repeat the steps outlined in the section on SET-UP OF THE CONTROLLER FOR THE SOOT SAMPLER above. Any inability to obtain expected test point readings may point towards defective components. Failures can also occur with the millivolt controller or the motor speed controller. The motor speed controller can be checked out by putting the exhaust system in 
the Constant volume, i.e., manual, mode. Turn the control potentiometer up and down to check that the motor can be cycled from zero to maximum speed. While the motor speed controller has a number of adjustable potentiometers on the chassis, it is not intended that any of these be adjusted by the user. Normally, any failures here will necessitate replacing the whole motor speed controller module. In some case, it is possible that an output short has developed. This will often burn up the SCR device only. This can be tested and replaced, once the short has been fixed.

It must be emphasized that the common point of the motor speed controller is NOT at neutral potential. In the course of testing the controller, if its common is accidentally connected to ground or to the enclosure, the SCR device will be destroyed!

The millivolt controller can also be malfunctioning because someone misadjusted it. See the section Calibrating the Exhaust FlOW CONTROLler.

\subsection{General gas analyzer problems}

A Cone Calorimeter installation may typically be fitted with a number of additional gas analyzers. These will, to some extent be checked out as they are individually zeroed and spanned. Most of the problems described below in connection with the oxygen measurement system can also occur with the other gas analyzers, except for barometric effects, which are small for these supplementary analyzers and are ignored.

Sometimes, after a test, the flow rates for a particular gas analyzer will be seen to have dropped below the normal reference value for that analyzer. This will, most typically, be due to clogging of a soot filter, or due to clogging of the Drierite or Ascarite cartridges. In all cases, in addition to the main (heated or unheated) soot filter, there is at least one stage of backup filtering. For both the $90 \mathrm{~mm}$ filters, there is a packing of loose-fill fiberglass to serve this function. In addition, the total hydrocarbons and the oxygen analyzers have additional filters associated with the analyzer. The hydrocarbon analyzer has two filter assemblies: a sintered-metal inline filter located at the sample gas inlet port, and a replaceable cartridge filter located inside the analyzer case. The oxygen analyzer has an external in-line filter located in the sample line directly ahead of the analyzer inlet. In case of dropping flows, if replacing the primary $90 \mathrm{~mm}$ filter does not restore the correct flow rate, it is 
necessary to remove and replace the fiberglass packing. Note that there is also a fiberglass packing associated with both the Drierite and the Ascarite cartridges.

Flows to the Thermo Environmental analyzers are controlled by critical orifices, located in front of the IR cell. These may become clogged. If so, they should be removed and cleaned out.

\subsection{Oxygen measurement system}

Oxygen measurement errors can arise from the following sources:

- Incorrect calibration cylinders

A paramagnetic analyzer is intrinsically a very linear device. Cylinders of nitrogen (zero gas), an intermediate oxygen/nitrogen mixture, and room air at $20.95 \%$ will form a 3 -point calibration. If one of these points is out, the cylinders should be compared against new cylinders, to see if they are in error. It is also possible to introduce an error by calibrating at a non-standard oxygen level in the room. Obvious safety concerns dictate that no operations should be done in a laboratory which is not adequately ventilated.

- Clogging of Ascarite or Drierite

If either of the cartridges is clogged, usually a slow response will be seen and a "tailing" will be noticed on the heat release rate data. Clean out and repack the cartridges.

- Leaks in sampling system

The instructions here assume that the daily calibration procedure was followed, and that the oxygen analyzer could be successfully spanned and zeroed to its expected values. If not, see the sections above. For a correctly set up analyzer, the typical orifice plate calibration error encountered is that the oxygen analyzer does not show enough drop in the oxygen concentration. Thus, if an orifice constant significantly greater than the normally expected reference value for the instrument is obtained, a leak in the sampling system may be suspected. A leak may also be suspected if the instrument is first calibrated at the $10 \mathrm{~kW}$ level, and a subsequent check at the $5 \mathrm{~kW}$ level does not show $5 \mathrm{~kW} \pm 5 \%$.

Small leaks in the sampling system will affect the results only if they are on the negative pressure (inlet) side of the sampling pump. This is because some 
room air is mixed in with the sample gas readings, and their concentrations are no longer correct. Out-leaks, on the positive pressure side, will not affect the results unless they are so large as to actually change the flow rate conditions. Good operating practice still suggests, however, that out-leaks be avoided.

Searching for in-leaks in the cold trap and sample lines is most easily done by using a tracer gas being played around the suspect fittings and watching the appropriate analyzer to see if there is a sudden increase in the concentration of this gas. Generally it is easiest to use $\mathrm{CO}_{2}$ as a tracer, since a $\mathrm{CO}_{2}$ analyzer is located in the same line as the oxygen analyzer and since $\mathrm{CO}_{2}$ is a safe and heavy gas. Oxygen could also be used, but it has two disadvantages. One is that the oxygen analyzer is set on a larger scale, typically $0-25 \%$ while the $\mathrm{CO}_{2}$ analyzer has a scale of only $0-5 \%$, so the oxygen indications are less sensitive. The second is that the $\mathrm{CO}_{2}$ is heavier than air and is less likely than the oxygen to get sucked up in the hood and give a false reading when checking the fittings. If the oxygen analyzer is all that is available, then using pure oxygen will have to do. Watch the output of the oxygen analyzer carefully as you play the oxygen discharge around the various fitting and the cold trap looking for leaks. Once the leak is found, it should be fixed and the orifice coefficient re-checked. Wait several minutes for the leak-tracing gases to clear from the system before doing the new calibration.

The two items most typically found to leak are the soot filter holder and the cold trap. The soot filter holder is the first place to check, because it is the only part of the sampling system regularly opened and closed. Check the holder to see if the top is properly seated on the O-ring and that there is no dirt or pieces of old filter paper keeping the top from seating properly. Wipe the seating area and the O-ring with a clean tissue to assure good contact. Also check to see if the metal screen holding the soot filter is seated squarely on its $\mathrm{O}$-ring. If this screen is cocked or tilted it will force the top up and prevent it from seating with its O-ring. Recheck the orifice coefficient. If this is still not at the expected value, then check the cold trap and sampling lines for leaks. The line fittings are less likely to develop leaks than the cold trap.

Line leaks often occur after the lines have been taken apart to be cleaned and have not been reassembled correctly. If the lines have just been taken apart for cleaning, then their fittings will certainly be suspect, but if the system has been working well and no maintenance has been performed on the lines recently, then the most likely place for a leak after the soot filter is in the cold trap. 


\section{- Defective analyzer}

This will typically be noted in the daily calibration procedure as an inability to zero or span the analyzer. Make sure that there is no failure in the plumbing to it. Then follow the manufacturer's instructions. Make sure that no particles of thread burr, Teflon tape, etc., have become lodged in the detector. An oxygen detector will seize up if solid particles enter into it. Make sure the final filter in front of the analyzer is in good condition.

- Poor analyzer inlet pressure control

Most of the analyzers used in fire testing are sensitive to the pressure which shows up at sample inlet. The most common failing here, other than clogging or a gross mis-setting, is if this pressure is not the same when specimen testing is being done as it was during both the span and the zero steps. If pressures are not kept identical for these three conditions, anomalous results will occur. Since the plumbing arrangement is normally not changed in operation, inlet flows are customarily metered instead of inlet pressures. A constant inflow rate becomes tantamount to a constant pressure at the inlet. Physical malfunctions may include a clogging or mis-setting of a mechanical regulator, or an electric failure if an electronic mass flow controller is used. These can be checked by removing them and bench-testing.

- Poor compensation for barometric pressure in the analyzer

Unlike most other analyzers, the oxygen analyzer is sensitive enough that care must be taken to isolate it from the effects of varying barometric pressure at its outlet. The effective pressure which the detector registers includes the barometric pressure component. Thus, the analyzer must either use a mechanical system for maintaining a fixed, absolute back-pressure on its outlet, or else, an electrical pressure transducer is incorporated which corrects the signal output.

Problems with barometric effects will manifest themselves as an unsteady baseline on stormy days. The system can be checked out by running a cylinder's span gas through the analyzer and alternatingly hooking up and disconnecting a throttling valve to the analyzer outlet. The signal should show only a small blip at the time of the changeover, but return to exactly the same baseline. If this does not happen, the pressure measuring system should be investigated. 
On the Servomex unit, make sure that the CAL/COMP switch located inside the front panel, on the $517 \mathrm{~B}$ module, is properly set to its COMP position. Also, on the Servomex unit a special precaution is in order. Its pressure compensation circuit will not work correctly unless a small amount of throttling is applied at the outlet. Follow the analyzer manual for guidance here, and make sure this throttling has not been disconnected.

- Analyzer front panel zero adjustment out of range (Servomex analyzer)

The zero-setting knob on the front panel may run out of adjustment range, without successfully zeroing the analyzer. The coarse-zero adjustment on the detector unit is incorrectly set for this to happen. To adjust, open the front panel of the analyzer case. The detector unit is a cubical assembly located on the top right hand corner. There is a coarse zero knob located on the left side of that unit. First, set the front panel zero knob to the midway point of its travel. Now use the coarse zero knob to set the zero on the analyzer.

- Unstable analyzer output (Servomex analyzer)

The detector element has a natural resonant frequency in the range of 120 to $200 \mathrm{hz}$. Unstable output will result if a mechanical exciting force is present in this range. Such an exciting force can result from either (a) vibrations coming through the case, or (b) pulsations through the gas stream flow. If this problem arises, both sources have to be explored. To pinpoint cabinet vibrations, it will normally be necessary to disconnect other vibrating equipment progressively. Gas stream pulsations can result due to pump characteristics or due to a flow controller which has a pulsating characteristic.

\subsection{Thermocouples}

Thermocouples are used for the cone heater itself, for the orifice plate exhaust flow measurement, for the laser smoke photometer, and for monitoring the cold trap. Additionally, thermocouples are incorporated into several of the gas analyzers. Finally, the heated sample lines contain both thermocouples and thermistors for monitor and control purposes.

The essential thermocouples are the ones in the heater circuit, in the exhaust duct, and at the photometer. Spares of all of these should be maintained.

While it is possible to buy thermocouple testing devices or to rig up boiling point and freezing point arrangements (using highly pure water!), it is normally uneconomi- 
cal to do so. It is easiest to maintain replacement thermocouples on hand, and replace as needed.

In case of faulty thermocouple indications, realize that the error can be in the thermocouple itself, in the indicating circuit (including wiring and computer hardware), or in the computer software.

Testing the thermocouples themselves is standard laboratory procedure. Note, however, that shielded thermocouples are prone to develop a short from the shield to one of the signal wires if the end connection has not been prepared properly. Always use the tool available from the manufacturer for making up the end connections.

To check the indicating circuit, use a high quality digital voltmeter and repeat the tests with the voltmeter hooked up to the thermocouple output. Compare the results of the voltmeter-read temperature (using a millivolt-to- ${ }^{\circ} \mathrm{C}$ table for Type $\mathrm{K}$ thermocouples) to what the program thought the actual temperature was. Remember to add the cold junction temperature to voltmeter readings taken directly from the thermocouple. If these two temperatures do not agree, then the source of the error must be located. There are several possible places where the error could originate. The data scanning multiplexer may be defective; the cold junction compensation may be broken; wires may be shorting out; the data system may be reading the wrong channel; or, some error may have been introduced into the computer program itself. Trace and identify these in turn. For doing this, a precision millivolt source is very convenient.

Any time that input scanners are repaired or replaced, it is very easily possible to end up with an improper treatment of cold-junction compensation, so that it is no longer done by either software or hardware, or else is done twice over. This can be checked by comparison of computer program reduced data to temperatures which are checked with thermometers.

To make a thorough check of the computer program, it is convenient to use a precision millivolt source as input to the program. Set the millivolt source to some reasonable output and see if the temperature channel reading from the program corresponds to what it should be, as found in a Type $\mathrm{K}$ thermocouple reference table. If this checks out correctly, then set the millivolt source to some lower level and check again, to see if the linearizing portion of the program is working. If these checks do not work, then the problem is in the program code and must be corrected.

For the stack thermocouple, a possible source of error is the connection of the stack thermocouple with the motor speed controller circuit. Stray current may be getting into the thermocouple by this path. If this is a possibility, then use a precision millivolt source, or at least separate the thermocouple from the motor speed control circuit 
when checking the output of the data acquisition system. If there is a measurable current leakage into the thermocouple circuit, be sure to locate and correct it before proceeding. Often, the simplest way to solve such problems is to install an additional separate stack thermocouple, located a short distance away from the first one. With such a two-thermocouple arrangement, one can be dedicated to the motor speed controller, while the second one is used for the data acquisition system.

\subsection{Pressure transducer}

The pressure transducer should normally be suspected if errors in obtaining the orifice calibration constant are found, and the stack thermocouple and the oxygen system were checked out successfully. If the pressure readings look low, check the voltage output from the pressure transducer before and after the $10 \times$ amplifier/smoother to be sure the data acquisition system is recording the same voltage $(\times 10)$ as the pressure transducer is generating. If the amplifier/smoother is correctly multiplying by 10 , but the pressures indicated are still not close to those expected, then the lines and hoses connecting the ports above and below the orifice plate to the pressure transducer should be checked for leaks. Leakage in the upper line will cause a reduction in the differential pressure. It is difficult to determine if the lines are actually sealed. If after tightening all the fittings on the lines, no improvement is noted in the differential pressure reading, try squirting a little water on the various fittings, while watching the output of the pressure transducer. If the leak is not too large, the water will temporally seal the leak and give an increase in the differential pressure. This is a risky procedure as water may get sucked into the lines or the transducer. A safer method is to remove the transducer from the lines and, plug the ends by the orifice plate, slightly pressurize the line with air and use a soap solution on the various joints. This will check all the fittings, except those which connect the lines to the transducer. Before re-attaching the transducer to its lines, zero the pressure transducer. See the LESS-FREQUENT CALIBRATION PROCEDURES Chapter for details on this zeroing. Reattach the lines to the pressure transducer and re-try the orifice flow constant. If the pressure transducer still does not give the appropriate response, then the span on the pressure transducer may be in error. If all other possibilities have been eliminated then the up-scale reading must be checked. See the calibration procedure for this check. 


\subsection{System checking with additional gas analyzers}

It will be assumed here that $\mathrm{CO}_{2}$ and $\mathrm{H}_{2} \mathrm{O}$ analyzers are available and have been fitted as in Fig. A14 of the construction drawings. In such laboratories, additional system check-out procedures are possible. These involve using methane and PMMA (polymethylmethacrylate) as test materials. These compounds have a simple, known composition, thus the yields of $\mathrm{CO}_{2}$ and water vapor, and the expected heats of combustion can be established. The methane used is the same high-purity methane as is used in normal calibrations. The block of PMMA used must be thick enough to show good steady-state readings, and the edge burning must be controlled. The normal size of PMMA blocks used is $100 \times 100 \mathrm{~mm} \times 25.4 \mathrm{~mm}$. These burn long enough even at the highest fluxes to give a steady-state burning rate. For these special calibration purposes, the specimens are prepared not by wrapping in aluminum foil, but by providing slow-burning side protection, so that the edges regress no faster or slower than the bulk of the block. For instructions on preparing calibration specimens for this purpose, consult the section on CALIBRATION SAMPLES, above.

- Check involving mass yields.

The test basically involves comparing the indicated values of $\mathrm{CO}_{2}(\mathrm{~kg} / \mathrm{kg})$ and $\mathrm{H}_{2} \mathrm{O}(\mathrm{kg} / \mathrm{kg})$ against expected values for PMMA and methane. For PMMA, load cell data are used to indicate the specimen mass loss rate. For methane, load cell data are, of course, not relevant. The mass flow rate for methane is, instead, directly computed and inserted into the computer program in the appropriate place. For these two reference materials, the expected values are given in Table 3 , below.

Readings which are too low compared to these reference values are indicative of possible leaks. If the values obtained are correct (as checked at several different heat release rate values), then the $\mathrm{CO}_{2}$ and $\mathrm{H}_{2} \mathrm{O}$ analyzers have been operationally checked out. Values which are too high are only rarely encountered, and would indicate some specific malfunction of the analyzer, rather than a problem with leaks. Separate checks are made on the $\mathrm{CO}_{2}$ and the $\mathrm{H}_{2} \mathrm{O}$ systems, because the analyzers are connected to two different sampling systems (one heated and one not heated). Within each sampling system, in-leaks can only occur on the inlet side of the pump. The split for $\mathrm{O}_{2} / \mathrm{CO} / \mathrm{CO}_{2}$ analyzers is on the outlet side of the pump, therefore, separate checking of leaks for each of these analyzers is not necessary. 
Table 3: Mass yields for reference materials

\begin{tabular}{|l|l|l|}
\hline ReF. MATERial & $\mathrm{CO}_{2}$ & \multicolumn{1}{c|}{$\mathrm{H}_{2} \mathrm{O}$} \\
& $(\mathrm{kg} / \mathrm{kg})$ & $(\mathrm{kg} / \mathrm{kg})$ \\
\hline \hline methane $\left(\mathrm{CH}_{4}\right)$ & 2.75 & 2.25 \\
PMMA $\left(\mathrm{C}_{5} \mathrm{H}_{8} \mathrm{O}_{2}\right)$ & 2.20 & 0.72 \\
\hline
\end{tabular}

- Check using mole ratios.

Additional checking can be done on a mole basis. For each combustible, the stoichiometrically correct mole ratios of $\frac{\mathrm{CO}_{2}}{\Delta \mathrm{O}_{2}}$ and $\frac{\Delta \mathrm{H}_{2} \mathrm{O}}{\Delta \mathrm{O}_{2}}$, as given in Table 4 below, should be attainable.

Table 4: Molar relationships for reference materials

\begin{tabular}{|l|l|l|}
\hline ReF. Material & $\frac{\mathrm{CO}_{2}}{\Delta \mathrm{O}_{2}}$ & $\frac{\Delta \mathrm{H}_{2} \mathrm{O}}{\Delta \mathrm{O}_{2}}$ \\
\hline \hline methane $\left(\mathrm{CH}_{4}\right)$ & 0.5 & 1.0 \\
PMMA $\left(\mathrm{C}_{5} \mathrm{H}_{8} \mathrm{O}_{2}\right)$ & 0.833 & 0.667 \\
\hline
\end{tabular}

The mole-concentrations needed here are not simply the meter readings, since it has been assumed that the $\mathrm{CO}_{2}$ sampling line has had $\mathrm{H}_{2} \mathrm{O}$ removed from it, while the $\mathrm{O}_{2}$ sampling line has had both $\mathrm{CO}_{2}$ and $\mathrm{H}_{2} \mathrm{O}$ removed. For such an analyzer implementation, the proper evaluation, assuming that the $\approx$ $0.04 \% \mathrm{CO}_{2}$ baseline has been directly subtracted from the $\mathrm{CO}_{2}$ readings, is:

$$
\frac{\mathrm{CO}_{2}}{\Delta \mathrm{O}_{2}}=\frac{X_{\mathrm{CO}_{2}}\left[1-X_{O_{2}}^{o}\right]}{\left[X_{O_{2}}^{o}-X_{O_{2}}\right]\left[1-X_{C O_{2}}\right]}
$$


and,

$$
\begin{aligned}
\frac{\Delta \mathrm{H}_{2} \mathrm{O}}{\Delta \mathrm{O}_{2}}= & \frac{X_{\mathrm{H}_{2} O}\left[1-X_{O_{2}}^{o}\right]}{\left[X_{O_{2}}^{o}-X_{O_{2}}\right]\left[1-X_{C_{2}}\right]\left[1-X_{H_{2} O}\right]} \\
& -\frac{X_{H_{2} O}^{o}\left[1-X_{O_{2}}\right]}{\left[X_{O_{2}}^{o}-X_{O_{2}}\right]\left[1-X_{C O_{2}}^{o}\right]\left[1-X_{H_{2} O}^{o}\right]}
\end{aligned}
$$

The $\frac{\mathrm{CO}_{2}}{\triangle \mathrm{O}_{2}}$ ratio will drop if there is a leak into the sampling line going to both the $\mathrm{O}_{2}$ and $\mathrm{CO}_{2}$ analyzers.

- Check using the heat of combustion.

Finally, the heat of combustion of PMMA can be verified. This should be slightly less than the reference value of $24.88 \mathrm{MJ} / \mathrm{kg}$. If the measured value is less than about 24.0, further troubleshooting should be done. Errors here can be also due to improper load cell calibration or errors in the computer data reduction program.

\subsection{Heat flux gauge}

The easiest way to maintain an accurate reference is to have available two, identical heat flux gauges. Compare and record their relative readings initially. Do not use the second gauge in normal operations; set it aside for use solely as a reference. Periodically compare the two gauges. If they show any drift, send back the working gauge to the manufacturer for recalibration, repair, or replacement. Laboratories which expect to be in continual operation will need three gauges-one reference gauge, one working gauge, and one more gauge which may be in repair or in transit.

Gauges which show a non-negligible change in calibration from the last time they were calibrated should be checked at multiple flux levels. If the gauge is beginning to show non-linearities in its flux vs. voltage relationship, it should be replaced.

Special precaution. When shipping a heat flux gauge via common carrier, etc., make sure that the water-cooling circuit has been thoroughly drained of water and dried out with compressed air. If this is not done, and the gauge is shipped during winter, it is possible that the held-in water will freeze; a burst gauge will result.

- Additional checks on proper irradiance.

The reference samples of PMMA serve an additional purpose. The ignition times will correspond directly to the irradiance given to the specimen. If a new 
PMMA test is made and the ignition times do not correspond, within normal test scatter, to the ignition times obtained when the Calorimeter was first set up and calibrated, it can be suspected that some error has been introduced into the measurement of irradiance. For instance, it may happen that the reference gauge was damaged, and then the working gauge was recalibrated to this erroneously reading gauge.

\subsection{Cone heater}

\subsubsection{Heater troubleshooting}

If the heater has failed by welding itself, it may also be necessary to replace the inner cone at the same time; thus, it is a good idea to maintain a spare.

If the fuse has blown in the power regulator, be sure to replace it only with a 25 A fuse of the "I $\mathrm{I}^{2}$ " or "sub-cycle" type. Do not use normal cartridge fuses, since they are not fast enough to protect an electronic power controller adequately.

- Drift

The initial temperature/heat flux tables should not be attempted until the unit has been run in by about a day's worth of operation, including burning some solid specimens. Once these tables are made up, drift should be very slow. A significant discrepancy from earlier values suggests problems in the heater circuit, or a failure of the gauge. Check the gauge, as described above.

- Inability to reach high fluxes

Inability to reach the maximum $110 \mathrm{~kW} / \mathrm{m}^{2}$ flux level usually indicates that a full $240 \mathrm{VAC}$ is not available to the heater element, or that the connection is corroded at the heater. Take apart and clean this connection. Measure the voltage being delivered with the temperature controller being set to the maximum feasible value. If less than $240 \mathrm{VAC}$ is indicated, check the house mains, the boost transformer, and the SCR power controller. If necessary, disconnect the signal line from the temperature controller and use a precision voltage source to apply the maximum $10 \mathrm{VDC}$ to the power controller. If a full 240 volts is obtained then, but not when using the temperature controller, test the temperature controller and double-check the wiring going to the power controller. 
For a heater being used for the first time, this problem could also arise because an incorrect heater was installed, was improperly wound (there should be $8-1 / 2$ turns of windings, evenly spaced), or was improperly installed (there should be no gaps in between the layers, and the connector ends should be of about equal length).

\section{- Erratic operation}

Erratic operation usually indicates that one of the three cone thermocouples is failing. This can be determined by progressively removing their plugs one by one and noting when the problem disappears. This approach is feasible since the thermocouples are joined in parallel. Removing one of them still permits a reasonable measurement to be made, although with less good representativeness.

- Non-uniform heating

When viewing an operational heater from the specimen's position, a uniform glow should be seen. It should be noted that there should be no gaps, and no turns of the coil must have jumped out of their normal position. If irregularities are noted, it may be possible to remove the coil and gently straighten these portions. If this does not alleviate the problem, a new coil must be fitted.

- The heater is dead

This may be due to a failure of any number of components: the temperature controller, the power controller, the heater element itself, the wiring, or the power circuit which supplies the $240 \mathrm{~V}$ to the power controller. Controllers can be checked out one-by-one by determining that their input and output voltages are reasonable. Heater element failure can be subtle or dramatic. A subtle failure may result from a corrosion of the contacts, or a broken contact slightly inside the element itself. A dramatic failure occurs when the heater fails by arc-welding itself. This is very similar to a corresponding failure on an electric oven heating element.

The heater is generally very long-lived and tends to die only from obvious damage. One source of damage to guard against is the deposition of substances evolved from the burning specimen. If any specimen is being burned which is ejecting material that gets deposited on the coils in a substantially thick layer, heater failure is likely to occur. (Some silicone products have been seen to do 
this). This is because the place where the buildup has occurred creates a zone of over-heating on the coils. Specimens which show this type of behavior cannot be tested in the orientation (horizontal or vertical) that exhibits this problem.

\subsubsection{Winding a heater element}

The heater element is wound using the tool shown in Fig. T1. The tool is inserted into a large lathe, but the lathe power is not used. Instead, the element is wound by turning the lathe slowly by hand, while feeding the rod. Start the winding process by clamping one end to the endplate with a C-clamp. When finished winding, make sure that the two straight ends are of similar length. It is important not to make too many mistakes in winding, since the element work-hardens, i.e., it is soft and easy to work the first time, but becomes stiff and difficult to bend once it has been bent some.

Until he has become expert in the winding operation, the user can expect to spoil some heater elements in the winding process. Thus, a sufficient number of elements should always be ordered to allow for this spoilage.

\subsubsection{Heater replacement}

A heater element may need to be replaced either because its windings have gotten too badly shifted out of place and cannot be re-aligned, or because it has burned out. To replace, disassemble the cone assembly and remove the heater. Check the thermocouples at the same time. This is a good time to replace any dubious thermocouples. Check that the refractory packing in between the outer and the inner cones is in good shape and has not all drooped to the bottom. Replace if necessary. When inserting a new heater, check that the heater has been wound so that the two connector ends are of approximately equal length. Fix the winding lengths if this has not been done properly. When inserting the heater element into the slots in the outer cone, it may be necessary to slightly bend the ends into a curve in order to be able to insert it. Do this carefully with a pair of gripper pliers. When the heater is installed, bend back the ends carefully to be straight. Do not grip the heater element by the electrical connectors in doing this; rather, grip the heater surface itself. Check that all the heater turns are smooth, without visible gaps. Check that the top winding is centered as well as possible in the top cone hole. Re-connect and re-insulate the electrical connection. 


\subsection{Load cell testing}

Most problems with the load cell are spotted during routine calibrations. Occasional problems which have been encountered include:

- The load cell reading is steady until the fan is turned on, at which point a lot of jitter is noted. This usually indicates that the specimen holder is not sitting true in its intended position, but is rocking, instead. To fix, file rough edges or otherwise correct physical irregularities.

- With no heating or burning taking place, the load cell signal, when examined on a strip chart recorder, shows periodic excursions which are large and are unexpected. This will typically be identified to be grounding or shielding problem. Step-by-step tracing of grounds, shields, and signal connections will usually enable the problem to be identified. If external, nearby equipment is causing interference, it may be necessary to fit electrical filtering devices to such sources.

\subsection{Laser smoke photometer}

\section{PRECAUTION}

The laser fitted to the smoke photometer emits light energy at the red wavelength of $632.8 \mathrm{~nm}$. Even though the laser fitted is the smallest output commercially available $\mathrm{He}-\mathrm{Ne}$ type $(0.5 \mathrm{~mW}$ nominal power), the user is still cautioned not to stare into the beam during any installation, maintenance, or repair operations.

Important: After any maintenance or repair procedures on the laser smoke photometer circuit, the user must make sure that all components associated with the photodetectors have been cleaned thoroughly with a solvent suitable for cleaning printed circuit boards. This includes contacts on the detectors themselves, contacts on all plugs in the circuit, and the associated circuit board. Fingerprints, soot, etc., deposited in these places are likely to result in noisy, unpredictable operation.

Among the various laboratories using Cone Calorimeters, there exist slight differences in the mechanical construction of the smoke photometer. The "original" version 
used only one beamsplitter and did not make any special provision for special slots for the insertion of neutral density filters. The "new" version has both photodetectors arranged in a symmetrical fashion, so that two beamsplitters are used. This version also incorporates two permanent slots for neutral density filters, one in front of the laser, the second in front of the main beam detector. Certain instructions below will be given in two variants, for the "original," and another for the "new" version, where necessary.

\subsubsection{Alignment of the laser smoke photometer}

During initial assembly, and any time the photometer assembly has been removed or the clamp which holds the two halves of the photometer has been removed, the alignment will have to be checked. Re-alignment may also have to be done if improper values for PMMA are being registered, and the electronics have been found not to be mis-calibrated.

For a unit already installed, there are several troubleshooting steps that can be taken to determine if mis-alignment exists.

- Remove the detector assemblies (do not disassemble the individual components there) and the end cap (if any). Successively, insert into each of these places the plastic target cap described in Fig. T2. Carefully examine the image: there should be two bright pinpoints of laser light. If more than two images are seen, or if there is a "halo" around these images, mis-alignment exists.

- In line with the laser image coming straight out the end of the main tube, put up a white paper target, about $1 \mathrm{~m}$ away from the tube. Mark a spot to indicate the two images. Now, gently push on the laser head itself. Push the laser up, down, left, and right. It should be possible to shift the image on the target by about $3 \mathrm{~cm}$ in each direction. If the image disappears, breaks up into multiple images, acquires a halo, or becomes suddenly broad and diffuse when moved in any of these directions, an indication of mis-alignment has been found.

- If the above procedures do not indicate mis-alignment, but such difficulties are still suspected, there is one other test available; it is, however, more timeconsuming. Remove the section of the main exhaust duct that is upstream of the photometer. Remove the ring sampler. Now, carefully inspect the purge-air tube openings from the inside of the duct. The laser light should be essentially 
invisible. If red spots are seen in the vicinity of the tubes, this indicates that some portion of the beam is improperly making contact with the tube walls.

- Re-install the detector assemblies and the end cap. If the duct section and ring sampler have been removed, re-install them. Take care the ceramic fiber gasket at the exhaust hood end is installed straight and is undamaged.

To perform a re-alignment, it will normally be necessary to remove the photometer and then to re-install, following the steps below. These same steps are also followed in performing the initial photometer installation.

- Remove photometer assembly by unscrewing the yoke connection. Also remove the ceramic fiber gasket around the duct.

- On the bench, remove the laser assembly, the detector assemblies, the main photometer tube end cap (new version), and the beamsplitter (two beamsplitters in the case of the new version). Do not remove the laser head itself from its mounting flange hardware; only unscrewing the three screws holding the laser flange is necessary. Also, do not disassemble the detector assemblies themselves, unless there is something specifically wrong to repair. The beamsplitters and the detector assemblies are each held in by hex setscrews onto the outside barrel. When these are loosened, the detector assembly should pull right out. The beamsplitters are set into inner tubes which slide within the main barrel. These assemblies may be more difficult to remove. It may be necessary to insert prying devices from the barrel end, from the detector opening, or both, in order to free out a beamsplitter tube. Do this carefully!

- Visually examine the purge-air tubes which are welded onto the exhaust duct. They should be straight, one collinear with the other, truly horizontal, and not deflected right-to-left. Next pass the metal alignment rod, shown in Fig. T2, through both tubes at the same time. There should be adequate clearances; no burrs or weld slag should be encountered. Next, examine the weld attaching the tubes to the exhaust duct. The weld should be small and clean, and should not form a fillet larger than about $2.5 \mathrm{~mm}$. (Large, sloppy welds will prevent the adequate seating of the yoke.) Correct any metalwork problems observed.

- Start the re-assembly by, first, making sure the refractory fiber gasketing collar is in good condition and is properly seated, encircling the periphery of the exhaust duct. 
- Now, bring up the two photometer halves onto the exhaust duct and snug them together. Pass the alignment rod through the air purge tube. Place an end cylinder (Fig. T2) onto each end of alignment rod, to allow clearances to be judged more accurately. Adjust the four clamping screws progressively until the end cylinders are well centered within each respective tube end. Then tighten up the assembly until it is snug. Remove the alignment rod and the end cylinders.

- Put in a translucent plastic target cap (Fig. T2) onto the end of the main barrel. Attach the laser assembly and turn on the laser. Check to see that the light image (since there are no beamsplitters, there will be only one) are centered within the central portion of the target and that there are no spurious images, diffuse images, or haloes. Adjust the three screws which retain the laser to the photometer, as necessary, until the proper light image is seen. If there is not enough adjustment in these screws, slightly changing the torque on the four main yoke screws can improve alignment. Then, tighten the counter-nuts on the yoke screws. Verify that the image has not been disturbed. Remove the plastic target cap.

- Using the white paper target described above, perform the same test of pushing the laser in each direction. Correct light image characteristics should be seen, as described above. Adjust the laser mount screws or re-torque the yoke to achieve this. Once this is achieved, spin up the counter-nuts on the laser mount to mark the correct insertion length of each screw, then remove the laser assembly.

- Carefully examine the beamsplitter tube(s) and the main barrel inside surface for any burrs or damage. Fix burrs. Re-insert the beamsplitter tube(s), making sure the glass is facing at the correct direction. Get the beamsplitter(s) into the approximately correct position by pushing them from the ends of the barrel and also moving them from the detector assembly openings.

- Re-install the laser assembly. Again, examine the characteristics of the light images on the white paper target. If necessary, slightly re-adjust the laser assembly screws. Tighten the laser assembly counter-nuts.

- Next, set up the final alignment of the beamsplitter(s). A small hand-held mirror may be necessary for this. Insert the plastic target cap at the place of the reference beam detector assembly. Check that the two light images are reasonably centered and have the proper light characteristics. If the spots are 
too close to the edge, make a note in what direction the spots should move, remove the target cap, insert a small, stiff, bent metal rod into the barrel opening and gently push the beamsplitter tube in the correct direction. (If you did not carefully remove all burrs and other obstacles to the free movement of the beamsplitter tube, this will prove to be impossible!). Re-insert the target cap and check that the images are now adequately centered. When successful, lock in the beamsplitter setscrew.

- For the new version, repeat the same operation with the second beamsplitter. The alignment of the main detector beamsplitter will be somewhat easier, since access for manipulating the beamsplitter tube is also available from the end of the main barrel.

- Install the normal end cap (new version) or the main beam detector onto the end of the main barrel.

- Check that the detector wiring is nowhere touching any hot surfaces. This completes the mechanical alignment of the photometer. At this point, the calibration of the smoke photometer electronics, described in the LESS-FREQUENT CALIBRATION PROCEDURES Chapter, would normally be performed.

\subsubsection{Troubleshooting of the photometer}

- Total lack of output.

This is most likely due to a failure of the laser. To check, remove the end cap (new version) or main beam detector assembly (original version), and check for laser light output. Replace laser head, if necessary.

- Zero offset large enough so it cannot be corrected by the front panel control.

This is generally due to a soot deposit on the optics. Such a deposit can happen if the hood system has not been cleaned in a long time, and then the exhaust blower is repeatedly cycled on and off. The pressure surges can then deposit soot on the optics. To correct, check the beamsplitter at the laser, and either main beam detector (if the instrument has not been fitted with a second beamsplitter) or the beamsplitter located above the main beam detector (if the instrument has two beamsplitters). Clean as necessary. Also, clean out the air purge tubes at the same time. 
- Excessively rapid sooting up of the optics.

Sooting up sufficient to require disassembly and cleaning should be occurring only every six months, or so. If rapid soot accumulation inside the photometer tubes or on the optics is noted, it may be suspected that the air purge holes in the outside tube barrel are not functioning properly. The repair is simple. Clean out the holes; remove any obstructions. If problem persists, it may be useful to increase hole diameter to the next drill size.

- Calibration with PMMA indicates excessively high smoke readings.

The simplest possibility is that the slope control in the signal electronics was not properly calibrated using neutral density filters. The instructions for checking this are given in the LESS-FREQUENT CALIBRATION PROCEDURES Chapter.

If a re-calibration of the electronics does not correct the problem, the next most likely possibility is optical alignment problems with the laser beam. See the preceding section for instructions.

- Calibration with PMMA indicates smoke readings too low by about $10 \%$

The function of the photometer thermocouple is to allow corrections to be made to the volume flow rate determined in the stack. The corrected value is supposed to indicate the actual volume flow rate at the photometer location.

This will typically be higher (very roughly by $10 \%$ ) than at the stack measuring location, due to the higher local temperature. An error of this magnitude will be made if (a) the photometer thermocouple is defective, or ( $b$ ) the data reduction software does not perform the needed adjustment. To remedy, check voltage readings from the two thermocouples, then check the software algorithm.

- Noisy, erratic, or incorrect smoke values recorded

The smoke values reported by the computer software include outputs from: the photometer circuit itself, the photometer thermocouple, the load cell, and the exhaust volume flow rate measurements (pressure and temperature). An error in any of these will result in improper smoke data being reported. When this condition is seen, the first diagnostic step is to determine which subsystem is at fault.

The source can usually be discovered by making a dump of the raw data channels and determining which channel is giving noisy or faulty data. If the 
problem is due to the exhaust duct pressure or temperature measurements or specimen mass loss rate values, these should be solved as explained in the preceding sections. Likewise, the procedures for checking and correcting problems with the photometer thermocouple are similar to those pertinent to the orifice plate flowmeter thermocouple (see above).

If the problem is now identified to be with the photometer circuit itself, first check if noise and erratic value problems disappear when exhaust fan is shut down. If they do, this indicates a mechanical problem. Check the various pieces (detectors, beamsplitters, laser) to make sure they are rigidly affixed. Then check that the whole photometer yoke is properly clamped onto the duct. This should clear up mechanical vibration problems.

If problems do not go away when the fan is turned off, this may be due to a wide variety of causes. The ones to consider first are:

$\triangleright$ Misalignment of the beam. Instructions for mechanical alignment are in the preceding section.

$\triangleright$ Dirty electrical contacts or circuit components. The detector circuitry is high impedance, and is very sensitive to the effects of grease, etc., on the connections, on the circuit board, and other places. Treat contacts with the spray recommended in the REGULAR MAINTENANCE Chapter above. Spray circuit traces, high-value resistors, and other critical components with a regular Freon-type electrical cleaning spray.

$\triangleright$ Defective photodetector diode(s). This is best checked by substitution. Check also that the diode is of the type currently recommended in the Construction Drawings, and is not of the older, less stable type.

$\triangleright$ Incorrect photodetector polarity. Unpredictable results may be experienced if a detector diode polarity is wrong. Check both detectors to see that polarity is correct. The tab on each diode should be located at the same place as the tab on the socket. This alone does not guarantee necessarily correct polarity, since someone may have wired the cable up wrong. Check all connections further, if necessary.

$\triangleright$ Incorrect components. Verify that the signal cable going to the detector diodes is of the Teflon type, and that a PVC, etc., type has not been substituted. Such a substitution may cause unacceptable drift in the output. 
Also, for the NBS version of the electronics, check that the bias resistors are of a proper low temperature coefficient type.

$\triangleright$ Defective laser output. A defective laser head, laser power supply, interconnect cable, or high voltage connector/receptacle can all show up as a wandering, unstable output of the photometer. First check the electric connections. If problem still persists, remove the beam detector or end cap from the end of the photometer tube and check laser output visually. If problem is isolated to either the power supply or the laser head, further troubleshooting by successively substituting these items will usually be necessary.

- Calibration controls are pegged out at the extremes of their range.

This will usually be due either to defective or significantly mismatched detector diodes, or due to some failure of connectors, wires, or plugs. Check the integrity of all wires and connections. Replace diodes with new diodes.

- Laser beam spot is not correct.

When the end cap is removed, the laser beam can be shined on the translucent alignment plug, or on an opposing wall. In either case, there should be one bright, well-formed laser spot. Two improper patterns are: (1) a diffuse glow surrounding the central laser spot, or (2) many small bright spots or 'streamers." The first problem is normally caused by mechanical mis-alignment of the photometer. With such mis-alignment, a portion of the beam strikes the side wall and undergoes multiple reflections. To correct, it is necessary to completely disassemble the unit and to re-assemble after mechanical straightening and readjustment (see the preceding section). In the case of multiple bright spots or streamers, soot deposited on the inside tube walls or on the beamsplitters is the cause. A simple cleaning by using the high-pressure air gun against the purge air holes may be all that is needed. If this does not suffice, it will be necessary to perform some disassembly for cleaning. Again, the instructions in the preceding section must be followed for re-assembly.

\subsection{Soot sampler}

This device is simple and should rarely go wrong. Some possibilities are: 
- Insufficient or dropping flow rates.

This may be due to clogging in some part of the system, failure of the vacuum source, or failure of mass-flow controller. Check the glass wool packing in the soot filter bell for clogging. If this is not clogged, then it is most likely due to a clogged condenser. Remove and replace the condenser. Check the line at the discharge end to make sure that there are no deposits built up there. If there are, a total cleaning of the system may be necessary, including disassembly of the mass flow controller. Another possibility is the failure of the vacuum source (house vacuum or vacuum pump, whichever is used).

- Erratic behavior.

This is most likely to be a problem of the control electronics. For proper functioning, the duct pressure and temperature signals must be properly obtained. Any problems in connections with these instruments could show up as failure to obtain a steady control mode. The causes may be varied; use standard troubleshooting techniques on the electronics.

\subsection{Cold trap}

- No cooling.

This is an electrical problem which may be due either to a malfunctioning power supply or a burned out thermoelectric module. The resistance of each cooling module will typically be not much more than $1 \Omega$. Disconnect the modules from the power supply and check out the resistance of each module separately. An open circuit would indicate a burned out module. In unusual cases, a module might fail by shorting to the case. To test for that, measure the resistance between either leg of the module's power connection and the outer case.

The power supply voltage will typically be somewhat less than 14 VDC when starting operation from room temperature. A very small voltage here would indicate either a power supply failure or, possibly, a failure of the temperature controller that is controlling it.

If the power supply has a current-limiting adjustment, make sure that it is set for somewhat less than $9 \mathrm{~A}$.

- Clogging with soot. 
Normally the soot filter and the backup to it will take care of all soot problems. In exceptional cases, it both of these have failed, it may be necessary to clean the insides of the thermoelectric cold trap. It is easy to disassemble and clean out the insides. It is much more difficult, however, to re-assemble the unit in a leak-free manner. Thus, it may be desirable to first try pumping a mild solvent through the trap, before disassembly is judged necessary. When disassembling, make sure the unit is on a horizontal surface, face up, or you will be trying to catch a plethora of glass beads. If the unit has been disassembled and needs to be re-assembled, first inspect the interior surfaces for any breaks in the Teflon coating, and consequent corrosive attack on the aluminum body. If the body has been damaged, replace the whole body. Otherwise, carefully clean away any sealant that may have been used in conjunction with the gasket. Examine the gasket and replace it, if it is damaged. Fill the space between the two flow spreaders with glass beads. Inspect the condition of the thermocouple; replace if necessary. Reassemble the whole box. Using a torque wrench, try to tighten all the fasteners to a uniform torque. Be very careful not to over-tighten. Since the assembly is made of aluminum, overtightening will not only damage the box, but will result in a greater propensity to leak, since surfaces will be distorted. After a uniform tightness, without distortion, has been achieved, re-connect the unit and leak test. If leaks are found, slightly changing the tightening torque may help. If this turns out to be very difficult to do, it can be helpful to disassemble again and to coat appropriate places with RTV silicone sealant.

- Leaks.

If leaks are detected, it will typically be necessary to disassemble the unit, find the cause and fix it. Follow the instructions in the item above. In a few cases a judicious re-torquing of the connecting bolts may solve the problems. Be careful not to warp the aluminum, however. 


\begin{tabular}{|c|c|c|c|}
\hline U.S. DEPT. OF COMM. & $\begin{array}{l}\text { 1. PUBLICATION OR } \\
\text { REPORT NO. } \\
\text { BIBLIOGRAPHIC DATA } \\
\text { SHEET (See instructions) }\end{array}$ & 2. Performing Organ. Report No & 3. Publication Date \\
\hline
\end{tabular}

4. TITLE AND SUBTITLE

USER'S GUIDE FOR THE CONE CALORIMETER

5. AUTHOR(S)

William H. Twilley and Vytenis Babrauskas

6. PERFORMING ORGANIZATION (If joint or other than NBS, see instructions)

7. ContracVGrant No.

NATIONAL BUREAU OF STANDARDS

U.S. DEPARTMENT OF COMMERCE

GAITHERSBURG, MD 20899

8. Type of Report \& Period Covered

Edition 1.0

9. SPONSORING ORGANIZATION NAME AND COMPLETE ADDRESS (Street. City. Stote, ZIP)

SAME AS ITEM 非6 ABOVE.

10. SUPPLEMENTARY NOTES

Library of Congress Catalog Card Number: 88-600556

Document describes a computer program; SF-185, FIPS Software Summary, is attached.

11. ABSTRACT (A 200-word or less factual summary of most significant information. If document includes a significant tibliography or literature survey, mention it here)

This document provides instructions for users of the Cone Calorimeter in installing, operating, maintaining, and repairing the instrument. It is intended for training new operators at NBS and at other laboratories. The troubleshooting and repair sections will be a useful reference section even for experienced operators, since remedies for a large number of potential instrument malfunctions are outlined there.

12. KEY WORDS (SIx to twelve entries; olphobetical order; capitalize only proper names; and separate key words ty semicolons) Keywords: Cone Calorimeter; installation; maintenance; service; spare parts; training.

13. AVAILABILITY

X] Unlimited

$\square$ For Official Distribution. Do Not Release to NTIS

$x$ Order From Superintendent of Documents, U.S. Government Printing Office, Washington, DC 20402.

14. NO. OF

PRINTED PAGES

[] Order From National Technical Information Service (NTIS), Springfield, VA 22161 

D

2

D 

(D) 


